\title{
Recovery Plan for U.S. Pacific Populations of the \\ Green Turtle \\ (Chelonia mydas)
}

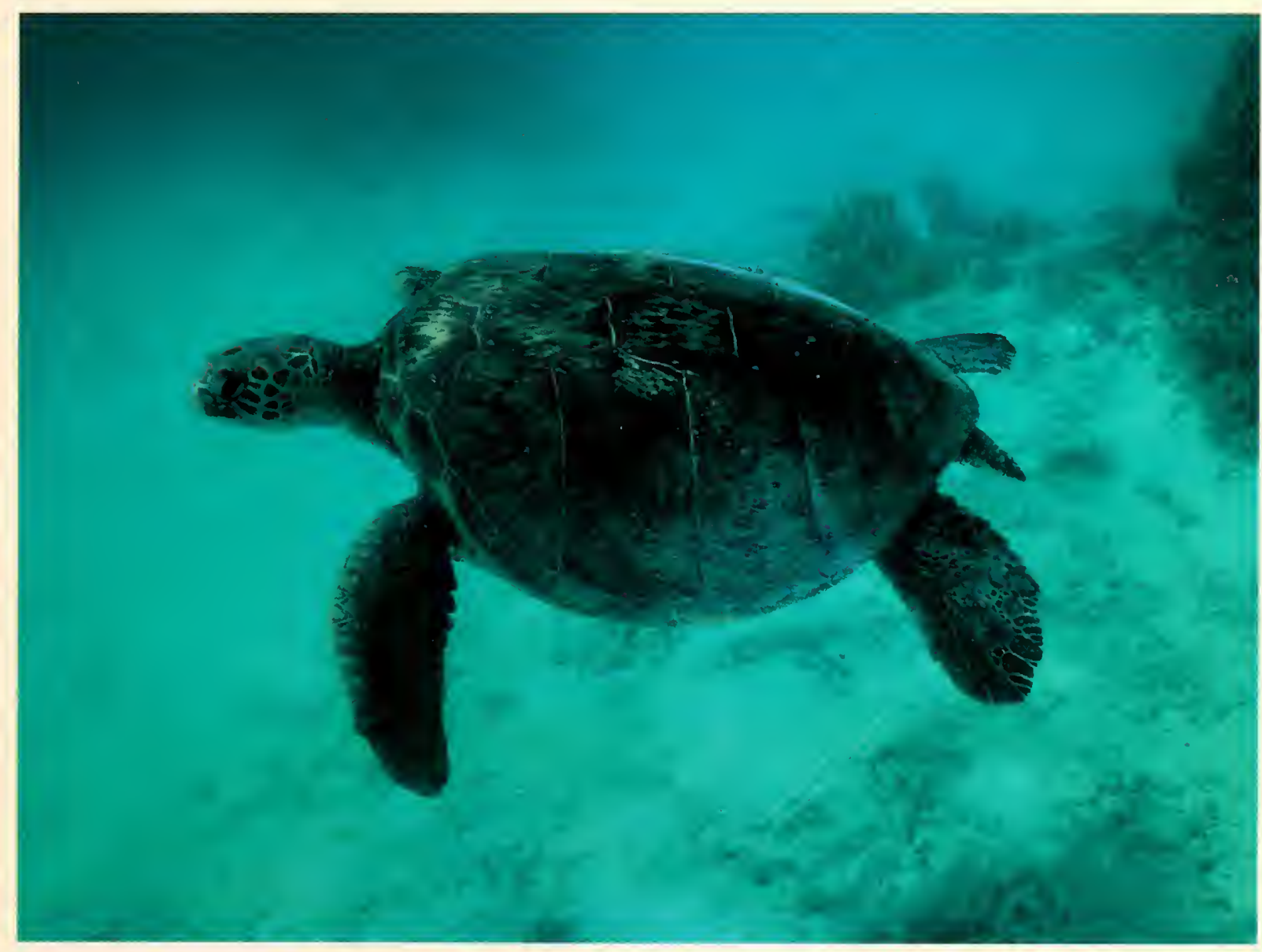

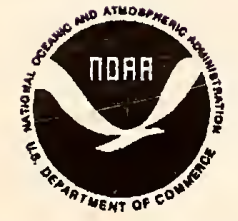

U.S. Department of Commerce

National Oceanic and Atmospheric Administration

National Marine Fisheries Service

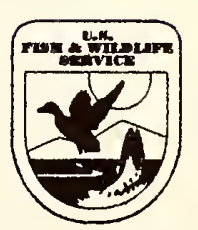

U.S. Department of the Interior U.S. Fish and Wildlife Service 
Cover Photograph Courtesy of George Balazs 


\title{
RECOVERY PLAN FOR U.S. PACIFIC POPULATIONS OF THE GREEN TURTLE
}

(Chelonia mydas)

\author{
Prepared by the \\ Pacific Sea Turtle Recovery Team
}

for

National Marine Fisheries Service

Silver Spring, Maryland

and

Pacific Region

U.S. Fish and Wildlife Service

Portland, Oregon

Approved:

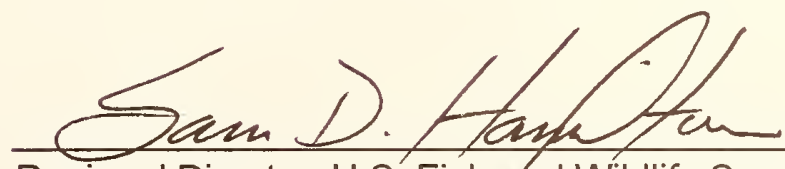

Regional Director, U.S. Fish and Wild life Service

Date: $|2-23-9\rangle$

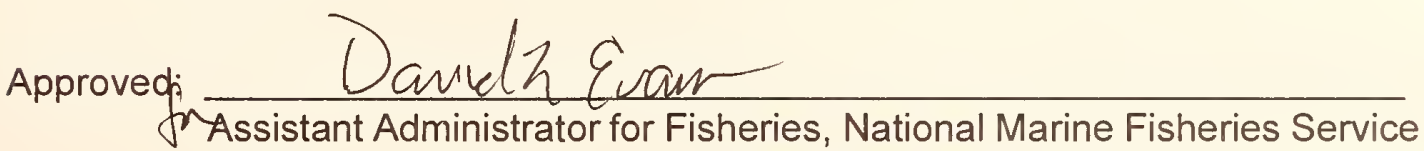

Date: $1 / 1498$ 
Recovery plans delineate reasonable actions which are believed to be required to recover and/or protect the species. Plans are prepared by the National Marine Fisheries Service (NMFS) and the U.S. Fish and Wildlife Service (FWS), and sometimes with the assistance of recovery teams, contractors, State agencies and others. Objectives will only be attained and funds expended contingently upon appropriations, priorities and other budgetary constraints. Recovery plans do not necessarily represent the views nor the official positions or approvals of any individuals or agencies, other than those of NMFS and the FWS which were involved in the plan formulation. They represent the official positions of NMFS and the FWS only after they have been approved by the Assistant Administrator for Fisheries or the Regional Director. Approved recovery plans are subject to modification as dictated by new findings, changes in species status and the completion of recovery tasís.

Literature citations should read as follows:

National Marine Fisheries Service and U.S. Fish and Wildlife Service. 1998. Recovery Plan for U.S. Pacific Populations of the Green Turtle (Chelonia mydas). National Marine Fisheries Service, Silver Spring, MD.

Additional copies of this plan may be purchased from:

Fish and Wildlife Reference Service

5430 Grosvenor Lane

Suite 110

Bethesda, Maryland 20814

(301)492-6403 or

$1-800-582-3421$

The fee for the plan varies depending on the number of pages of the plan. 


\section{TABLE OF CONTENTS}

(Green)

PREFACE

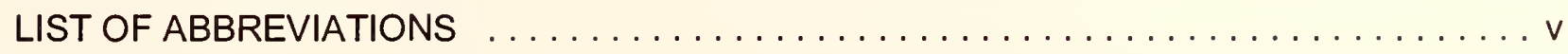

EXECUTIVE SUMMARY

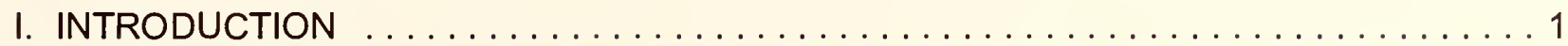

A. Geographic Scope ............................. 1

B. Historical and Cultural Background $\ldots \ldots \ldots \ldots \ldots \ldots \ldots \ldots \ldots \ldots$

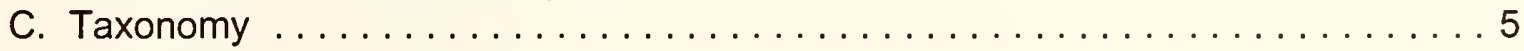

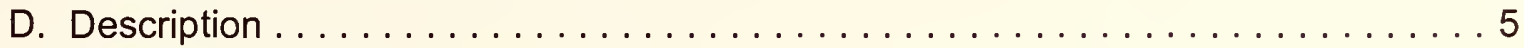

E. Population Distribution and Size $\ldots \ldots \ldots \ldots \ldots \ldots \ldots \ldots \ldots \ldots \ldots \ldots \ldots \ldots \ldots \ldots \ldots \ldots$

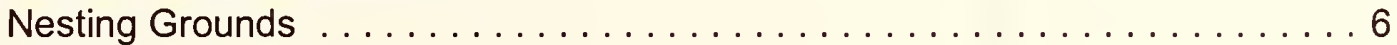

Insular and Pelagic Range ......................... 8

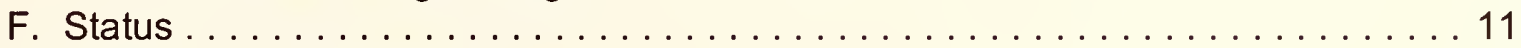

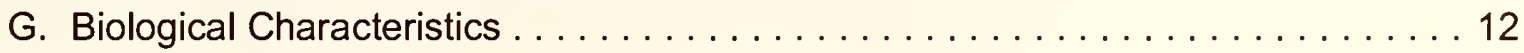

Migration and Movements .......................... 12

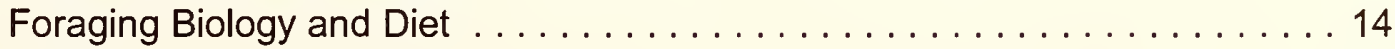

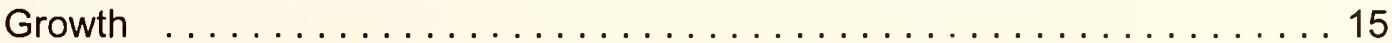

Reproduction ................................ 16

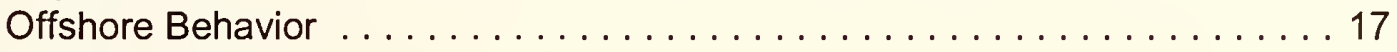

Health Status ............................... 17

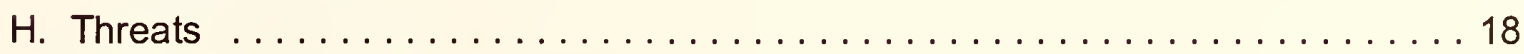

Pacific Synopsis .............................. 18

Regional Summaries ............................ 20

U.S. West Coast . . . . . . . . . . . . . . . . . . . . . 20

American Samoa . . . . . . . . . . . . . . . . . . . . . . . . . 20

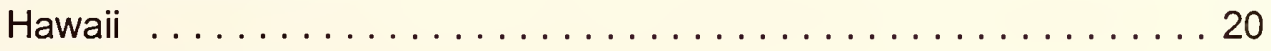

Guam ...................................21

Republic of Palau ......................... 21

Commonwealth of the Northern Mariana Islands (CNMI) . . . . . . . 22

Federated States of Micronesia (FSM) . . . . . . . . . . . . . . 22

Republic of the Marshall Islands (RMI) . . . . . . . . . . . . . . 23

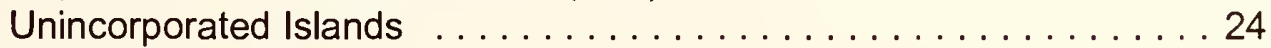

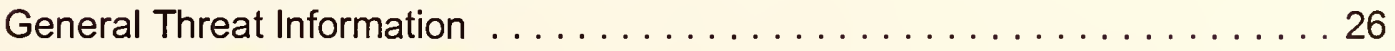

Nesting Environment ......................... 26

1. Directed Take ...................... 26

2. Increased Human Presence . . . . . . . . . . . . . . . 28

3. Coastal Construction ....................28 28

4. Nest Predation $\ldots \ldots \ldots \ldots \ldots \ldots \ldots \ldots \ldots \ldots 29$

5. Beach Erosion . . . . . . . . . . . . . . . . . . . . 30 
6. Artificial Lighting $\ldots \ldots \ldots \ldots \ldots \ldots \ldots \ldots \ldots . \ldots \ldots$

7. Beach Mining ......................... 32

8. Vehicular Driving on Beaches ............... 33

9. Exotic Vegetation . . . . . . . . . . . . . . . . . . 33

10. Beach Cleaning ............................ 33

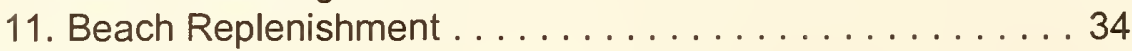

Marine Environment ........................... 34

12. Directed Take ........................ . . 34

13. Natural Disasters ....................... 35

14. Disease and Parasites . . . . . . . . . . . . . 36

15. Algae, Seagrass, and Reef Degradation . . . . . . . . 36

16. Environmental Contaminants . . . . . . . . . . . 37

17. Debris (Entanglement and Ingestion) . . . . . . . . . 39

18. Fisheries (Incidental Take) . . . . . . . . . . . . . . 40

19. Predation ........................4 41

20. Boat Collisions .....................4 41

21. Marina and Dock Development ...............4 41

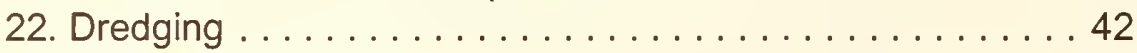

23. Dynamite "Fishing" . . . . . . . . . . . . . . 43

24. Oil Exploration and Development .............43 43

25. Power Plant Entrapment . . . . . . . . . . . . . . 43

26. Construction Blasting ..................43

I. Conservation Accomplishments . . . . . . . . . . . . . . . . . . . . . . 44

Legislation .............................. 44

Traditional Controls .................................... 44

Protected Areas .................................... 45

Other Plans and Regulations ... . . . . . . . . . . . . . . . . . . . 47

Headstart and Hatchery Programs $\ldots \ldots \ldots \ldots \ldots \ldots \ldots \ldots \ldots . \ldots . \ldots 4$

Sea Turtle Conservation and Management Plans . . . . . . . . . . . . . 48

Research and Education ...........................48 48

Effectiveness of Conservation Accomplishments . . . . . . . . . . . . 48

II. RECOVERY ........................................ 50

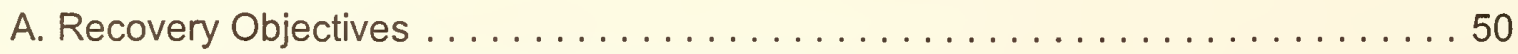

B. Step Down Outline and Narrative for Recovery . . . . . . . . . . . . . . . . 51

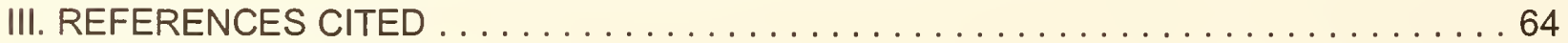

IV. IMPLEMENTATION SCHEDULE $\ldots \ldots \ldots \ldots \ldots \ldots \ldots \ldots \ldots \ldots \ldots$ 


\section{PREFACE}

The National Marine Fisheries Service (NMFS) and the U.S. Fish and Wildlife Service (FWS) share responsibilities at the Federal level for the research, management, and recovery of Pacific marine turtle populations under U.S. jurisdiction. To accomplish the drafting of this recovery plan, NMFS appointed a team of professional biologists experienced with marine turtles in the Pacific region. This document is one of six recovery plans (one for each of the five species plus one for the regionally important population of the East Pacific green turtle).

While similar in format to previously drafted sea turtle recovery plans for the Atlantic, Caribbean, and Hawaii, the unique nature of the wider Pacific region required some modification of the recovery plan format. The geographic scope of the present plan is much larger than any previously attempted and considers areas from the western coastal United States extending to Guam. Furthermore, the amount of jurisdictional overlap between nations, commonwealths, territories and compact-of-free-association-states and their various turtle populations required a broader management perspective than has been attempted previously. Finally, sea turtles have not been studied as comprehensively in the Pacific as in other U.S. areas, and thus there are many areas in the Pacific where basic biological and ecological information must be obtained for management purposes. Thus, these plans have more extensive text on the general biology of the turtles, so that they might act as a resource to managers seeking a handy reference to the species. The plans are also subdivided into U.S. jurisdictional areas (i.e., the various territories and the commonwealth), so that local managers can address issues within their respective regions more easily.

Because of the previously noted aspects of marine turtle distribution in the Pacific (e.g., wide geographic range, multiple jurisdictions), the Recovery Team relied on the input and involvement of a large number of advisers, as can be noted by the lengthy Acknowledgments section. It is hoped that the resulting document is one that acts as a pragmatic guide to recovering the threatened and endangered sea turtle populations in the Pacific Ocean.

The members of the Pacific Sea Turtle Recovery Team and the authors of this document are:

Scott A. Eckert, Ph.D. (Team Leader)

Hubbs-Sea World Research Institute

Javier Alvarado, Ph.D.

Universidad de Michoacan, Mexico

George Balazs

National Marine Fisheries Service

Richard Byles, Ph.D.

U.S. Fish and Wildlife Service

Peter Craig, Ph.D.

Office of Wildlife and Marine Resources, Government of American Samoa

Peter Dutton, Ph.D.

Texas A\&M University
Karen Eckert, Ph.D.

Wider Caribbean Sea Turtle Conservation Network (WIDECAST)

John Engbring

U.S. Fish and Wildlife Service

James Maragos, Ph.D.

East-West Center

Robert Pitman

National Marine Fisheries Service

Susan Pultz

U.S. Fish and Wildlife Service

James I. Richardson. Ph.D.

University of Georgia 


\section{ACKNOWLEDGMENTS}

The team wishes to thank and acknowledge the following technical advisors and contributors to these recovery plans:

David Aldan, Department of Natural Resources, Saipan, MP

Pablo Arenas, Inter-American Tropical Tuna Commission

Representative Mariano W. Carlos, Palau

Chuck Cook, The Nature Conservancy

Donald David, FSM

Gerry Davis, Division of Aquatic and Wildlife Resources, Dept. Agriculture, Guam

Oscar DeBrum, former Chief Secretary, RMI

Adrienne Farago, SPREP/RMTCP, Western Samoa

Michael Guilbeaux, Georgia Sea Turtle Cooperative

Vincent Hachiglou, Marine Resources Management Division, Yap State Government

Heidi Hirsh, Andersen Air Force Base, Guam

Paul Holthus, IUCN Biodiversity Program

Luciana Honigman, The Nature Conservancy

Noah Idechong, Division of Marine Resources, Palau

John lou, Marine Resources Management Division, Yap State Government

Bruce Jensen, Pacific Magazine

Harry Kami, Hilo, Hawaii

Angela Kay Kepler, Athens, Georgia

Steve Kolinski, Marine Resources Management Division, Yap State Government

Colin Limpus, Queensland National Parks and Wildlife Service, Australia

Becky Madraisau, Micronesian Mariculture Demonstration Center, Republic of Palau

B. Renè Màrquez-M., P.N.I.T.M./INP, Mexico

Donna McDonald, Ocean Planet Research

Ken McDermond, U.S. Fish and Wildlife Service, Honolulu

Jeffery Miller, Queensland Department of Environment \& Heritage, Australia

Susan Miller, South Pacific Regional Environment Program (SPREP)

Karen Miller McClune, Hubbs-Sea World Research Institute

Moses Nelson, Marine Resources Division, FSM

Peter Oliver, RMI

Arnold Palacios, Division of Fish and Wildlife, Dept. of Natural Resources, CNMI

Peter Pritchard, Florida Audubon Society

Georgita Ruiz, Colonia Irrigacion, Mexico

Laura Sarti, Universidad Naçional Autonoma de Mexico, Mexico

Fumihiko Sato, Ogasawara Marine Center, Japan

Katsufumi Sato, Kyoto University, Japan

Asterio Takesy, Secretary of Resources and Development, FSM

Natasha Tuato'o-Bartley, Department of Marine and Wildlife Resources, American Samoa

Itaru Uchida, Port of Nagoya Public Aquarium, Japan

Richard Wass, U.S. Fish and Wildlife Service

Phil Williams, National Marine Fisheries Service 


\section{LIST OF ABBREVIATIONS}

$\mathrm{CCL}$

CITES

CNMI

COE

DAWR

EEZ

ENSO

EPA

ESA

ETP

FENA

FSM

FWS

HSWRI

IATTC

INP

IUCN

$\mathrm{MHI}$

MIMRA

MMDC

MRMD

mtDNA

NMFS

NOAA

NPS

NRCS

NWHI

PNG

RMI

SCL

SDG\&E

SPREP

TAMU

TED

UNAM

USCG

USVI

WIDECAST curved carapace length

Convention on International Trade in Endangered Species of Wild Fauna and Flora

Commonwealth of the Northern Mariana Islands

U.S. Army Corps of Engineers

Division of Aquatic and Wildlife Resources

Exclusive Economic Zone

El Niño - Southern Oscillation

U.S. Environmental Protection Agency

Endangered Species Act

Eastern Tropical Pacific

females estimated to nest annually

Federated States of Micronesia

U.S. Fish and Wildlife Service

Hubbs-Sea World Research Institute

Inter-American Tropical Tuna Commission

Instituto Nacional de Pesca

International Union for the Conservation of Nature

Main Hawaiian Islands

Marshall Islands Marine Resource Authority

Micronesian Mariculture Demonstration Center

Marine Resources Management Division, Yap State government

mitochondrial DNA

National Marine Fisheries Service

National Oceanographic and Atmospheric Administration

National Park Service

Natural Resources Conservation Service (Soil Conservation Service)

Northwest Hawaiian Islands

Papua New Guinea

Republic of the Marshall Islands

straight carapace length

San Diego Gas \& Electric

South Pacific Regional Environment Program

Texas A \& M University

Turtle Excluder Device

Universidad Naçional Autonoma de Mexico

U.S. Coast Guard

U.S. Virgin Islands

Wider Caribbean Sea Turtle Conservation Network 


\section{EXECUTIVE SUMMARY}

Current Status: The green turtle is listed as Threatened under the Endangered Species Act (ESA) throughout its Pacific Range, except for the Endangered population nesting on the Pacific coast of Mexico which is covered under the Recovery Plan for the East Pacific green turtle. In reviewing this species' current status, the Recovery Team found that, outside of Hawaii, the green turtle populations have seriously declined and should probably be classified as Endangered. By far, the most serious threat to these stocks is from direct take of turtles and eggs, both within U.S. jurisdiction and on shared stocks that are killed when they migrate out of U.S. jurisdiction (e.g., nesting turtles from American Samoa migrate to Fiji and French Polynesia to feed). In Hawaii, green turtle populations appear to have a somewhat less dire status, probably due to effective protection at the primary nesting areas of the Northwest Hawaiian Islands and better enforcement of regulations prohibiting take of the species. However, the relatively recent increase in the incidence of the tumorous disease, fibropapillomatosis, in the Hawaiian green turtle threatens to eliminate improvements in the status of the stock. Another serious threat to green turtle populations throughout the Pacific is associated with increasing human populations and development. In particular, human development is having an increasingly serious impact on green nesting beaches.

Goal: The recovery goal is to delist the species.

Recovery Criteria: To consider de-listing, all of the following criteria must be met:

1) All regional stocks that use U.S. waters have been identified to source beaches based on reasonable geographic parameters.

2) Each stock must average 5,000 (or a biologically reasonable estimate based on the goal of maintaining a stable population in perpetuity) females estimated to nest annually (FENA) over six years.

3) Nesting populations at "source beaches" are either stable or increasing over a 25-year monitoring period.

4) Existing foraging areas are maintained as healthy environments.

5) Foraging populations are exhibiting statistically significant increases at several key foraging grounds within each stock region.

6) All Priority \#1 tasks have been implemented.

7) A management plan to maintain sustained populations of turtles is in place.

8) International agreements are in place to protect shared stocks.

Actions Needed: Eight major actions are needed to achieve recovery (not in order of priority). 
1) Stop the direct harvest of green sea turtles and eggs, through education and law enforcement actions.

2) Eliminate the threat of fibropapillomas to green turtle populations.

3) Reduce incidental harvest of green turtles by commercial and artisanal fisheries.

4) Determine population size and status through regular nesting beach and in-water censuses.

5) Identify stock home ranges using DNA analysis.

6) Support conservation and biologically viable management of green turtle populations in countries that share U.S. green turtle stocks.

7) Identify and protect primary nesting and foraging areas for the species.

8) Eliminate adverse effects of development on green turtle nesting and foraging habitats.

9) Control non-native predators of eggs and hatchlings, e.g., mongoose, feral cats, and pigs, in the Hawaiian population. 



\title{
RECOVERY PLAN FOR U.S. PACIFIC POPULATIONS OF THE GREEN TURTLE (Chelonia mydas)
}

\author{
Written by the \\ U.S. Pacific Sea Turtle Recovery Team
}

\section{INTRODUCTION}

\section{A. Geographic Scope}

Defining the geographic range of a population of sea turtles in the Pacific Ocean is difficult. Sea turtles are highly migratory, and the life histories of all species exhibit complex movements and migrations through geographically disparate habitats. Because the U.S. Pacific Sea Turtle Recovery Team is required to focus on sea turtle populations that reside within U.S. jurisdiction, we must delineate what constitutes a population where individuals reside permanently or temporarily within U.S. jurisdiction and what actions must be taken to restore that population. This has proven to be quite challenging because sea turtles do not recognize arbitrary national boundaries and in most cases we have only limited data on stock ranges and movements of the various populations. In this recovery plan we have tried to make these judgements with the best information available, and to suggest means by which the United States can promote population recovery.

Geographic scope (from a U.S. jurisdictional perspective) for all six of the U.S. Pacific sea turtle recovery plans (written for five species and one regionally important population) is defined as follows: in the eastern Pacific, the west coast of the continental United States (Figure 1a); in the central Pacific, the state of Hawaii and the unincorporated U.S. territories of Howland, Baker, Wake, Jarvis, and Midway Islands, Johnston Atoll, Palmyra Atoll, and Kingman Reef; in Oceania, Guam, the Commonwealth of the Northern Mariana Islands (CNMI), and American Samoa (see Figure 1b). The U.S.-affiliated but independent nations of the Republic of the Marshall Islands (RMI), Federated States of Micronesia (FSM), and the Republic of Palau are also included. The FSM consists of the states of Yap, Pohnpei, Chuuk, and Kosrae. While independent, all retain clearly defined administrative links to the United States in the areas of defense, natural resource management, and some regulatory issues. Thus, we include them here in an advisory capacity. Finally, where eastern Pacific sea turtles are held in common with Mexico, discussion of the status and recovery of these stocks will also include discussion of the resource under Mexican jurisdiction. In all cases where U.S. sea turtle stocks are held in common with other sovereign states, we have tried to suggest means by which the United States can support efforts at management of those stocks by those states. We recognize that other nations may have different priorities than the United States and we have sincerely attempted to avoid establishing policy for those nations.

By virtue of the highly migratory behavior of the adult turtles, and the shifting habitat requirements of post-hatchlings and juveniles, it is known that at least some of the populations of green turtles in this vast region cross international boundaries. The adjacent ocean and island-areas of Polynesia, Micronesia, Melanesia, and even the Philippines (including the South China Sea), indonesia, Taiwan, and possibly the Bonin islands of Japan, may constitute shared habitats for green turtles. This is acknowledged in the following discussions. 


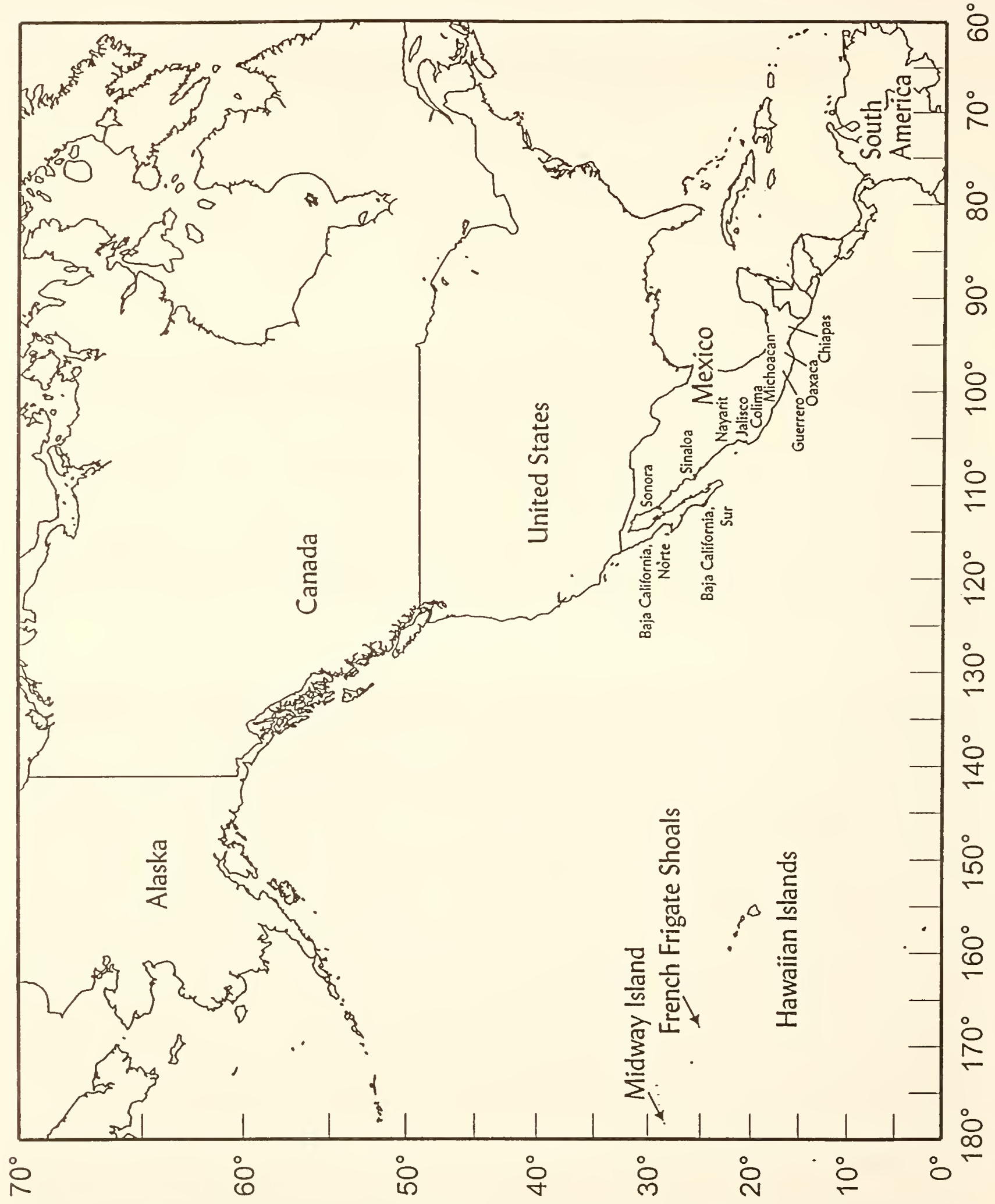

Figure 1a. Western coasts of the United States, Canada and Mexico (as well as Central and northern South America) constitute a shared habitat for Pacific sea turtles. 


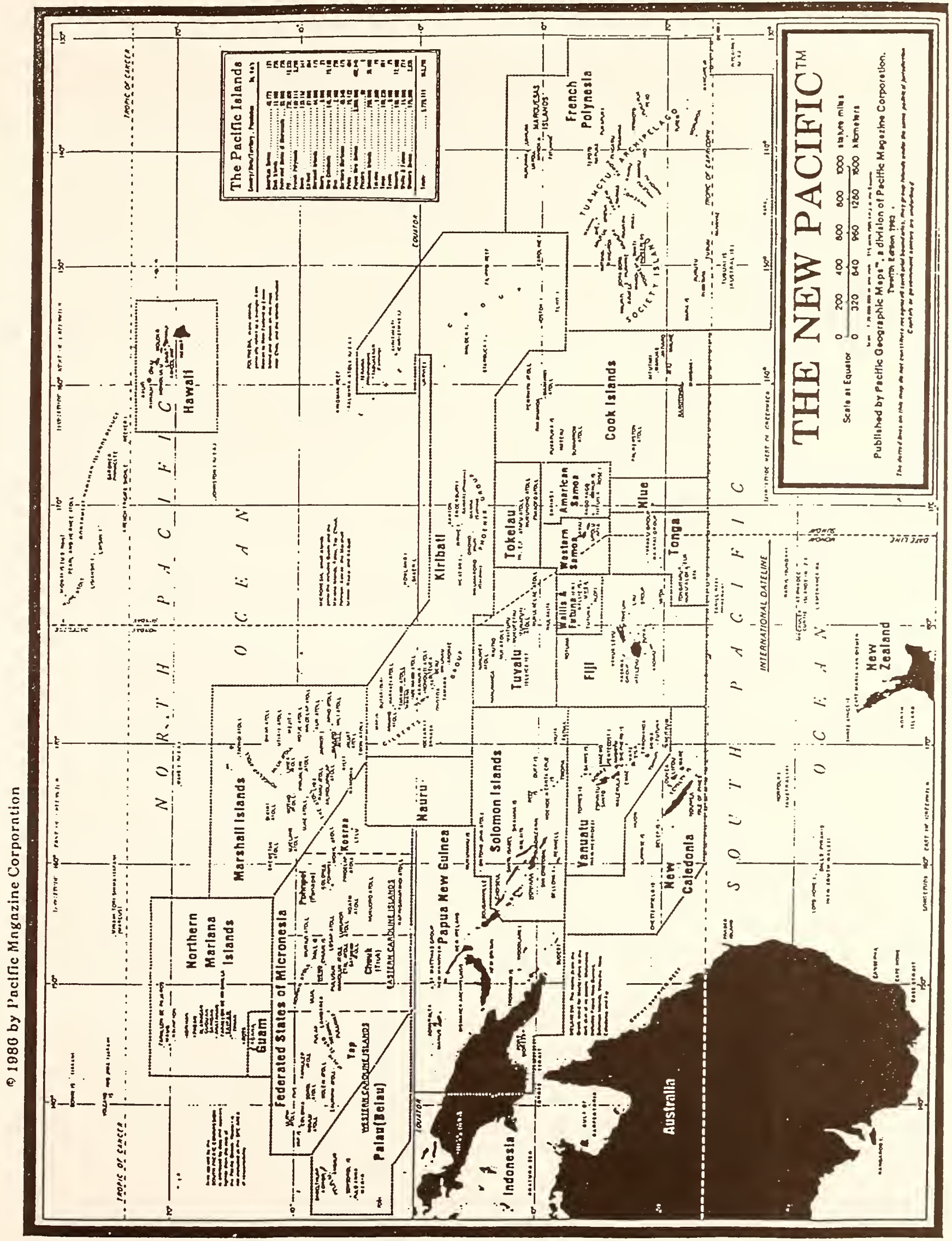

Figure 1b. The western Pacific constitutes a shared habitat for Pacific sea turtles. 
A separate Recovery Plan has been prepared for the East Pacific green turtle (also called the black turtle) Chelonia mydas whose geographic range extends along the coastal waters of the North, Central and South American continents including the Galapagos Islands of Ecuador.

\section{B. Historical and Cultural Background}

Wherever and whenever available, green turtles and their eggs have been eaten and esteemed for centuries by the native inhabitants of the insular Pacific region (Johannes 1978, 1986; Lessa 1984; McCoy 1974, 1982; Smith 1991; South Pacific Region Environment Programme [SPREP] 1991). The red meat, viscera, and eggs of the green turtle have supplied a nutritious and succulent alternative to the more common items usually available, such as fish, birds, shellfish, coconuts, breadfruit and taro. The adult female turtles are especially prized due to their large quantities of fat.

The utilization of green turtles for food and other purposes was often under strict control, usually by some form of an island council or tribal chief. In both Polynesia and Micronesia turtles were considered the property of royalty, and harvest was often restricted to special occasions. In the Samoan Islands, certain families in the village were designated turtle hunters, upon whom the village chief would rely to catch turtles when requested. In other areas such as the RMI, only the harvest of nesting females was regulated with a nesting turtle considered the property of the atoll chief. Turtles caught in the water were the property of the fisherman who caught them (Glen Lokjohn, Wotje Atoll resident pers. comm.). In some areas the green turtle was reserved for feasts which were attended exclusively by men. In the Hawaiian Islands, in ancient times, women were entirely prohibited from eating turtles (Balazs 1980). Certain parts of the green turtle, such as the fat, were also used for medicinal purposes to treat burns and other skin disorders. In addition, dried carapaces of the green turtle were used as containers, and the disarticulated bones were used for kitchen utensils, sewing needles, fish hooks and agricultural tools. While green turtle scutes are also known to have been fashioned into ornaments and utensils, the thicker and more attractive plates of the hawksbill were preferred for this purpose whenever available. Live hatchlings were (and in some places still are) commonly raised as pets where they eventually died or were released or eaten when they grew to a certain size.

Religious, ceremonial, and other traditional restrictions on the capture, killing, distribution and consumption of green turtles played an important role in their utilization. For example, in the Hawaiian Islands there were families that considered the green turtle to be a personal family deity or "aumakua", not to be eaten or harmed. One legendary turtle in particular named Kauila was believed to be able to change at will into human form to watch over village children playing along the shoreline. Artistic elements of green turtles have also been featured prominently in some cultures of the region, such as in petroglyphs and tattoo designs.

The green turtle's decline combined with significant alteration and modernization of nearly all island cultures within the region has reduced the cultural importance of green turtles. Green turtles have declined in many areas due to an increased ability to hunt them locally and more efficiently with modern fishing gear, and to travel great distances with motorized vessels to gather mating and nesting turtles at formerly remote breeding sites. At the same time, canned foods, refrigeration, and associated modern technologies have been imported and embraced by most if not all island societies. Family and village social structures have been altered by immigration, emigration, the introduction of cash and commercial market economies, and the institution of state or federal 
government control of natural resources. Nevertheless, green turtles retain some level of cultural and culinary importance throughout the Pacific (for example, see Smith 1991).

Additional information on the historical and cultural significance of green turtles in the region can be found in Tuato'o-Bartley et al. (1993), Balazs (1982c, 1983a, 1983b, 1985c), Hiatt (1951), Johannes (1981), Lessa (1962), Tobin (1952), and Tobin et al. (1957).

\section{Taxonomy}

The green turtle was first described by Linnaeus in 1758 as Testudo mydas, with Ascension Island in the Atlantic as the type locality. Schweigger in 1812 first applied the binomial Chelonia mydas in use today.

The current taxonomic status of the green turtle is uncertain. Mitochondrial DNA research conducted by Bowen et al. (1992) showed a fundamental phylogenetic split distinguishing all green turtles in the Atlantic-Mediterranean from those in the Indian-Pacific Oceans. There is no evidence for genetic distinctiveness of the often-recognized taxonomic form in the east Pacific called the East Pacific green, or the black turtle, Chelonia mydas (agassizii) (Bowen et al. 1992; Dutton et al. 1996). Although trinomials have been applied to various populations in the past, they are generally not in use today with the exception of the East Pacific green turtle. Hirth (1971a) concluded that "it is best to use the binomial, Chelonia mydas, for all green turtles until a detailed taxonomic study is made." Until additional morphological and genetic research is conducted, Hirth's advice remains valid.

A geographic population substructure within each ocean basin involves fixed or nearly fixed genotypic differences between nesting populations. This suggests a strong propensity for natal homing by the females (see also Meylan et al. 1990). MtDNA data suggest that the global matriarchal phylogeny of Chelonia mydas has been shaped by the ocean basin separations and regionally by the natal homing behavior. The shallow evolutionary structure of Chelonia populations within ocean basins likely resulted from extinction and colonization of rookeries over time-frames that are short by evolutionary standards, but long by ecological standards (Bowen et al. 1992). Consequently, in terms of conservation and management, the available evidence indicates that breeding sites must be considered as demographically independent units. For additional discussions of the systematics of the green turtle see Hirth (1980), Pritchard and Trebbau (1984) and Groombridge and Luxmoore (1989).

\section{Description}

The green turtle is the largest of the cheloniids, with adults that can exceed one meter in carapace length and $100 \mathrm{~kg}$ in body mass. Green turtles nesting at French Frigate Shoals in the Northwestern Hawaiian Islands (NWHI) average $92 \mathrm{~cm}$ in straight carapace length (SCL; range 81-106 cm, $n=379$ ) (Balazs 1980). At Olimarao Atoll, Yap, FSM, 27 adult females handled during 1990 averaged $104 \mathrm{~cm}$ in curved carapace length (CCL; range 93-117 cm), and approximately 140 $\mathrm{kg}$ in body mass (range 97 to greater than $181 \mathrm{~kg}$ ) (Kolinski 1991). Hatchlings average about 4.7 to $5.4 \mathrm{~cm}$ in carapace length, and 22 to $31 \mathrm{~g}$ in weight (Márquez 1990 in Eckert 1993). 
Characteristics that distinguish the green from other species of sea turtles include a smooth carapace with four pairs of lateral scutes, a single pair of prefrontal scales, and a lower jaw-edge that is coarsely serrated, corresponding to strong grooves and ridges on the inner surface of the upper jaw (Carr 1952; Hirth 1971a; Pritchard and Trebbau 1984).

The term "green" refers not to the external coloration, but to the color of the turtle's subdermal fat. The carapace of adult green turtles is light to dark brown, sometimes shaded with olive, with radiating wavy or mottled markings of a darker color or with large blotches of dark brown (Carr 1952). The carapace coloration changes as the turtle grows from a hatchling to an adult. Juveniles measuring 35-65 cm in the insular Pacific region have streaked or radiating sunburst patterns of yellowish-gold, olive, light and dark brown, reddish brown, and black. Dorsal coloration of the green turtle likely has adaptive significance as camouflage from chief predators (e.g., tiger sharks) while the turtle rests motionlessly on the bottom amongst coral and other benthic substrate. The adult plastron ranges from yellowish to orange, although in the East Pacific form there is considerable grayish pigment. All hatchling green turtles have a black dorsal surface and a pure white venter. However, in some Pacific populations such as at French Frigate Shoals NWHI, (Balazs 1986) and Mopelia in French Polynesia, post-hatchlings go through a radical pigment transformation of the plastron from white to nearly all black, and then returning to white again. This occurs during the period of growth between $5-15 \mathrm{~cm}$ in carapace length. The adaptive significance of this ontogenetic switch and just how widespread it may be throughout the Pacific region and elsewhere worldwide, are unknown.

\section{E. Population Distribution and Size}

The green turtle is a circumglobal species found in tropical seas and, to a lesser extent, in subtropical waters with temperatures above $20^{\circ} \mathrm{C}$. Worldwide distribution has been described at length by Hirth (1971b), Groombridge (1982), and Groombridge and Luxmoore (1989). Insular populations of the Pacific are summarized by Forsyth and Balazs (1989).

\section{Nesting Grounds}

Groombridge (1982) estimates that there are approximately 150 extant nesting colonies (demographically independent units) worldwide for the green turtle. However, only 10-15 of these are large enough to involve 2,000 or more nesting females per year. None of these large colonies occur within the insular Pacific region, although Australia's Great Barrier Reef does serve as such a site (see Limpus 1978, 1982).

Nesting by ten or fewer females each year takes place at scattered, but probably not very numerous locations throughout this vast oceanic region (e.g., in Guam and CNMI) (see Balazs 1982a; Pritchard 1977, 1982b). A review of critical nesting habitats for green turtles at certain U.S. sites in the Pacific has been presented by Dodd (1978) and Balazs (1978).

The patterns of green turtle exploitation, both historically and more recently at an accelerated pace, have affected the present distribution of the remaining breeding sites. This distribution illustrates the historical decline of the species by the fact that the only extant island-breeding sites of any consequence are those that have not been permanently inhabited by humans, or have not been visited frequently for exploitation. The recognition of this important demographic point serves 
to emphasize what has happened to the green turtle in the past. It also highlights the fact that more effective, intensive, and sustained conservation measures are needed in the near future to prevent this valued resource from declining even further.

Because sea turtles remain faithful to their natal beaches, the excessive harvesting of turtles at a nesting site will not be replenished by the recruitment of turtles from other nesting sites. This view is consistent with the distributional pattern of remaining nesting sites in relation to human exploitation, as noted in the previous section.

It should be stressed that, with the exception of French Frigate Shoals, all of the following estimates are based on very limited and fragmentary data that require verification by additional research spanning at least three, and preferably five or more, consecutive years of monitoring and tagging at each site. Nevertheless, based on the information presently available, at least the orders of magnitude of these estimates are believed to be reasonably correct (Balazs 1991; Edson and Curren 1987; Hendrickson 1972; Hirth 1971a; Kolinski 1991; Smith 1991; Tuato'o-Bartley et al. 1993; Thomas 1989; Holthus et al. 1993; and various unpublished information from correspondents including S. Kolinski, A. Smith, T. Herring, D. Itano and others).

\section{U.S. West Coast}

No known nesting.

\section{Hawaii}

Nesting occurs throughout the Hawaiian archipelago, but over $90 \%$ occurs at French Frigate Shoals, Northwest Hawaiian Islands (NWHI), where 200-700 females are estimated to nest annually (FENA = Females Estimated to Nest Annually) (see Balazs et al. 1992). Low level nesting (less than 25 FENA) is known or is likely to occur at Laysan Island, Lisianski Island, and Pearl and Hermes Reef.

\section{American Samoa}

The major nesting site for this area is Rose Atoll, with an estimated 25-35 FENA (Tuato'oBartley et al. 1993). Low level nesting may occur at Tutuila and the Manua Group.

\section{Guam}

There is some regular low-level nesting of green turtles on Guam (Pritchard 1982a; Gerry Davis, Guam, Division of Aquatic and Wildlife Resources (DAWR), pers. comm.).

\section{Republic of Palau}

Helen Reef was until recently uninhabited and may have supported 100-500 nesting females. A 1991 survey found eight residents on the island and only a few turtles nesting (Geermans 1992) and there is concern that this colony may be in the process of being extirpated (J. Maragos, EastWest Center, pers. comm.). Merir had 100 FENA in 1991 and is the most important nesting area of Palau (Geermans 1992). Sonsorol, Fanna, Tobi and Pulo Anna have less than 25 FENA 
(Geermans 1992; Maragos et al. 1994). There are also a few green turtles nesting at Kayangel Atoll and at the uninhabited Ngeruangal Atoll (Maragos 1994) and also at Anguar, Peleliu, and coastal Babeldaob (M. Guilbeaux, University of Georgia, pers. comm.).

\section{Commonwealth of the Northern Mariana Islands (CNMI)}

Fewer than ten green turtles nest on the islands of Saipan, Tinian and Rota each year. The extent of nesting on the northern islands is unknown.

Republic of the Marshall Islands (RMI)

Bikar Atoll may have 100-500 nesting females. During one short stay (11 nights) late in the nesting season 48 turtles were tagged in 1992 (Puleloa and Kilma 1992). Breeding colonies in Erikub and Jemo may each consist of 25 - 100 FENA (Puleloa and Kilma 1992). Low level nesting (less than 25 FENA) occurs at Enewetak and Bikini.

\section{Federated States of Micronesia (FSM)}

Sites thought to host breeding colonies of 100-500 FENA include Oroluk Atoll, Pohnpei; Olimarao Atoll, Yap; and Gielop, Yap (322 were tagged in 1991). Elato, Lamotrek, Pikelot, West Fayu and Gaferut in Yap may have 25 to 100 FENA during most years (S. Kolinski, Marine Resources Management Division [MRMD], Yap State govt., pers. comm. to G. Balazs). Harvesting pressure on greens at Pikelot and West Fayu has increased in recent years corresponding to a decline in nesting turtles, based upon observations and interviews of M. McCoy and J. Maragos at Satanal (Yap State) in June-July 1995.

Information compiled by Fosberg (1969), Johannes (1978), McCoy $(1974,1982)$, and Pritchard $(1977,1982 a, b)$ on the sea turtles of Micronesia provides valuable background information for several of these sites. Iar, an islet close to Gielop just outside Ulithi Atoll in Yap, may host several hundred nesting females annually and is clearly a priority site (along with Gielop) for future research in the FSM (S. Kolinski, pers. comm.).

\section{Unincorporated U.S. Island Territories}

Low density nesting was recorded along the west coast of Jarvis Island in the 1930s (Bryan 1974 in Balazs 1982a) as well as a low level of nesting on Palmyra Atoll in 1987 (pers. comm. Stewart Feffer to James Maragos), other areas are unknown.

\section{Insular and Pelagic Range}

The pelagic range of post-hatchling and juvenile green turtles in the insular Pacific region is not known. A similar situation exists for all sea turtle populations worldwide. There are three inherent problems which impede research of pelagic-phase turtles. First, the whereabouts of the turtles are not known, although they are generally assumed to be at, or near, the ocean surface along drift lines where surface waters are brought together by advection and downwelling (Carr 1987a). Secondly, once the pelagic locations of the turtles have been identified, there are problems in devising an efficient and safe sampling technique so that statistically significant numbers of turtles 
can be captured. Lastly, a means to determine the origin of the turtles with respect to the nesting beaches where they were hatched will be needed. Some advances in genetics research have already been made in this area (see Bowen et al. 1992).

Pelagic-dwelling juvenile green turtles have been captured during recent years, albeit in relatively low numbers, by commercial driftnet vessels fishing in international waters to the north and west of the Hawaiian Islands (Balazs and Wetherall 1991; Wetherall et al. 1993). These turtles may originate from nesting beaches in Hawaii, the Bonin Islands (Suganuma 1991), or possibly even the RMI. Juvenile green turtles have also been observed by research vessels operating thousands of miles from land in the southeastern Pacific (Eckert 1993).

\section{U.S. West Coast}

Stranding reports (Cordaro, NMFS, pers. comm.) indicate that Chelonia is a regular visitor in waters off the southwest coast of the United States. A small (30-50) group resident in San Diego Bay, California shows physical characteristics of both the Mexican and the Hawaiian breeding populations (Dutton and McDonald 1990). The turtles appear to remain as residents in the area because of the warm water effluent from a power generating station. A northern record of a stranding in Homer, Alaska, was reported in 1993 (Loshbaugh 1993), although this turtle may have died in waters further south and drifted north with the current.

Hawaii

Green turtles inhabiting the Hawaiian Islands are among the best known in the Pacific in terms of their nearshore benthic foraging pastures and associated underwater habitats. Important resident areas have been identified and are under study along the coastlines of Oahu, Molokai, Maui, Lanai, Hawaii, as well as at Lisianski Island and Pearl and Hermes Reef (Balazs et al. 1987; Balazs 1979, 1980, 1982b). The shallow waters within French Frigate Shoals have been identified as inter-nesting habitat for adult females and also adult males that migrate to breed at this key site (Dizon and Balazs 1982). The available evidence indicates that the range of adult green turtles using French Frigate Shoals is confined to the 2,400 km expanse of the Hawaiian Archipelago (Balazs 1976, 1983b) and to Johnston Atoll immediately to the South, where algal foraging pastures occur (Balazs 1985a).

\section{American Samoa}

Green turtles occur in the waters off Tutuila and the Manua Group of American Samoa, but apparently not in great numbers. The green turtles that nest at Rose Atoll likely feed elsewhere in the central South Pacific where sea grasses and algae are abundant. Distant recoveries of two turtles tagged at Rose Atoll were made in Fiji, where they were taken by net and eaten (Balazs 1991; Tuato'o-Bartley et al. 1993) and one other was taken at Vanuatu (G. Balazs, NMFS, pers. comm.). Three satellite-tagged females migrated to Fiji after nesting at Rose Atoll (Balazs 1994), and one other migrated to French Polynesia (Craig and Balazs 1995). All four turtles were believed to have returned to their resident foraging pastures. 
Green turtles have been sighted throughout the area during all months of the year, particularly during December to February and May to June. There was a total of 783 turtle sightings during surveys from 1975 through 1979 (Pritchard 1982a).

Republic of Palau

Very little information exists on the range of green turtles foraging at Palau, although Helen Reef provides an important foraging area (Jim Maragos, pers. comm.). Because Palau contains excellent sea grass and algal beds (Maragos et al. 1994) green turtles are probably found throughout the area. Specific foraging areas have been at Helen Atoll, Angaur Island, Peleliu Island, off the Southern Lagoon, and off major seagrass beds at Babeldaob, south of Oreor and Sar Passage.

\section{Commonwealth of the Northern Mariana Islands}

Green turtles are caught by divers in the Northern Marianas (Pritchard 1982a) and according to Honigman (1994) green turtles are found commonly in the waters of Tinian.

\section{Republic of the Marshall Islands}

Very little information exists on the range of green turtles foraging in the RMI. According to fisheries officers of the Marshall Islands Marine Resources Authority (MIMRA), Arno Atoll provides an important area for feeding green turtles of various size classes (V. Alfred, MIMRA, pers. comm.). Green turtles have also been caught in the waters of Wotje Atoll and probably occur around most of the islands and the Atolls in the RMI.

\section{Federated States of Micronesia}

Very little information exists on the range of numerous green turtles foraging in the FSM. Benthic foraging habitats for green turtles nesting in the FSM appear to include coastal waters of neighboring nations to the west and north as indicated by long-distance tag returns.

SCUBA divers have reported green turtles feeding in the lagoon at Oroluk Atoll (Naughton 1991; Holthus et al. 1993). There are undoubtedly many other feeding sites throughout the region, but diving surveys have not been undertaken and the existing local knowledge has not been comprehensively collected and reported upon.

\section{Unincorporated U.S. Island Territories}

Aggregations of resident green turtles are known to occur at Wake Island and Palmyra Atoll, but only a few turtles have been seen in the waters around Howland, Baker, Jarvis, and Kingman Reef during recent years (Balazs 1982a and unpubl. data). 


\section{F. Status}

The green turtle is listed as Endangered worldwide by the International Union for the Conservation of Nature and Natural Resources (IUCN) (Groombridge 1982), and the species appears on Appendix I of the Convention on International Trade in Endangered Species of Wild Fauna and Flora (CITES). In 1978, under the U.S. Endangered Species Act (ESA) of 1973, the green turtle was listed and classified as Threatened, except for breeding populations in Florida and on the Pacific coast of Mexico, which were classified as Endangered. Both categories afford substantial protection under rules promulgated at the time of listing (50 CFR 17.11).

When green turtles were listed under the Act in 1978, a provision was included for their "subsistence use" by native peoples living within the U.S. Trust Territory of the Pacific Islands. At that time, the FSM, RMI, CNMI, and the Republic of Palau comprised the Trust Territories of the Pacific. Under this regulatory exemption only green turtles less than 30 inches could be taken and only from below the high-tide mark for non-commercial sustenance purposes. During 1984 a comprehensive review of this subsistence exemption was undertaken by the National Marine Fisheries Service (NMFS) to determine its validity, and whether or not there was justification to expand it to other U.S. areas of the Pacific, such as Guam, American Samoa and the State of Hawaii. The original subsistence exemption, along with its original geographical restriction of the Trust Territory, was subsequently reaffirmed (Johannes 1986; NMFS 1985a, 1985b). However, none of these island nations remain a part of the trust territory today.

Green turtles were originally listed under the ESA because of overexploitation for commercial and other purposes, the lack of adequate regulatory mechanisms and effective enforcement, evidence of declining numbers, and habitat loss and degradation. Overall, the survival status of green turtles throughout the insular Pacific region has likely continued to decline due to directed harvest (both illegal and legal) and negative impacts to essential habitats. For example, when interviewed by a member of the Recovery Team, turtle fishermen and biologists from the Marshall Islands suggested that turtle populations have declined $50 \%$ in the last 20 years due to uncontrolled harvest of nesting turtles.

While green turtles in the Hawaiian Islands (Figure 2) have demonstrated some encouraging signs of population recovery after 17 years of protective efforts, the conservation outlook for the future is seriously compromised by the mortality of turtles from poaching, capture in nearshore gillnets, and the increasing scope and magnitude of a tumor affliction disease known as fibropapilloma (Balazs et al. 1992; Balazs and Pooley 1991). 


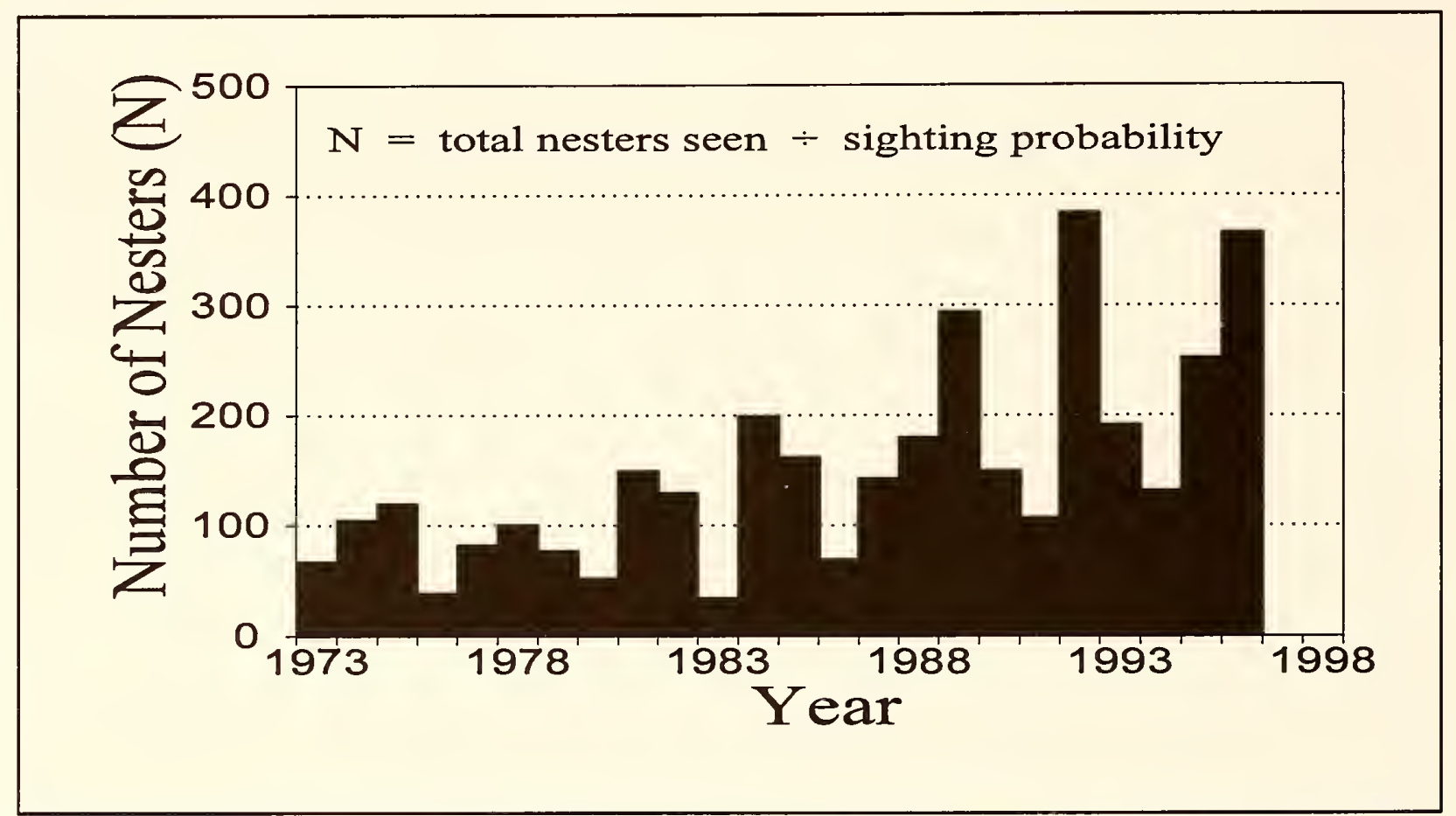

Figure 2. Green turtle nesting at East Island, French Frigate Shoals, Hawaii, has tripled since enactment of the Endangered Species Act.

Additional up-to-date information on the status of sea turtles and their historical decline can be found in National Research Council (1990) and Groombridge and Luxmoore (1989).

\section{G. Biological Characteristics}

Several valuable reviews covering the biological characteristics of the green turtle have been published during recent years, including ones by Hirth (1980), Groombridge (1982), Ogren (1984), and Pritchard and Trebbau (1984). Similar reviews containing more specific information on green turtles in the Pacific Basin can found in Limpus (1978), Balazs (1980), Forsyth and Balazs (1989) and Eckert (1993).

The following sections discuss in synoptic form the basic biological characteristics of the green turtle with particular relevance to the insular Pacific region. As previously indicated, many facets of the green turtle's life history and ecology remain unknown. This absence of essential information constitutes a serious impediment to the long-term conservation and recovery of the affected populations.

\section{Migration and Movements}

Adult green turtles periodically undertake reproductive migrations between resident foraging pastures and distant sites where copulation and egg laying take place. These migrations are 
carried out by members of nearly all populations worldwide, even though in many cases there would appear to be acceptable sites for nesting much closer to the turtles' home range. The reason for migrating is therefore something of an evolutionary enigma, although the proper dispersal of hatchlings by ocean currents off a particular nesting beach may be a crucial factor (Collard and Ogren 1990). The oceanic routes taken by the adults on their migrations, whether or not they travel together, and the navigational techniques employed while migrating, are generally unknown. Adult females migrate to breed once every two or more years, while the adult males often migrate on an annual basis, at least in the Hawaiian islands (Balazs 1983b). Sufficient evidence exists to show that the turtles return to the same resident foraging areas following their time spent at the breeding grounds.

Some important migrations by green turtles in the Pacific have been documented by tag and recapture studies and satellite telemetry studies. In the Hawaiian Islands green turtles migrate to French Frigate Shoals from foraging pastures located both to the northwest and the southeast, involving one-way distances up to $1300 \mathrm{~km}$. In 1991, three females were satellite-tracked from their nesting grounds at French Frigate Shoals to foraging grounds in Kaneohe Bay and Johnston Atoll. All three traveled beyond sight of land in water thousands of meters deep, two of them against prevailing winds and currents (Balazs 1994). In American Samoa, five green turtles migrated to Fiji, one to Vanuatu and another to French Polynesia after nesting at Rose Atoll (Balazs et al. 1994b). At Scilly Atoll north of Tahiti in French Polynesia, green turtles tagged during the nesting season have been recovered (i.e., captured and eaten) at several island groups far to the west, including Fiji, Tonga, Vanuatu, and New Caledonia (see Pritchard 1982b; Meylan 1982; and Forsyth and Balazs 1989; Balazs et al. 1995). Scilly Atoll is over $4000 \mathrm{~km}$ from New Caledonia. A nesting turtle tagged during 1991 at Gielop in Yap was recovered in the Philippines. Another turtle tagged while nesting at Oroluk in Pohnpei during 1986 was recovered (and released) in healthy condition in Nan-way Bay on the western side of the southern tip of Taiwan (Edson and Curren 1987). The turtle's capture and its release on a certain date, determined by numerical considerations of the local religion, was believed to be a sign of good luck ( $G$. Balazs, pers. comm.).

The movements of immature green turtles are less well known. This is because tagging to document the movements of the immature life stages requires that turtles be captured in marine benthic habitats or, even more difficult, their pelagic habitats. Nevertheless, the tagging that has been done in the Hawaiian Islands (including Johnston Atoll) and in Australia suggests that the immature turtles reside for many years at the same location, provided there is suitable food, shelter, and environmental stability. The movement to a different foraging and resting location may only occur when the turtle grows to a size where the existing habitat can no longer fulfill its needs.

The pelagic movements of post-hatchling and young juveniles are undocumented. Once they emerge from the nest, hatchling green turtles move directly to the ocean and swim vigorously seaward well beyond the nearshore environment. Their subsequent movements are presumably influenced by ocean currents, winds, and other surface conditions until the turtles are large enough for self-directed swimming (see section on Offshore Behavior).

The dispersal of green turtle hatchlings from natal beaches in the insular Pacific region has only been considered for one nesting site, French Frigate Shoals, NWHI. Surface drift trajectories were computed from composite oceanographic data to estimate the theoretical dispersal of hatchlings 
for the principal months of emergence (July-October) and for each subsequent month thereafter while adrift (Balazs 1976, 1980). These trajectories predicted a general movement to the west, with pronounced hatchling dispersal to the north of French Frigate Shoals over a two month period for those hatchlings departing during August (the peak month for nest emergence). However, serious limitations of this preliminary analysis include the unknown influence of localized eddies and gyres, and to what extent the turtles engage in self-directed swimming as they grow.

\section{Foraging Biology and Diet}

Green turtles that have grown large enough (ca. $30-35 \mathrm{~cm}$ ) to reside in the nearshore benthic environment have a nearly exclusive herbivorous diet consisting of selected macroalgae and sea grasses. The diets of post-hatchlings and juveniles living in pelagic habitats appear to be entirely carnivorous (e.g., invertebrates and fish eggs), but records are only known from the occasional turtles encountered. Information on the diet and nutrition of the green turtle has been comprehensively reviewed by Mortimer (1982) and Bjorndal (1985). Algae and sea grasses occur in the insular Pacific region, but their distribution, abundance, and utilization by green turtles are only known for a few areas.

Seagrass beds are abundant in the high islands of the FSM (Kosrae, Pohnpei, Chuuk, Yap) and the Republic of Palau (Koror, Babeldaob), concentrated on mostly fringing reef flats especially in lagoons and a few barrier reef flats. Seagrasses are also present on some low coral islands and atolls in the FSM and Marshalls. Exceptionally large seagrass meadows occur off northern Babeldaob and northeast of Peliliu Island in Palau. The Palau Southwest Islands and Kayangel Atoll in Palau also support small seagrass flats. Sea grasses are also present on some low coral islands and atolls in the FSM and Marshalls.

Seagrasses are rare in the Mariana, Marshalls and Hawaiian Islands and absent in American Samoa and the unincorporated islands. Guam supports well-developed seagrass beds on many reef flats but only a few seagrass beds are found in the CNMI. Likewise only a few seagrass beds have been reported on the atolls of the Marshall Islands (Arno, Kwajalein, Majuro).

At certain nearshore habitats of the Hawaiian Islands, green turtles feed heavily on benthic algae of the genera Codium, Amansia, Pterocladia, Ulva, and Gelidium. In addition, two ubiquitous species of exotic algae, Acanthophora spicifera and Hypnea musciformis, are widely consumed. The former was believed to have been accidentally introduced from Guam on the hull of a barge during the early 1950s. The latter species was intentionally brought from Florida in 1974 to the island of Oahu (and subsequently spread on its own elsewhere) as part of a seaweed farming experiment (see Balazs et al. 1987; Russell and Balazs 1994). Green turtles in the Hawaiian Islands also forage on hila hawaiiana, the endemic and only sea grass that occurs there. However, it is not widespread nor abundant except for a few localized sites such as in Kaneohe Bay on Oahu, South Molokai, and Anini on Kauai.

Green turtles resident to Johnston Atoll feed almost exclusively on the green algae, Caulerpa racemosa and Bryopsis pennata. These two species grow in abundance along the south shore of the main islet (Johnston Island) where an untreated human sewage outfall and chemical weapons incineration plant are located (Balazs 1985a). 
Analysis of stomach samples from 518 turtles from eastern Australia showed that algae (various species of Rhodophyta, Cholorohyta and Phaeophyta) comprised over $99 \%$ of the diet in most cases, although the hydrozoan jelly, Physalia sp., and unidentified gelatinous mollusk egg cases were also consumed (Forbes 1994). The same study showed that the algal turf assemblage was "heavily exploited by the Heron Reef green turtles", and that the turtles undertook dietary shifts when certain algae became available.

\section{Growth}

Green turtles living in the wild exhibit slow growth and delayed sexual maturity. The growth rates of immature green turtles have been studied by in-water tag and recapture techniques conducted in the Hawaiian Islands, Johnston Atoll, Australia, and at several sites in the western Atlantic. Except for the first two locations, no research on growth of green turtles has been undertaken anywhere else in the insular Pacific region.

Growth rates have been found to vary considerably at several discrete foraging sites in the Hawaiian Islands located between the archipelago's extremities of latitudes $19^{\circ}-28^{\circ}$ North, and longitudes $155^{\circ}-178^{\circ}$ West. The growth rates here ranged from about $1-5 \mathrm{~cm}$ per year in SCL for turtles measuring 37-59 cm (Balazs 1979, 1982b, Balazs et al. 1994a). Some of the turtles living at a foraging site situated at the lowest latitude $\left(19^{\circ} \mathrm{N}\right)$ demonstrated the fastest rate of growth (5 $\mathrm{cm} /$ year). The forage quality, algal species availability, and abundance were believed to play a significant role in the turtles' relatively rapid growth. Turtles residing at this site fed exclusively on the red alga, Ptercladia capillacea. It is speculated that substantially faster growth rates may result at certain pastures having an abundance of high quality forage located at low latitudes closer to the equator. Seagrass and algae beds in Fiji, the Gilbert Islands and the Gilbert Islands and the Phoenix Islands (Kiribati), Western Samoa, Vanuatu, and Papua New Guinea offer such a possibility (see Zug and Balazs 1985).

Continuing studies through 1991, which included additional Hawaiian green turtle foraging pastures, indicated an overall average annual rate of growth of about two $\mathrm{cm} /$ year for all size classes ranging from $35-82 \mathrm{~cm}$. The minimum size observed for nesting females in Hawaii is 81 $\mathrm{cm} \mathrm{SCL}$ (Balazs 1982b). Based on these data, it is estimated that an average of at least 25 years would be needed to achieve sexual maturity (i.e., first breeding migration to French Frigate Shoals). While these data are subject to more comprehensive analysis, results of a preliminary study using skeletochronological aging techniques were consistent with the above findings (Zug and Balazs 1985).

Growth studies conducted in Australia have indicated that the length of time required for green turtles to attain minimum breeding size exceeds what has thus far been found in the Hawaiian Islands (Limpus and Walter 1980). Investigations of green turtles in the western Atlantic conducted by Mendonca (1977), Frazer and Ehrhart (1985), Frazer and Ladner (1986), Bjorndal and Bolten (1988), and Boulon and Frazer (1990) all suggest comparatively slow growth rates, albeit slightly faster than what has thus far been found in the Pacific. Carapace measurements of adult females recorded on nesting beaches over several seasons have shown that green turtles grow at an exceedingly slow rate $(0.5 \mathrm{~cm} /$ year in the Hawaiian Islands) once sexual maturity has been attained (see also Carr and Carr 1970). 
There are no records of growth in the wild for post-hatchling and juvenile green turtles residing in pelagic habitats. In those pelagic areas where an abundance of high quality food may be available, growth on a carnivorous diet might be expected to exceed that which results from herbivory in benthic habitats.

\section{Reproduction}

According to Owens (1980 in Eckert 1993), mating precedes egg-laying by 25-35 days. Adult female green turtles emerge at night to excavate nests and deposit eggs during the warmer months of the year at sites usually far removed from their resident foraging pastures (see Migrations and Movements). Descriptions of the nesting sequence have been reviewed by Ehrhart (1982). The influence of beach sand characteristics on the reproductive aspects of the green turtle has been investigated by Mortimer (1990) in a study that includes several nesting sites from the insular Pacific region.

In Hawaii, greens lay up to six clutches of eggs per season, with a mean of 1.8 (Balazs 1980). Hendrickson (1958 in Eckert 1993) reported greens nesting up to 11 times at Sarawak Turtle Island. Clutches consist of about 100 eggs each, laid at 10-15 day intervals. As previously mentioned, the females migrate to breed only once every two or possibly many more years, although the common remigration intervals reported for several rookeries worldwide are two and three years. Limpus et al. (1994) report that the modal remigration interval for Heron Island, Australia is five years; laparascopic examination of females tagged on nesting beaches and recaptured at their foraging grounds has confirmed that most females wait five or more years between breeding seasons. Once the eggs are laid and covered they incubate in the sand unattended for about two months (54-88 days in Hawaii, with a mean of 64.5 [Balazs 1980]). The hatchlings dig upward in a communal effort and take 2-3 days before reaching the surface and emerging usually under the coolness of night. Newly emerged hatchlings are strongly photopositive and can be disoriented away from their path to the sea by artificial lighting.

All sea turtles are now known to have temperature-dependent sex determination (Mrosovsky and Yntema 1980; Yntema and Mrosovsky 1980; Morreale et al. 1982). Eggs that incubate below a pivotal temperature produce hatchlings that are predominantly males, while eggs incubated above the pivotal temperature are predominantly females. Alvarado and Figueroa (1987) reported that for East Pacific green turtles nesting in Michoacan, Mexico, average temperatures less than $27^{\circ} \mathrm{C}$ during the middle trimester resulted in $100 \%$ males. Temperatures greater than $31^{\circ} \mathrm{C}$ produced $100 \%$ females, while those in between produced mixed clutches.

The degree of predation on eggs and hatchlings on a nesting beach varies considerably between breeding sites, and it should not be assumed that mortality is always high. For example, at French Frigate Shoals in the NWHI there is virtually no predation on eggs and, while numerous seabirds including frigate birds inhabit the area, no evidence of avian predation on hatchlings has been detected during studies. Predation on hatchlings at French Frigate Shoals when they pass through the nearshore waters en route to the open ocean does not appear to be high either (Balazs 1980). However, this factor is far more difficult to quantify. Each breeding site must be individually investigated. Conclusions reached for one site must not be applied to another without supporting documentation. 
At least in some populations, there is strong nest site fidelity within a season. In the Sarawak Turtle Islands, only $3.7 \%$ of 5,748 records showed turtles changing islands in between nestings after an average internesting interval of ten days, and most of those only shifted between islands less than 500 m apart (Hendrickson 1958 in Eckert 1993).

Comparatively little is known about the reproductive biology of male green turtles (but see Balazs 1983b). Except for in the east Pacific, copulation occurs early in the breeding season but not after a female lays her first clutch of eggs. In contrast, black turtles in the east Pacific are reported to periodically continue to copulate between the female's successive egg clutches throughout the season.

\section{Offshore Behavior}

Based on the behavior of post-hatchlings and juveniles raised in captivity, it is presumed that those in pelagic habitats live and feed at or near the ocean surface, and that their dives do not normally exceed several meters in depth. As mentioned earlier, it is also presumed that drift lines or surface current convergences are preferential zones due to increased densities of likely food items. In the western Atlantic, drift lines commonly contain floating Sargassum capable of providing small turtles with shelter and sufficient buoyancy to raft upon. In the insular Pacific region there is nothing similar in the way of floating algae to correspond with the phenomenon present in the Atlantic.

Certain nearshore marine habitats of the insular Pacific region, as elsewhere worldwide, constitute essential living space for juvenile, subadult, and adult green turtles. Behavior at these discrete benthic sites includes: foraging on marine vegetation (algae and/or sea grass), lying motionless on the ocean bottom to "rest" or possibly to avoid predators, being groomed by fishes to remove ectoparasites (see Balazs et al. 1994a; Losey et al. 1994), and courtship and copulation in waters proximal to nesting beaches. In contrast, post-hatchling and juvenile green turtles up to about $35 \mathrm{~cm}$ in carapace length inhabit pelagic or open-ocean habitats far removed from land. Adults of both sexes also use the pelagic environment when they periodically migrate between their resident foraging pastures and distant breeding sites. The spatial limits, or range, of these two types of habitats (nearshore benthic and pelagic) are not well known for green turtles of the insular Pacific region.

In the remote NWHI, and especially at French Frigate Shoals, adult male and female green turtles regularly haul out during the daytime to bask along the shoreline (Balazs 1980; Whittow and Balazs 1982). This behavior is not known to occur elsewhere in the insular Pacific region, although diurnally emerging non-nesting green turtles have been reported from the Galapagos and certain (but by no means widespread) sites in Australia.

\section{Health Status}

Green turtles residing in certain benthic habitats of the Hawaiian Islands are afflicted by lobulated tumors (fibropapillomas) on their skin, scales, scutes, eyes, oral cavities, and viscera (Balazs and Pooley 1991). The tumors begin as small, localized lesions that rapidly grow to exceed $30 \mathrm{~cm}$ in diameter, greatly interfering with or even prohibiting swimming, feeding, breathing, or seeing. The lesions have been classified as fibropapillomas, based on established histologic 
criteria for tumor classification. The cause of this disease is unknown, but a herpes virus is highly suspected based on recent research (Herbst 1994). The disease has increased to epidemic proportions in Hawaii since the mid-1980s. Similar severe outbreaks in green turtles over the same time period have also been reported in Florida, several Caribbean nations, and at a few other sites worldwide. In the Hawaiian population, the disease represents the single most significant threat to the green turtle's survival and is considered of highest priority for ongoing research.

During the 1991 nesting season, three turtles were seen at Gielop in Yap with abnormal growths on the carapace that have been diagnosed as fibropapillomas (Kolinski 1994).

Green turtles are known hosts for an array of internal parasites, especially blood flukes, which may play some debilitating role in the impact of the fibropapilloma disease. In addition, Ozobranchus leeches, burrowing Stephanolepas barnacles, and other external parasites (including ticks at nesting beaches) are commonly present, but again their impact on health status, and potential as vectors for disease, are entirely unknown (see Balazs and Pooley 1991).

\section{H. Threats}

This section presents a brief overview of threats to green turtles in the Pacific basin, followed by summaries of major threats in each U.S.-affiliated island group. A third section then presents more detailed information specific to each island group.

"Threats" to sea turtles are broadly defined as any factor that jeopardizes the survival of turtles or impedes the recovery of their populations. Twenty-six kinds of threats have been identified in this and previous Recovery Plans, but it is readily apparent that all are not equally important and that threats in one Pacific area may not be relevant in another area. Consequently, each island group was evaluated separately based on information received from the Recovery Team and Technical Advisors. Table 1 lists the 26 threats and ranks their significance. Definitions of the threats are provided in subsequent text.

When viewing Table 1, it should be recognized that there are limitations inherent in this tabulation. First, generalizations are made. Some island groups, such as the Republic of Palau, consist of over 500 islands; consequently, the data presented in Table 1 are limited to a general statement about conditions for the group as a whole. Similarly, most of the island groups possess both sparsely inhabited remote islands and heavily inhabited main islands. The distribution of turtles and the kinds of threats they face would obviously differ in these two types of islands. Specific information about individual islands, if available, is presented in 'General Threat Information'. Second, there are data limitations. For most islands, information about turtle threats is sparse (see 'Pacific Synopsis').

\section{Pacific Synopsis}

The eight U.S.-affiliated island groups in the Pacific consist of several thousand islands spread across a region twice the size of the continental United States. This vast and diverse area is inhabited primarily by two species: green and hawksbill turtles. 
A fundamental problem for the Pacific region is that, with few exceptions, there is a serious shortage of information on all aspects of turtle ecology. For many areas, the most basic information (e.g., population size, nesting beaches, distribution, migration patterns) is extremely rudimentary. While this lack of data may not be a direct threat to the turtles themselves, it will certainly hamper effective recovery efforts for them. For example, it will slow the protection of important nesting habitat because many such beaches have not yet been identified. The principal exception to this information void is Hawaii, where turtle studies have been conducted for many years.

Based on knowledgeable accounts, turtle populations have declined dramatically in the Pacific islands. Harvest by humans is by far the most serious problem turtles face, particularly green turtles which have historically been used for food. This is illustrated in Table 1, which shows that harvests of turtles on nesting beaches and in coastal water were identified as major threats in most of the eight U.S.-affiliated island groups reviewed in this report.

Turtles have been harvested for centuries by native inhabitants of the Pacific region. In modern times, however, a severe overharvest has resulted from a variety of factors, among which are the loss of traditional restrictions that had limited the numbers of turtles taken by island residents, modernized hunting gear, easier boat access to remote islands where turtles nest, extensive commercial exploitation for turtle products in both domestic markets and international trade, loss of the spiritual significance of sea turtles, inadequate regulations and lack of enforcement. One often-mentioned aspect of this problem is the pillage of wildlife on remote islands by supply ships, commercial fishing crews, and sometimes government vessels.

A greatly complicating aspect about turtle harvests is that stocks of turtles can be heavily harvested at both ends of their migratory routes -- first by one group of people when the turtles nest on beaches in one location and later by a second group of people when the same turtles migrate far away to their feeding areas at another location. Conservation efforts at only one end of this pathway are useful, of course, but may not be successful without similar conservation efforts at the other end.

Other than harvest, the major problems are those associated with habitat losses due to rapid expansion of resident human populations and/or increased urban and tourism development. As a generalization, the eight U.S.-affiliated islands can be divided into three groups based on their major turtle threats or problems: (1) Urbanized islands (main islands of Hawaii, CNMI, Guam) where the major threats are habitat loss and problems associated with rapidly expanding tourism, (2) Rural or developing islands (American Samoa except Rose Atoll, Republic of Palau, the inhabited islands of CNMI, FSM, RMI) where human consumption and the lack of basic biological information about turtle stocks prevail, and (3) Protected, uninhabited or military-controlled islands (the unincorporated islands, Rose Atoll, the uninhabited islands of CNMI, FSM and RMI, and Hawaiian Islands) where threats are negligible but biolocical information about turtle stocks is needed.

Another potential problem is the incidental take of turtles in distant-water fisheries, but data are generally lacking for this threat. 


\section{Regional Summaries}

\section{U.S. West Coast}

Primary turtle threats: See East Pacific green turtle Recovery Plan

\section{American Samoa \\ Primary turtle threats: directed take increased human presence algae/seagrass/reef degradation}

The main islands of American Samoa are steep volcanic islands with limited land suitable for human habitation and agriculture. The fast-growing human population $(46,600$ people, $3.7 \%$ growth rate, doubling time $=19$ years ) is concentrated along the southern coastline of Tutuila Island where significant pre-emption of former turtle nesting beaches has occurred due to village expansion and the placement of the island highway and structures to protect them from coastal erosion. The harvest of any turtles and eggs encountered, is the major threat to turtle recovery in American Samoa. Although only a rough estimate, turtle populations have seriously declined and now may number only about 120 nesting females (greens and hawksbills, combined) per year. More data are needed to assess this trend.

Turtle tag returns show that American Samoa is dealing with a shared resource in the South Pacific Ocean. Nesting turtles have been tracked to foraging grounds in Fiji and French Polynesia. In order to recover this population, turtle conservation must be pursued in these countries as well.

\section{Hawaii}

Primary turtle threats: disease nest predation directed take fisheries incidental take boat collisions

The Hawaiian Archipelago consists of 132 islands spread over 2,450 km. Most of the 1.2 million inhabitants live in the eight Main Hawaiian Islands (MHI) which account for $99 \%$ of the State's land mass. Fewer than 10 people live in the NWHI.

The primary threats to green turtle recovery and conservation include the loss of foraging habitats to nearshore development in $\mathrm{MHI}$ (e.g., marina construction, artificial beach development, siltation from agricultural runoff, contamination of forage areas from toxic spills, resort development, and increased vessel traffic), entanglement and ingestion of marine debris, incidental take in sport and commercial fisheries, poaching, and proliferation of disease (fibropapillomas) throughout the turtle population. While human impacts can be readily identified and corrected or mitigated in some 
cases, the potential adverse impacts of fibropapilloma disease may have no reasonable remedy, as its cause is still unknown.

\section{Guam}

Primary turtle threats: directed take increased human presence coastal construction nest predation algae/seagrass/reef degradation

There is limited information available regarding turtle threats in Guam. The DAWR, in past correspondence, indicated that the two principal threats to sea turtles in Guam are thought to be habitat destruction and harvest. Habitat destruction has resulted mainly from construction and development due primarily to growing tourism. In 1990, over 740,000 tourists visited the island and their numbers are expected to increase. On the northern portion of Guam, where the majority of nesting occurs, the military base has limited public access and development, but landowners in the Uruno area are attempting to develop their land as well, which would put some of the last nesting sites in danger. Another effect of development is sedimentation which has damaged Guam's coral reefs, and presumably, food sources for turtles.

Turtles were traditionally taken by residents for celebrations, and recent reports indicate that illegal harvesting still occurs. There is also poaching by immigrants, fishing crews, and tourists, especially those from areas where they are accustomed to eating turtles legally. The language problem for non-English speaking immigrants and lack of knowledge about local regulations has caused the majority of such problems. Incidental catch of turtles in coastal waters by commercial fishing vessels probably also occurs.

Republic of Palau

Primary turtle threats: directed take increased human presence algae/seagrass/reef degradation

The Republic of Palau consists of two distinctive island groups, a northern group consisting of several large islands and over 200 small islands collectively called the Rock Islands, and a southwest group of the six small southwest Palau islands located $300-600 \mathrm{~km}$ south of the Rock Islands. Most of the 15,000 residents of the Republic of Palau dwell on the northern islands of Koror, Babeldaob, and Peleliu.

The Southwest Islands are small and sparsely populated (about 100 people). Green turtles nest there, particularly on Merir, and large populations forage at Helen Atoll. These populations have been reduced by commercial fishing crews, residents, and crews of supply vessels out of Koror. Although the Southwest Islands are remote, humans are present on all green turtle nesting 
beaches in the area. Transportation between these islands and the central Palau Archipelago continues to increase, with inevitable increases in the exploitation of turtles.

By far the greatest threat in both island groups is the directed take of turtles in coastal waters (which is legal during seven months of the year) and nesting turtles and eggs (which is illegal). Enforcement is lacking.

Commonwealth of the Northern Mariana Islands (CNMI)

Primary turtle threats: directed take increased human presence coastal construction algae/seagrass/reef degradation

The Mariana Archipelago consists of 15 major islands, stretching approximately $675 \mathrm{~km}$ from Guam to Farallon de Pajaros. The islands are politically divided into two governing bodies: Guam (a U.S. Territory) and CNMI which includes the remaining islands. In CNMI, Saipan, Tinian and Rota are the largest islands and contain over $95 \%$ of the total population. Saipan is the major business and tourist center for CNMI. The ten islands north of Saipan are relatively small, isolated and sparsely inhabited, primarily due to active volcanic activity. Due to the rapidly expanding development on Saipan, Tinian and Rota, hotels and human activities are beginning to dominate beaches used by nesting turtles.

Sea turtles are considered a traditional food and are readily taken on nesting beaches or in coastal waters. Nesting seasons and sites, as well as feeding areas, are well known to the indigenous fisherman.

Federated States of Micronesia (FSM)

Primary turtle threats: directed take nest predation dynamite fishing

FSM covers a vast oceanic region of the Caroline Islands and extends $2,500 \mathrm{~km}$ from one end to the other. It has 600 islands (65 are inhabited) divided among four states: Pohnpei, Kosrae, Chuuk, and Yap. There has been a general decline in numbers of nesting turtles throughout FSM, though hard data are lacking. Turtles remain common only in some remote areas, such as the outer islands of Yap where traditional customs limit the numbers of turtles harvested for food although the customs are being disregarded on more and more islands.

Pohnpei State (population 33,000) consists of the main island of Pohnpei and eight atolls. The remaining principal turtle nesting area is Oroluk Atoll, where numbers have declined. Only 7-10 green turtles per year are now thought to nest there. Oroluk was uninhabited for many years but the Pohnpei State government now leases the island to a group of settlers from Kapingamarangi 
Atoll. Houses and pig pens on Oroluk beaches probably continue to interfere with turtle nesting. No nesting has been observed on other islands of Pohnpei, although sporadic usage may occur.

Kosrae (population 7,200 ) no longer has any significant nesting area, but turtles are common in coastal waters.

Chuuk State contains about 300 islands and 50,000 people. There is one major nesting site on East Fayu Island and probably some use of other islands. Unfortunately the turtle population at East Fayu was on the verge of extinction when visited several years ago ( $M$. Nelson, Marine Resources Division, FSM, pers. comm.), because turtles were sold commercially as well as taken for subsistence. Important turtle nesting beaches in Chuuk lagoon have all been depleted of turtles, except for one or two islands of the southern barrier reef.

Yap State includes the four closely associated high islands of Yap (commonly referred to as Yap Proper), three coral islands and 12 coral atolls. Turtles and turtle eggs have been exploited in Yap State for as long as people have inhabited these islands. Turtles continue to play a subsistence role and are an important part of traditional culture. A common perception among the people is that, over the years and despite annual fluctuations, there has been a gradual decline in the number of turtles visiting or residing within this region. Harvesting levels have increased at the remote uninhabited islands of West Fayu and Pikelot due to increased access using motorized skiffs from the nearest inhabited atolls (Lamatrek, Elato, Satanal).

Traditional systems regarding turtles vary somewhat throughout the islands. Some of these systems appear to restrict the level of human interaction with turtles, though conservation of the resource does not appear to have been a motivating factor. In general, the people of Yap State have taken advantage of greater abilities to harvest turtles and turtle eggs through the use of introduced foreign technologies and materials. Over-harvesting, coupled with the gradual loss of a number of traditional practices related to the taking of turtles and turtle eggs, appears to be the main threat to turtle populations. Turtles tagged in YAP and recovered in the Philippines and Majuro, RMI indicate that the FSM is dealing with a shared resource. In order to recover this population, turtle conservation must be pursued in these countries as well.

\section{Republic of the Marshall Islands (RMI)}

\section{Primary turtle threats: directed take nest predation fisheries incidental take}

There is limited information available regarding turtle threats in the 29 Atolls and south islands of RMI. The consumption of nesting turtles and their eggs appears to be the single-most important source of turtle mortality. Turtle harvest has expanded to all of the atolls, with Majuro, Ebeye, and the Southern Islands purchasing turtles from the Northern Islands where they nest. There is little or no control over the harvest on any of the islands, although informal control comes from the owner of the land (upon which the turtles are nesting). The turtles are primarily harvested from the nesting beaches and are generally taken for celebrations. Turtle eggs are regularly eaten. Also, eggs are hatched and the young kept as pets. In some cases the practice of raising young is 
mistakenly believed by the islanders to be a good conservation practice. The harvest of nesting turtles and their eggs is illegal, but few know of these regulations. The major turtle nesting beaches on Bikar Atoll, Jemo Island, and Erikub Atoll, and possibly Ailinginae are not continuously uninhabited. However, the high price paid for turtles and improvements in boating and harvest technologies have led to increased levels of harvest at the uninhabited atolls by Marshallese from adjacent inhabited atolls.

A second major threat to nesting turtles comes from Polynesian rat predation on nests. The feral predators have been documented to consume large numbers of eggs on Erikub and Bikar Atolls.

Unincorporated Islands (Wake, Johnston, Kingman, Palmyra, Jarvis, Howland, Baker, Midway)

Primary turtle threats: coastal construction nest predation

beach erosion

environmental contamination

The unincorporated islands consist of protected islands in the National Wildlife Refuge system (Johnston, Howland, Baker, Jarvis), islands with military facilities (Wake, Johnston, Palmyra ), and one island with no permanent land (Kingman Reef). Some are used by nesting green turtles, and all probably provide marine feeding grounds for green and perhaps hawksbill turtles. Other than Johnston Atoll which is inhabited by $800-1,000$ people and Wake and Midway islands where smaller numbers of people live, few or no people live on the other islands. While there are no major threats to sea turtles at the present time, little is known about the biology of the turtles in this region. Currently the only identified problems are in regard to activities associated with human presence such as coastal construction, beach erosion and feral animal predation of nests.

Midway, at the northwest end of the Hawaiian chain is presently under U.S. Navy jurisdiction, but the naval station is being closed. Midway and the other unincorporated islands may revert to the jurisdiction of the state of Hawaii. 
TABLE 1. Threat checklist for green sea turtles in the

western and central Pacific Ocean.
Codes $1=$ major problem

$2=$ moderate problem

$3=$ minor problem
$-=$ not current problem

$?=$ unknown

$P=$ known problem but extent unknown

\begin{tabular}{|c|c|c|c|c|c|c|c|c|c|c|}
\hline \multicolumn{2}{|c|}{ Threat } & $\begin{array}{l}\text { U.S. } \\
\text { West }\end{array}$ & $\begin{array}{l}\text { Amer. } \\
\text { Samoa }\end{array}$ & Hawaii & Guam & Palau & CNMI & FSM & RMI & $\begin{array}{l}\text { Un- } \\
\text { incorp. }\end{array}$ \\
\hline \multicolumn{11}{|c|}{ Nesting Environment } \\
\hline \multirow[t]{2}{*}{1} & Directed take - eggs & - & 1 & - & 1 & 1 & 1 & 1 & 1 & - \\
\hline & Directed take - turtles & - & 1 & - & 1 & 1 & 1 & 1 & 1 & - \\
\hline 2 & Increased human presence & - & 2 & - & 1 & 1 & 1 & 3 & 3 & - \\
\hline 3 & Coastal construction & - & - & - & 1 & - & 1 & 3 & 3 & 3 \\
\hline 4 & Nest predation & - & - & 2 & 2 & $\mathrm{P}$ & $?$ & 1 & 1 & 3 \\
\hline 5 & Beach erosion & - & 3 & 3 & $?$ & 3 & $?$ & $P$ & 3 & 3 \\
\hline 6 & Artificial lighting & - & $P$ & $P$ & $\mathrm{P}$ & 3 & $P$ & - & $\mathrm{P}$ & - \\
\hline 7 & Beach mining & - & - & - & ? & - & - & - & - & 3 \\
\hline 8 & Beach vehicle driving & - & - & 3 & $\mathrm{P}$ & - & $?$ & - & - & - \\
\hline 9 & Exotic vegetation & - & - & - & - & - & - & - & - & - \\
\hline 10 & Beach cleaning & - & - & - & - & - & - & - & - & - \\
\hline 11 & Beach replenishment & - & - & - & - & - & - & - & - & - \\
\hline \multicolumn{11}{|c|}{ Marine Environment } \\
\hline 12 & Directed take & - & 1 & 2 & 1 & 1 & 1 & 1 & 1 & - \\
\hline 13 & Natural disasters & - & $P$ & $P$ & $P$ & - & $P$ & $P$ & $P$ & $P$ \\
\hline 14 & Disease/parasites & - & $?$ & 1 & $?$ & $?$ & $?$ & 2 & - & $?$ \\
\hline 15 & $\begin{array}{l}\text { Algae/Seagrass/Reef } \\
\text { degradation }\end{array}$ & - & 2 & 3 & 2 & 2 & 2 & 3 & 3 & $P$ \\
\hline 16 & $\begin{array}{l}\text { Environmental } \\
\text { contaminants }\end{array}$ & - & $P$ & $P$ & $?$ & $P$ & 3 & - & 3 & 3 \\
\hline 17 & Debris (entangle/ingest) & - & $P$ & 3 & $?$ & - & $P$ & $P$ & $P$ & $\mathrm{P}$ \\
\hline \multirow[t]{3}{*}{18} & Fisheries (incidental take) & & & & & & & & & \\
\hline & -domestic waters & - & 3 & 2 & $?$ & $\mathrm{P}$ & $P$ & $P$ & 2 & $\mathrm{P}$ \\
\hline & -international & - & $\mathrm{P}$ & 2 & $?$ & $P$ & $\mathrm{P}$ & $P$ & 3 & $\mathrm{P}$ \\
\hline 19 & Predation & - & $?$ & $?$ & $?$ & $?$ & $?$ & $?$ & $?$ & $?$ \\
\hline 20 & Boat collisions & - & - & 2 & - & 3 & - & - & - & - \\
\hline 21 & Marina/dock development & - & - & - & $?$ & - & - & - & 3 & - \\
\hline 22 & Dredging & - & - & $\mathrm{P}$ & $?$ & $\mathrm{P}$ & - & $?$ & 2 & - \\
\hline 23 & Dynamite "fishing" & - & $P$ & $P$ & $P$ & $P$ & $P$ & 2 & $P$ & $P$ \\
\hline 24 & Oil exploration/development & - & - & - & - & - & - & - & - & - \\
\hline 25 & Power plant entrapment & - & - & - & - & - & - & - & - & - \\
\hline 26 & Construction blasting & - & - & - & - & - & - & - & 3 & 3 \\
\hline
\end{tabular}


General Threat Information with comments on specific U.S. jurisdictions.

This section provides the supportive information used to rank the 26 turtle threats listed in Table 1. Each threat is defined and then evaluated separately for each of the eight U.S.-affiliated island groups (where applicable). The first 11 threats pertain to the turtle's nesting environment, the latter 15 to the marine environment.

\section{Nesting Environment}

\section{Directed Take}

The harvest of sea turtles and/or their eggs for food or any other domestic or commercial use constitutes a widespread threat to these species. Removing breeding adults from a population can accelerate the extinction of local stocks, and the persistent collection of eggs guarantees that future population recruitment will be reduced. This category includes only the harvest of sea turtles (typically nesting females) and their eggs on land. Harvest at sea is discussed in a later section. (see Recovery - Section 1.1.1)

\section{U.S. West Coast: Not a current problem.}

American Samoa: Turtle harvest is a significant source of mortality in the Territory. Turtles and their eggs, when found, are consumed. The concept of turtle conservation faces several difficulties in contemporary American Samoa. For example, many people are unaware that it is illegal to take sea turtles within the Territory. Public acceptance of conservation issues is a challenging problem. Although many people acknowledge that there are considerably fewer turtles on their beaches than when they were children, few indicated concern for the future of turtles. Some residents expressed the view that turtles were placed in the ocean by God for man to take, and others felt that if they did not take the turtle, someone else would. Another aspect of the problem is that villagers may keep hatchlings as pets, which eventually die. Also the implications of nest beach fidelity and how this factor can accelerate extirpation of nesting stocks on specific islands are not well understood or acknowledged.

Hawaii: Because most green turtles nest at French Frigate Shoals, which is far removed from populated islands, their take from nesting beaches is not a current problem.

Guam: Directed take is one of the major threats to turtles in Guam. Turtles were traditionally taken by residents for celebrations, and reports indicate that illegal harvesting still occurs. Poaching also occurs by immigrants, fishing crews, and tourists, especially those from areas where they are accustomed to eating turtles legally. The language problem for non-English speaking immigrants and lack of knowledge about local regulations has caused the majority of such problems. When turtle poachers are convicted, all gear and vehicles (car, boat) are confiscated and fines and/or penalties are levied.

Republic of Palau: Directed take is considered to be a major problem. The seasonal harvest from coastal waters has been legal, but the take of nesting turtles and their eggs is not. Enforcement is lacking, however and both local and federal regulations are widely ignored. The illegal harvest of turtles and eggs at remote islands and atolls beyond the watchful eye of local authorities is also 
a problem. In October 1994, Palau became an independent nation in free association with the United States, therefore ESA and other federal laws no longer apply to actions in Palau.

CNMI: In CNMI, turtles are a traditional delicacy for most ethnic groups. Knowledge of existing regulations does not inhibit many people from eating turtles or their eggs. Female turtles crawling toward the nesting area are taken even before the eggs are laid.

FSM: Turtle harvest is the most significant source of mortality within the region. In general, both turtles and eggs are consumed if encountered (direct take varies from island to island based on rights to the resource). Nesting has apparently been extirpated from one state (Kosrae) due to overharvest of nesting females. People also raise hatchlings as pets which generally die in captivity, but the impact of this is thought to be low.

Laws dealing with the harvesting of turtles and eggs are in need of revision. Both present and future laws will remain unenforceable and unagreeable to the people unless the people themselves enact and enforce them at the community level. A few islands (Elato, Lamotrek, Satawal) have introduced their own regulations controlling the take of turtles (such as waiting until after a nesting turtle lays eggs before harvesting it). Nevertheless, turtle harvesting continues to increase, even among the populations of these islands.

Marine Resources Management Division (MRMD) has, in cooperation with specified island residents, been collecting data on the number of turtles caught and consumed throughout the outer islands. Most of the outer islands within the state have generally sent in this type of information. These data have not yet been analyzed.

The introduction and use of motorized boats have increased peoples' ability to reach islands where turtles nest. Travel by traditional methods of transportation (outrigger canoes) was and is restricted by weather patterns, the length of the voyages, etc. Motorized craft have allowed for an extended travel season as well as for an increased frequency of visits to the uninhabited islands.

RMI: The consumption of nesting turtles and their eggs is the single-most important source of mortality to turtles. Turtle harvest has expanded to all of the atolls, with Majuro and the Southern Islands importing turtles from the Northern Islands. On Ebeye and Majuro, imported turtles sold for about $\$ 300.00$ U.S. dollars in 1988 (Jim Maragos, pers. comm.). There is little or no control over the harvest on any of the islands, although informal control comes from the owner of the land (upon which the turtles are nesting). The turtles are primarily harvested from the nesting beaches and are generally taken for celebrations. Turtle eggs are regularly eaten. Also, eggs are hatched and the young kept as pets --in some cases the practice of raising young is considered a good conservation practice. The harvest of nesting turtles and their eggs is illegal, but few know of these regulations.

Unincorporated: Not a current problem. Nesting activity, if it ever occurred at Johnston, is prevented by the construction of vertical seawalls. 


\section{Increased Human Presence}

Human populations are growing rapidly in many areas of the insular Pacific and this expansion is exerting increasing pressure on limited island resources. Threats to sea turtles include increased recreational and commercial use of nesting beaches, the loss of nesting habitat to human activities (e.g., pig pens on beaches), beach camping and fires, an increase in litter and other refuse, and the general harassment of turtles. Related threats, such as coastal construction, associated with increasing human populations are discussed separately. (see Recovery - Sections 1.1,1.2)

\section{U.S. West Coast: Not a current problem.}

American Samoa: Continued incremental loss of habitats occurs due to varied activities of a rapidly expanding human population. American Samoa has one of the fastest growth rates in the world; the doubling time is only 19 years.

Hawaii: Not a problem for green turtles nesting at remote NWHIs.

Guam: Habitat destruction is a major threat to Guam turtles. Guam had over 740,000 tourists in 1990. With tourism expected to increase, the number of hotels and other beachfront development and usage will also increase.

Republic of Palau: Most nesting beaches occur on inhabited islands (Helen Atoll, Merir, Tobi, Kayangel). Residents of these remote nesting areas have been dependent on green sea turtles for food. As transportation to these remote areas improves, pressures on turtle stocks are bound to increase.

CNMI: Nesting habitat along the sand beaches of the Saipan Lagoon is rapidly disappearing due to rampant development.

FSM: Minor problem due to construction on nesting beaches of livestock pens at Oruluk Atoll.

RMI: Minor problem, primarily limited to Majuro Atoll.

Unincorporated: Generally a minor problem.

\section{Coastal Construction}

The most valuable land on most Pacific islands is often located along the coastline, particularly when it is associated with a sandy beach. Construction is occurring at a rapid rate and is resulting in a loss of sea turtle nesting areas. This section discusses construction-related threats to the region's sea turtle nesting beaches, including the construction of buildings (hotels, houses, restaurants), recreational facilities (tennis courts, swimming pools), or roads on the beach; the construction of sea walls, jetties, or other armoring activities that can result in the erosion of adjacent sandy beaches; clearing stabilizing beach vegetation (which accelerates erosion); and the use of heavy construction equipment on the beach, which can cause sand compaction or beach erosion. (see Recovery - Sections 1.2.2, 1.2) 
U.S. West Coast: Not a current problem.

American Samoa: Few green turtles occur around the inhabited islands of American Samoa.

Hawaii: Not a current problem for green turtles at remote NWHIs.

Guam: Habitat destruction is a major threat to Guam turtles. Over 740,000 tourists visited Guam in 1990. With tourism expected to increase, the number of hotels and other beachfront development and usage will also increase.

Republic of Palau: Not a current problem. However, the newly independent Republic of Palau and the relaxation of U.S. environmental controls have opened opportunity for considerable road and resort planning and development during the past two years, some of which will lead to coastal construction.

CNMI: On Saipan, golf course, hotel and tourism-related development has severely impacted most of the historical nesting areas on the western portion of the island and residential development is beginning to threaten the eastern portion of the island. On Rota, nesting beaches appear limited to undeveloped private land due to heavy recreational use and shoreside tourist developments. Many of these "undeveloped" beaches are slated for development. On Tinian, the majority of the nesting beaches are on military-leased land where no construction is presently expected. Development of a large resort and casino on the southern side of the island will likely increase human disturbance on nesting beaches.

FSM: Construction of pig pens on turtle beaches is a problem at Oruluk Atoll, while coastal construction on the islets of Chuck lagoon has caused beach erosion (though no known nesting beaches have yet been affected).

RMI: Coastal construction is a moderate problem on Majuro Atoll, but no known nesting beaches are threatened. Military construction and activity at the U.S. missile testing facility at Kwajalein Atoll will occur near several turtle nesting beaches on the small outer islets.

Unincorporated: Generally a minor problem, except at Johnston Atoll where seawall construction has preempted use of beaches by nesting turtles.

\section{Nest Predation}

The loss of eggs to non-human predators is a severe problem in some areas. These predators include domestic animals, such as cats, dogs and pigs, as well as wild species such as rats, mongoose, birds, monitor lizards, snakes, and crabs, ants and other invertebrates. (see Recovery - Section 1.1.3)

U.S. West Coast: Not a current problem.

American Samoa: Not a current problem due to a recent rat eradication project. Rats had formerly been observed to attack hatchlings. 
Hawaii: Possibly a moderate problem at the primary nesting areas in French Frigate Shoals due to predation by ghost crabs, mongooses, cats, dogs, birds, and possibly rats and feral pigs.

Guam: Predation by crabs, feral dogs and pigs is a problem. In one nest, $20 \%$ of the eggs were eaten by crabs. Some nests are fenced to keep pigs out.

Republic of Palau: Not known as a current problem, however at Ngerecher-Ngerkeklau islands where pig predation is likely and at Merir dog predation is likely a problem.

CNMI: Not known to be a problem.

FSM: Impacts are area dependant. Out of 33 nests monitored on Olimarao Island, 15 (45\%) were attacked by ghost crabs. Twelve $(36 \%)$ of these were completely destroyed, the other three produced only 47 hatchlings. However, it is quite possible that tampering with the nests increased the likelihood that these nests would be invaded. In any event, predation by ghost crabs should be considered a potential threat to nests deposited on the two islands within this atoll (S Kolinksi, A. Smith, pers. comm.).

On Gielop Island, one or more ghost crabs were present in four of the 15 nests $(27 \%)$ at the time of examination (post-hatch). Predation damage appeared to have been minimal with the exception of one nest where 113 eggs produced only 42 hatchlings. Coconut crabs were commonly seen feeding on eggs strewn from 28 disrupted nests by the digging of other nesting turtles.

On Losiep Island (near Gielop island), Ulithi residents report that the introduction of monitor lizards by the Japanese has been the main cause for the virtual collapse of this island's nesting turtle population. Reports indicate that Losiep was once one of the main turtle islands for the region. Monitor lizards apparently feed on the turtles' eggs as they are being deposited, and may be able to dig down into a buried nest. On Oruluk Atoll, pig pens encroach on nesting beach areas.

RMI: According to a 1992 survey by Puleloa and Kilma (1992), Polynesian rat predation is very severe at Bikar. Because of the importance of Bikar (largest nesting area for green turtles in the $\mathrm{RMI}$ ) this must be considered extremely serious.

Unincorporated: Apparently a minor problem.

\section{Beach Erosion}

Weather events, such as storms, and seasonal changes in current patterns can reduce or eliminate sandy beaches, degrade turtle nesting habitat, and cause barriers to adult and hatchling turtle movements on affected beaches. (see Recovery - Section 1.2.1,1.1.5.2)

\section{U.S. West Coast: Not a current problem.}

American Samoa: Weather records indicate that a severe tropical storm or hurricane hits somewhere in the Samoan island chain every three years on average, causing extensive erosion. A predicted rise in sea level due to global warming would increase erosion problems. 
Hawaii: Minor problem. Hurricane storm waves, tsunamis and coastal subsidence are known to cause erosion problems.

Guam: No information, but typhoons are frequent and likely to cause beach erosion.

Republic of Palau: Occasional storm erosion occurs, and this is a distinct problem at Helen Island.

CNMI: Not thought to be a threat to turtle populations, but typhoons are frequent and likely to cause beach erosion.

FSM: Likely a problem, although severe tropical storms and typhoons are common for this region. Seasonal changes in wind direction (which occur towards the end of the main nesting season - late July/early August) cause erosion. Only one nest on Olimarao and no nests on Gielop Island were jeopardized by shifting shoreline sands. Yap State's low coralline atolls are extremely vulnerable to rises in sea levels and will be adversely affected if hypothesized rises occur. Some erosion of nesting beaches at Oroluk was reported in 1990 after passage of Typhoon Owen.

RMI: Moderate problem. Shoreline erosion occurs naturally on many islands in the atolls of the Marshalls due to storms, sea level rise from ENSO's (EI Niño - Southern Oscillation) and currents. On the outer atolls, erosion has been aggravated by airfield and dock development, and by urban development on Majuro and Kwajalein Atolls.

Unincorporated: This is a problem at Palmyra Atoll.

\section{Artificial Lighting}

Hatchling sea turtles orient to the sea using a sophisticated suite of cues primarily associated with ambient light levels. Hatchlings become disoriented and misdirected in the presence of artificial lights behind (landward of) their hatching site. These lights cause the hatchlings to orient inland, whereupon they fall prey to predators, are crushed by passing cars, or die of exhaustion or exposure in the morning sun. Nesting adults are also sensitive to light and can become disoriented after nesting, heading inland and then dying in the heat of the next morning, far from the sea. Security and street lights, restaurant, hotel and other commercial lights, recreational lights (e.g., sports arenas), and village lights, especially mercury vapor, misdirect hatchlings by the thousands throughout the Pacific every year. (see Recovery - Sections 1.1.2, 1.1.4)

\section{U.S. West Coast: Not a current problem.}

American Samoa: Possibly a problem in coastal villages, although there are no documented cases of disoriented turtle hatchlings.

Hawaii: Not a current problem for green turtles at remote NWHIs, but possibly a problem on the $\mathrm{MHI}$ group.

Guam: A problem with unknown impact. 
Republic of Palau: Recently in 1994, the village of Melekeok (Melekeok State) reported that green turtle hatchlings were attracted into lighted houses and to street lights (M. Guilbeaux pers. comm.). Campfires and houselights are a problem at Angaur, Peleliu, Kayangel and the Southwest Island beaches.

CNMI: High potential as a future problem in Rota where resort development is flourishing. Presently not a problem on Tinian, but there is a potential problem as development continues. Most houses and hotels adjacent to the lagoon area of Saipan usually have some form of beach lighting. The Division of Fish and Wild life routinely reviews all major development projects adjacent to beach fronts through the Coastal Zone Management permitting process. A permitting condition restricts the orientation of night lights onto the lagoon beach area, and most establishments comply with this.

FSM: Not a current problem. Only two islands within two separate atolls (Falalop Ulithi and Falalop Woleai) have electricity. These islands are not known to have significant numbers of nesting turtles. Light beacons for ships have been placed on two of the small uninhabited islands (Woleai, Ulithi Atoll), but the impact on hatchling orientation is unknown.

RMI: Portions of Majuro and Kwajalein are lighted, but the impact is unknown.

Unincorporated: Not a current problem.

\section{Beach Mining}

Sand and coral rubble are removed from beaches for construction or landscaping purposes. The extraction of sand from beaches destabilizes the coastline (e.g., reduces protection from storms), removes beach vegetation through extraction or flooding and, in severe cases, eliminates the beach completely. When mining occurs on or behind a nesting beach, the result can be the degradation or complete loss of the rookery. In addition, females can become confused when they emerge from the sea only to find themselves heading down slope into a depression formed by mining activities; too often the outcome is that the female returns to the sea without laying her eggs. Even when eggs are successfully deposited, reduced hatch success results if nests are flooded or excavated during mining. (see Recovery - Section 1.2.2)

\section{U.S. West Coast: Not a current problem.}

American Samoa: Despite educational attempts and enactment of protective laws, the tradition of removing sand and coral rubble from shorelines continues at a surprisingly high rate (100 cubic yards/week) for a small island with limited beaches. However, the impact to turtles is probably not significant because affected beaches are usually along the island roadway, and most of these beaches are too narrow (due to road placement) to be suitable for turtle nesting. In some areas, shoreline erosion, exacerbated by beach mining, jeopardizes the island highway.

Hawaii: Not a current problem.

Guam: No information. 
Republic of Palau: Not a current problem.

CNMI: Not a current problem.

FSM: Not a current problem. Beach mining does occur on the island of Falalop Ulithi in Yap State and in Phonpei and Chuuk and may occur on other inhabited islands.

RMI: Mining of beach sand is a serious problem on Majuro, although not at the only known nesting beach (Iroij Island). Otherwise, beach mining does not appear to be a problem.

Unincorporated: Minor problem.

\section{Vehicular Driving on Beaches}

Driving on the beach causes sand compaction and rutting, and can accelerate erosion. Driving on beaches used by turtles for egg-laying can crush incubating eggs, crush hatchlings in the nest, and trap hatchlings after they emerge from the nest cavity and begin their trek to the sea. In the latter case, hatchlings are exposed to exhaustion and predators when they fall into and cannot climb out of tire ruts that are typically oriented parallel to the sea. (see Recovery - Section 1.2.6)

American Samoa: Not a current problem. In some areas (e.g., Sailele), a non-paved village road crosses upper beach areas where turtles may nest, but such areas are already heavily impacted by the villages and there is generally no available space to re-route the road.

Hawaii: Not a current problem for green turtles nesting in the NWHIs, but may be a minor problem on MHIs.

Guam: Vehicle traffic is extensive on nesting beaches.

CNMI: Although beach driving is a pastime on Saipan, the impacts are unknown.

Other areas: Not a current problem.

\section{Exotic Vegetation}

Introduced species can displace native dune and beach vegetation through shading and/or chemical inhibition. Dense new vegetation shades nests, potentially altering natural hatchling sex ratios. Thick root masses can also entangle eggs and hatchlings. (see Recovery - Section 1.2.3)

All areas: Not a current problem.

10. Beach Cleaning

Removal of accumulated seaweeds and other debris from a nesting beach should be accomplished by hand-raking only. The use of heavy equipment can crush turtle eggs and hatchlings and can remove sand vital to incubating eggs. (see Recovery - Section 1.2.5) 
All areas: Not a current problem. In CNMI, beach cleaning occurs in front of the major tourist hotels, but this is not thought to be a threat to turtle populations.

\section{Beach Replenishment}

The nourishment or replacement of beaches diminished by seawalls, storms, or coastal development can reduce sea turtle hatching success by deeply burying incubating eggs, depositing substrate (generally from offshore deposits) that is not conducive to the incubation of sea turtle eggs, and/or obstructing females coming ashore to nest by machinery, pipelines, etc. (see Recovery - Section 1.2.4)

All areas: Not a current problem.

\section{Marine Environment}

\section{Directed Take}

The harvest of juvenile and adult sea turtles for food or any other domestic or commercial use constitutes a widespread threat to these species. In particular, the exploitation of large juveniles and adults can accelerate the extinction of both local and regional stocks. This category includes only the harvest of sea turtles at sea. Harvest on the nesting beach was discussed in a previous section. (see Recovery - Section 2.1)

\section{U.S. West Coast: Not a current problem.}

American Samoa: Turtle harvest is the most significant source of mortality in the Territory. Turtles and their eggs, when found, are consumed. The concept of turtle conservation faces several difficulties in contemporary American Samoa. For example, most people are unaware that it is illegal to take sea turtles within the Territory. Public acceptance of conservation issues is a challenging problem. Although many people acknowledge that there are considerably fewer turtles on their beaches than when they were children, few indicated concern for the future of turtles. Some residents expressed the view that turtles were placed in the ocean by God for man to take, and others felt that if they did not take the turtle, someone else would. Another aspect of the problem is that villagers may keep hatchlings as pets, which eventually die. Also the implications of nest beach fidelity and how this factor can accelerate extirpation of nesting stocks on specific islands are not well understood or acknowledged.

Hawaii: A moderate problem in Hawaiian waters. Turtles are taken using spears, harpoons, nets, grappling hooks, firearms from shore, underwater bang sticks, nooses, and by hand capture.

Guam: See previous comments in Nesting Environment.

Republic of Palau: Green turtles are taken in nearshore waters year-round. However, it is legal to harvest turtles at sea with a minimum carapace length $(\mathrm{CCL} \geq 76.2 \mathrm{~cm}$ ) during two periods (seven months) of the year: February-May and September-November. Adults and large juveniles 
are preferred for special occasions such as funerals and other custom events. There are no statistics for the numbers of green turtles harvested or the distribution of the sizes taken.

CNMI: Sea turtles are considered a traditional food item and are hunted illegally to this day. Federal laws protecting turtles are known, but hotly contested by the public. CNMI Customs Officers routinely confiscate turtle handicrafts (combs, jewelry, etc.) at the airport. Confiscation of turtle products is the extent of prosecution. Most of the turtle products originate from the Republic of Palau (Belau) or FSM.

FSM: Significant problem for both legal and illegal harvests. Motorized boats, masks and snorkels, spear guns, and hooks have aided man in catching turtles. Mating turtles are often taken because they are easier to approach. A method involving tethering a female to attract males is occasionally practiced. In Pohnpei, it is legal to hunt large green turtles (greater than $76.2 \mathrm{~cm}$ ) in marine waters during two periods (February - May and September - November), but they are actually taken yearround. See previous comments in Nesting Environment.

RMI: Although harvests consist mostly of nesting turtles and their eggs, some turtles are taken by snorkelers in nearshore waters.

Unincorporated: Not a current problem.

\section{Natural Disasters}

Natural phenomena, such as cyclones, can contribute to the mortality of turtles at sea, particularly in shallow waters. Disease epidemics and other debilitating conditions that affect prey items (sea grass, coral, sponges, reef invertebrates) can also harm sea turtle populations. Storms can alter current patterns and blow migrating turtles off course into cold water. Unseasonable warm water incursions from subtropical regions into the northeastern Pacific, known as "El Niño" events, may cause green turtles to migrate north where they "cold stun" once they encounter colder water. El Niño events can also cause reduced food production for some turtle species which can reduce growth and fecundity. (see Recovery - Sections 2.1.6, 2.1.7, 2.2.1, 2.2.2)

\section{U.S. West Coast: Not a current problem.}

American Samoa: Mortality due to natural disasters is unknown. Recent weather trends indicate that a severe tropical storm or hurricane hits somewhere in the Samoan islands every three years on average.

Hawaii: Probably a minor problem. Turtles have been reported thrown ashore by tsunamis. Nesting sites have also been covered by lava flows, but only rarely (for example Halape, Kaimu).

Guam: An undetermined problem, although Guam is in an area that is regularly hit with typhoons.

Republic of Palau: Not thought to be a problem.

CNMI: An undetermined problem, although CNMI is in an area that is regularly hit with typhoons. 
FSM: Mortality due to natural disasters is unknown. A recent typhoon (1990/1991) nearly devastated some of the outer islands, but the impact to turtles in those regions is unknown.

RMI: Moderate problem, however the low elevation of these islands makes them particularly susceptible to typhoons, large waves and sea level rise.

Unincorporated: Minor problem.

\section{Disease and Parasites}

There are few data to assess the extent to which disease or parasitism affects the survivability of sea turtles in the wild. (see Recovery - Section 2.1.6)

\section{U.S. West Coast: Not a current problem.}

Hawaii: The tumor disease "fibropapilloma" has recently received a great deal of attention, and may now affect more than $50 \%$ of the green turtles in Kaneohe Bay, Hawaii. The disease is characterized by grayish tumors of various sizes, particularly in the axial regions of the flippers and around the eyes. This debilitating condition can be fatal. Neither a cause nor a cure has been identified.

FSM: Moderate problem with unknown impact. Four of 416 female green turtles (1\%) tagged at Gielop Island had large lesions covering large portions of their carapace. Lesions consisted of raised bubbly, papillary-like projections with numerous individual nodules and crevices. The largest lesions measured $136 \mathrm{~cm}$ in circumference and $10 \mathrm{~cm}$ in height. Carapace lesions were observed only on the vertebral and costal scutes. Upon examination, none of the lesions could be associated with any other obvious forms of external damage. The lesions appeared to be different from those identified as fibropapilloma on Hawaiian green turtles. Lesions of this type have also been reported on turtles foraging around Yap proper as well as turtles in the Elato and Lamotrek regions.

RMI: Green turtles in the RMI appear to be free of fibropapillomas (as of 1992).

Other areas: Unknown.

\section{Algae, Seagrass, and Reef Degradation}

Most sea turtle species depend upon sea grass and/or coral reef habitats for food and refuge. The destruction or degradation of these habitats is a widespread and serious threat to the recovery of depleted sea turtle stocks. The general degradation of these habitats can be affected by eutrophication, sedimentation, chemical poisoning, collecting/gleaning, trampling (fishermen, skin and SCUBA divers), anchoring, etc. (see Recovery - Section 2.2)

\section{U.S. West Coast: Not a current problem.}

American Samoa: A general degradation of coral reef habitats on the south side of Tutuila Island is occurring, due to both human impacts (particularly sedimentation resulting from erosion on steep 
agriculture slopes) and natural disturbances (recent hurricane damage). There are no known seagrass beds in the Territory, although some may occur in nearby Western Samoa.

Hawaii: Seagrass and coral reef habitat along the south coast of Molokai has been degraded from upland soil erosion and siltation. Coral reefs in Kaneohe Bay (Oahu), Hanalei Bay, Hanamaulu Bay, Nawiliwili Harbor (Kauai), Maalaea Bay (Maui) and Hilo Bay (Hawaii), and along the northeast coast of Lanai have all been degraded by sedimentation, sewage, or coastal construction.

Guam: Sedimentation has damaged Guam's coral reefs.

Republic of Palau: Offshore sand mining occurs in Palau, with possible implications for foraging habitat degradation. At the mouth of Lighthouse Channel (eastern side of Malakal Harbor) in 90 feet of water, green sea turtles used to be found foraging on seagrass beds but are no longer seen there as they once were ( $\mathrm{N}$. Idechong, Div. of Marine Resources, Palau, pers. comm.). This is a site for sand mining.

CNMI: Saipan is the only island that has extensive seagrass meadows inside the reef system, but impacts to seagrass meadows are not known.

Saipan's coral reef ecosystem, located along the western side of Saipan, is currently being impacted by terrigenous runoff and nutrient loading associated with sewage discharge from the Sadog Tasi Water Treatment Plant. Actual impacts to the reef are not known, but some sections of the reef system appear to be dying. Other islands do not have a well-developed fringing reef system or extensive seagrass meadows.

FSM: Coral reefs and seagrass beds have been severely degraded within the urban centers of the four states of the FSM: Pohnpei, Yap, Chuuk, and Kosrae.

RMI: Coral reefs and seagrass habitat off the lagoon shoreline of Kwajalein islands and Majuro have been degraded by coastal construction and/or eutrophication from sewage.

Unincorporated: Not a current problem, though the sewage outfall at Johnston may be a problem.

16. Environmental Contaminants

Chemical pollutants, such as petroleum, sewage, pesticides, solvents, industrial discharges, and agricultural runoff are responsible for an unknown level of sea turtle mortality each year. Environmental contamination also harms biologically important nearshore ecosystems, including seagrass, coral, mangrove, and algae communities. The declining productivity of seagrass and coral communities, in particular, can be hazardous to sea turtles that depend on these systems for nutrition and shelter. (see Recovery - Section 2.2.4)

\section{U.S. West Coast: Not a current problem.}

American Samoa: In populated and agricultural areas on the main island of Tutuila, some degradation of coastal waters is occurring due to silt-laden runoff from land and nutrient enrichment from cannery discharges and human/pig wastes. A more serious pollution problem occurs in Pago 
Pago Harbor where both fish and sediments are grossly contaminated with heavy metals, PCBs, pesticides, and petroleum products. A health risk analysis indicated that the concentration of lead alone may reach levels that cause mental retardation in people who regularly consume fish from the harbor.

Hawaii: Impact unknown.

Guam: No information.

Republic of Palau: Sewage effluent is a problem around Koror State, particularly Malakal Harbor, and near urban areas.

CNMI: With the exception of sewage, environmental contamination is not documented. One potential source of contamination is the unregulated Puerto Rico landfill in the Saipan Lagoon adjacent to American Memorial Park. This landfill was originally a U.S. military dump which the Trust Territory continued to use. Recent efforts by the government to relocate the dump to the Marpi area have meet with some success, and if additional funds are generated, the Puerto Rico dump may be closed by the end of 1992 . Other islands may also have "hazardous waste" areas, most likely associated with World War II activities.

With respect to sewage, Saipan has two wastewater treatment plants at Agingan Point and the Sadog Tasi. The Agingan Point plant discharges untreated sewage into the ocean between Saipan and Tinian. The area of discharge is a dynamic current area and is adjacent to deep waters. The Sadog Tasi plant adequately treats all sewage (secondary level) before discharging into the Saipan Lagoon near Charlie Dock, the main shipping port. However, the outfall has been damaged and is in need of repair.

The current wastewater treatment plant situation does not appear to be a direct threat to sea turtles; however, habitat and food may be affected. In addition, a cumulative effect of general habitat degradation could be occurring from the numerous drainage ditches which empty into the lagoon.

FSM: Unknown but assumed not to be a significant problem at this time. A seemingly large number of fishing boats and other vessels have grounded on Yap State reefs and spilled fuel. The effects of this are unknown. Garbage dumps are overflowing and contaminating nearshore waters in Chuuk and Pohnpei, and to a lesser extent, Kosrae.

RMI: Minor problem. Possibly some problems at Kwajalein, Bikini and Anewetok, where toxic and hazardous waste have been dumped into coastal waters during the era of military missile testing.

Unincorporated: Minor problem. Military toxic and hazardous waste have contaminated coastal waters at Johnston Atoll (Agent Orange, radionucleotides) during the 1960's and a toxic and hazardous waste dump left over from 1950's - 60's U.S. military occupation of Palmyra Atoll was reported along the coast of a northern island about five kilometers from known nesting and other turtle feeding areas. 


\section{Debris (Entanglement and Ingestion)}

The entanglement in and ingestion of marine debris threatens the survival of sea turtles in the Pacific. Such debris includes not only discarded or abandoned fishing gear (lines, ropes, nets), but also plastic bags, plastic sheets, "6-pack" rings, tar balls, styrofoam, and other refuse that might ensnare or be consumed by a sea turtle. Severely entangled individuals can neither submerge to feed nor surface to breathe; they may lose a limb to the offending net or fishing line, or attract a predator with their struggling. Stranding data and necropsies provide evidence that some turtle mortalities have resulted from ingested garbage, such as plastic or tar. Death or debilitation can result from poisoning or from obstruction of the esophagus. (see Recovery - Sections 2.1.3)

Pelagic-phase turtles are clearly at risk from the ingestion of (and entanglement in) plastics and other buoyant and persistent synthetic debris discarded into the ocean (Balazs 1985b; Carr 1987b). Human intervention on nesting beaches, to manipulate eggs and hatchlings for intended conservation purposes, should only to conducted as a last resort to more conservative in situ methods of protection (see Hirth 1971b).

\section{U.S. West Coast: Not a current problem.}

American Samoa: A possible problem in nearshore waters due to local practice of discarding garbage into streams and onto beaches. Entanglement in fishing gear is not a current problem in coastal waters because there are virtually no commercial fisheries in the Exclusive Economic Zone (EEZ). However, fishing debris including potentially entangling fishing lines and nets were spilled on the reef at Rose Atoll, after the grounding and breakup of a Taiwanese Longliner fishing vessel in late 1993. Debris-related problems in offshore waters are unknown.

Hawaii: Thought to be a minor problem.

Guam: No information.

Republic of Palau: Not a current problem.

CNMI: A possible threat; however, there have been no reports of turtle deaths due to debris entanglement or ingestion.

FSM: Unknown impact. Debris is dumped freely and frequently off boats and ships (including government ships). Landfill areas are practically nonexistent in the outer islands and have not been addressed adequately on Yap proper or on Chuuk and Pohnpei. The volume of imported goods (including plastic and paper packaging) appears to be consistently increasing. Some people have observed plastic debris in the gut contents of harvested turtles, but the extent of this problem is unknown.

RMI: Debris and garbage disposal in coastal waters is a serious problem on Majuro Atoll and Ebete Island (Kwajalein Atoll) both which have inadequate space, earth cover and shore protection for sanitary landfills. This problem also exists to a lesser extent at Daliet Atoll.

Unincorporated: Minor problem. 


\section{Fisheries (Incidental Take)}

Sea turtles are accidentally taken in several commercial, subsistence and recreational fisheries. These include bottom trawls, off-bottom trawls, purse seines, haul seines, beach seines, bottom longlines, surface longlines, hook and line, gillnets, and driftnets. The Inter-American Tropical Tuna Commission (IATTC; unpubl. data) reported sea turtles - mostly unidentified, but probably olive ridleys or greens - feeding directly off bait (usually shark or dorado) used by tuna fishermen in the eastern Pacific. Mortality associated with entanglement in active and abandoned fishing gear has not been fully quantified, but is very likely to involve tens of thousands of Pacific sea turtles each year. (see Recovery - Section 2.1.4)

\section{U.S. West Coast: Not a current problem.}

American Samoa: Subsistence gillnets set along the shoreline occasionally catch turtles in Pala Lagoon and probably elsewhere. Catches farther offshore in the EEZ are not a problem because little fishing occurs there. However, limited tagging data indicate that Samoa's turtles migrate great distances in the South Pacific, so impacts of distant fisheries must be considered. Bycatch of turtles in these fisheries is not known.

Hawaii: Incidental catches of turtles occur, primarily in nearshore nets. Now terminated (June 1, 1993) driftnet fisheries in offshore waters in the North Pacific had taken many turtles. In 1990, the total bycatch of turtles in these fisheries was 6,100 turtles (at least 1,700 of which were dead), mostly loggerheads, followed by leatherbacks and green turtles. Recent increases in longline fisheries may be a serious source of mortality. Greens comprised $14 \%$ of the annual observed take of all species of turtles by the Hawaiian-based longline fishery between 1990-1994 (NMFS 1995). The predicted annual take level by this fishery is 119 green turtles and although most are recovered and released alive, the post-release mortality remains unknown. While these numbers appear to be relatively low, they could be significant if the animals affected belong to severely depleted stocks.

Guam: The harvest of turtles through bycatch probably occurs within Guam's EEZ. Laws prohibiting this are hard to enforce because there is only a single Coast Guard vessel available for Guam. A large amount of longline fishing for tuna occurs just beyond the EEZ, and this is also expected to pose a threat to turtles.

RMI: The recent addition of a Chinese longline fleet (10-22 boats) to the RMI waters may provide a serious threat to green turtles.

Other areas: Incidental catches by offshore fleets and in international waters may be a problem, but the impact is unknown. 
19. Predation

Few predators, with the notable exception of orcas (killer whales), large sharks, and marine crocodiles, can consume a full-size sea turtle. Predation on hatchlings is believed to be relatively high and, again, the species most often implicated are coastal and pelagic sharks.

All areas: Unknown impact.

20. Boat Collisions

Sea turtles can be injured or killed when struck by a boat, especially an engaged propeller. Recreational equipment, such as jet skis, also poses a danger due to collisions and harassment. (see Recovery - Sections $2.1 .4,2.1 .5,2.1 .7$ )

All areas: Unknown but probably inconsequential, except in Hawaii where serious injuries and mortalities have been documented (Balazs et al. 1994a) and possibly the Republic of Palau where high speed skiffs constantly travel throughout the lagoon south of the main islands.

\section{Marina and Dock Development}

The development of marina and docking facilities pose direct and indirect threats to sea turtles. Direct consequences can be seen when foraging grounds and nesting beaches are dredged or otherwise permanently altered in the process of construction and maintenance. Altered current patterns and increased levels of ship traffic, pollution, and general activity which displace or injure local sea turtles constitute indirect consequences that should also be considered. (see Recovery Sections 1.2.1, 2.2)

\section{U.S. West Coast: Not a current problem.}

American Samoa: Not a current problem.

Hawaii: Not a current problem for green turtles in the remote NWHIs.

Guam: No information.

Republic of Palau: Not a current problem.

CNMI: The major shipping area on Saipan is Charlie Dock, an outdated structure from World War II. Plans to expand and modernize the dock facilities may not be completed for another five years due to monetary constraints.

FSM: A dock extension project is currently underway on Yap proper but it is not thought to pose problems for turtles around that island.

RMI: Minor problem. 
Unincorporated: Not a current problem. Docks are also under construction at Bikini Atoll. Recent dock construction at Ine and Arno villages at Arno Atoll degraded nearby coral reefs. Many other docks for the outer Atolls are in the planning stages with some possibly funded by foreign aid.

\section{Dredging}

Active dredging machinery (especially hopper dredges) may injure or kill sea turtles, and channelization may alter natural current patterns and sediment transportation. Coral reef and sea grass ecosystems may be excavated and lost, and suspended materials may smother adjacent coral and seagrass communities. (see Recovery - Section 2.2.5)

\section{U.S. West Coast: Not a current problem.}

American Samoa: Not a current problem.

Hawaii: Possible though intermittent problem.

Guam: No information.

Republic of Palau: Dredging and filling for Ollei Dock (Ngerechelong), Ngetpang Dock and Melekeok dock have modified current and sedimentation patterns and degraded or destroyed seagrass, mangrove and coral reef habitats. More dock construction is likely in the Republic of Palau.

CNMI: Very little dredging is done in CNMI waters, however there are two dredging projects on Saipan that will most likely be completed within the next two years: (1) a channel/marina dredging project in Garapan, and (2) the deepening of the harbor area and expansion of the present Charlie Dock facilities in Tanapag Harbor (Garapan area of Saipan).

The Tinian harbor facilities, originally constructed by the U.S. military, have been under discussion for rehabilitation, however, no proposal has been submitted for review. The harbor area is known for turtles and therefore, minimizing impacts to sea turtles will become part of the permitting process if this project is approved. No dredging activities are known for the remaining Islands.

FSM: Impact unknown. A limited amount of dredging occurs on a fairly regular basis around Yap proper. Recently, dredging occurred in Yap proper in an effort to widen one channel and establish another.

RMI: Dredging and filling for outer island airfields and docks may have caused minor changes to longshore processes and shoreline erosion. Dredging and filling for house lots, road causeways and sources of construction fill constitute moderate impacts at Majuro and Kwajalein Atoll.

Unincorporated: Not a current problem. 


\section{Dynamite "Fishing"}

The use of explosives to stun or kill fish destroys coral, degrading or eliminating foraging habitat and refugia for all sea turtle species (except the leatherback). (see Recovery - Section 2.2.7)

\section{U.S. West Coast: Not a current problem.}

FSM: Dynamite fishing in Chuuk lagoon (FSM) is widespread and has caused the degradation of about $10 \%$ of the reef.

All other areas: Dynamite fishing is an outlawed technique in many areas but occasionally occurs.

\section{Oil Exploration and Development}

Oil exploration and development poses direct and indirect threats to sea turtles. A rise in transport traffic increases the amount of oil in the water, such as from bilge pumping, as well as the likelihood of a major spill. Oil spills, such as those resulting from blow-outs, ruptured pipelines, or tanker accidents, can kill sea turtles. Indirect consequences include destruction of foraging habitats by drilling, anchoring, and pollution. (see Recovery - Section 2.2.8)

All areas: Not a current problem.

\section{Power Plant Entrapment}

Entrapment in the water intake mechanisms of power generating facilities can result in death to sea turtles of all size classes.

All areas: Not a current problem.

\section{Construction Blasting}

Blasting can injure or kill sea turtles in the immediate area. The use of dynamite to construct or maintain harbors, break up reef and rock formations for improved nearshore access, etc. can decimate coral reefs, eliminating food and refuge for sea turtles. Some types of dynamiting have minimal impact to marine life, such as placing explosive in pre-drilled holes (drilling and shooting) prior to detonation. This is the standard practice to secure armor rock. (see Recovery - Section 2.2.7)

RMI: Charges are used to fracture rock used in construction projects on Ebeye and could pose a danger if used incautiously.

All other areas: Not a current problem. However, in Tinian Harbor (CNMI), caution must be observed if dynamite is used due to the numerous sightings of turtles there. 


\section{Conservation Accomplishments}

\section{Legislation}

At present, the ESA applies only to actions taken within the Territory of Guam, State of Hawaii, Territory of American Samoa, CNMI, and the eight unincorporated U.S. islands (Midway, Wake, Johnston, Palmyra, Kingman, Jarvis, Howland, and Baker) within the geographic area covered by this recovery plan. The RMI, FSM and Republic of Palau are independent countries no longer subject to U.S. environmental jurisdiction, including the ESA, for activities conducted within these countries. Export of sea turtles or their products to the United States is prohibited, under CITES.

\section{Protected Species Statutes in the Republic of Palau}

National law protects all sea turtle eggs, hatchlings, and nesting adults on all Palauan beaches at all times. Green turtles with a CCL of less than $76.2 \mathrm{~cm}$ are protected in the water, and larger animals may not be taken during the seven month closed season of February to May, and September to November. In addition, the States of Koror, Ngeremlengui and Kayangel have expressed the need and may now be taking action to establish state-level regulations for protecting green sea turtles found within their jurisdictional areas, including northern Ngeremeduu Bay, Kayangel, and Ngeruangl Atoll where nesting sea turtles and eggs are being taken. Unfortunately, protective measures are proving very difficult to enforce throughout Palau, as there is a segment of the population that has not been convinced to take such laws and regulations seriously. Without a strong cooperative effort between Palau federal government and the traditional leadership of Palau's States, enforcement of existing conservation measures will remain next to impossible, with little beneficial effect accruing to the conservation of Palau's green turtles at the present time or in the foreseeable future.

\section{Traditional Controls}

For hundreds, if not thousands of years, the traditional societies of the Mariana, Caroline, Marshall, Samoan, and Hawaiian Islands exerted controls over the taking of sea turtles, especially at nesting beaches. These controls have been effectively eliminated from the Hawaiian, Mariana, and American Samoan Islands due to a combination of a colonial takeover by western powers and transition from subsistence to cash economics. These changes eroded the power of ruling clans and introduced modern technologies that led to rapid depletion of turtle stocks.

Only in the Marshalls, FSM, and Palau are traditional controls still in effect, although only at rural or uninhabited atolls away from the urban centers. The introduction of a western "elected" political system to these islands has challenged traditional authorities and further eroded protection of sea turtles. Landowners in parts of the Marshalls and FSM still claim ownership of adjacent reef areas which discourages taking of turtles by other groups. The FSM, Palau, and Marshall Islands also established "pantry reserves" at uninhabited atolls near inhabited atolls. Examples of these include Ngeruangl Atoll and Fanna Island in Palau, Gaferut, Pikelot, and West Fayu in the FSM; and Bokaak and Bikar in the Marshalls. These so-called "traditional reserves" were only visited by sailing canoes during favorable weather conditions in the old days. However, these reserves are now much more accessible due to availability of the outboard motor, modern skiffs, and modern navigation equipment. Modern supply boats and patrol boats also have easy access to these 
islands. Most of the uninhabited islands are now being rapidly depleted of their nesting sea turtles and many of these sites are the last remaining nesting populations of sea turtles in their respective countries.

\section{Protected Areas}

\section{Republic of Palau}

Until recently Palau has had the only designated protected area in Micronesia, the Ngerukuid Nature Reserve, also known as the 70-islands Nature Reserve located within Koror State. Reserve status has worked to protect nesting green turtles and their eggs on the six beaches within the Reserve for the last several decades, particularly during daylight hours. However, the Reserve is small, and the illegal take of nesting turtles and eggs at night has been clearly documented by the Palau Division of Marine Resources as significant over the last ten years (see Section on Nesting Environment - Directed Take). The Division of Conservation and Entomology has six conservation officers for all of Palau. There are, in addition, Koror state marine rangers willing and able to patrol the Reserve with authority to detain but not to arrest. Poachers, therefore, are rarely apprehended, and prosecution of illegal acts within the reserve has been nil. As a result, the effectiveness of the Ngerukuid Nature Reserves as a sea turtle conservation preserve is less than its potential.

\section{Guam}

The Government of Guam is proposing the establishment of Territorial Reserves to protect wildlife including sea turtles, but so far no reserves that protect sea turtles have been established by the Territorial Government. However, the U.S. Fish and Wildlife Service (FWS), the U.S. Navy, and the U.S. Air Force have all established protected areas in Guam. The Andersen Air Force Base beach reserves on the north coast of Guam afford protection to nesting sea turtles. Moreover, military installations discourage public access to their lands and waters which in effect serves as an enforcement mechanism against unauthorized harvest of turtles or eggs.

\section{American Samoa}

The American Samoa Government cooperatively has established a National Marine Sanctuary with National Oceanographic and Atmospheric Administration (NOAA) at Fagatele Bay, Tutuila. Beaches at Fagatele appear suitable for turtle nesting although no data are available. Certainly foraging and nesting sea turtles would be afforded protection in the sanctuary due to its inaccessibility from nearest villages.

The U.S. National Park Service (NPS) has recently established a new National Park in American Samoa with three units: SW Ofu, Central Ta'u and northern Tutuila. The Ofu unit which includes beaches and a coral reef along the SW Coast of Ofu will likely afford protection to sea turtles, since the coast is only sparsely inhabited. The Ta'u unit may protect foraging sea turtles of the remote south coast of Ta'u. The northern Tutuila unit includes several bays, beaches and potential foraging and nesting habitat for sea turtles. Several villages claim subsistence access to resources in the Park and along the entire northern coastline. It remains to be seen whether the new National Park will promote the conservation of sea turtle populations in American Samoa. 
Rose Atoll is a National Wildlife Refuge and administered by the U.S. FWS. The Refuge affords protections for nesting turtles on the beaches of the atoll, and potential foraging habitat for turtles on the atoll's reefs and lagoon. The American Samoa Government's Division of Aquatic and Wildlife Resources (DAWR) co-administers the refuge.

\section{CNMI}

The government of the CNMI has not established protected areas in the Commonwealth although Managaha Island and reefs off western Saipan and the three Maug Islands have been candidate parks for some time. The CNMI government is presently evaluating a number of candidate protected areas throughout the Commonwealth, some of which may benefit nesting or foraging sea turtles.

\section{$R M I$}

No reserves or protected areas have been established although several were recommended in the Northern Marshall's by Thomas et al. (1989) and Maragos (1994).

FSM

No reserves or protected areas have been established in the FSM. Oroluk was recommended as a reserve by Holthus et al. (1993) although it has yet to be established.

\section{Unincorporated Islands}

Howland, Jarvis, Baker and Johnston are National Wildlife Refuges administered by the U.S. FWS although Johnston is jointly administered by the U.S. Department of Defense (Air Force and Army). Wake is the northernmost of the Marshall Islands (Marshallese name Enen Kio) claimed by the United States and administered as an Air Force station. The Air Force has established small wildlife management areas on the non-inhabited parts of the atoll. Midway Atoll is a Naval Air Station that is about to be closed. Sand Island and Eastern Islands on Midway support beaches and potentially important nesting habitat for turtles. The lagoon supports potentially important foraging habitat for turtles. The future use of Midway at this time (July 1995) is not known, but the prospect is the designation of the entire atoll as a wildlife refuge of the state of Hawaii.

Palmyra is an uninhabited and privately owned atoll of U.S. sovereignty. The owners are proposing residential and resort development of a portion of the atoll and refuge status for the remainder. The U.S. FWS is interested in Palmyra as a potential National Wildlife Refuge. The atoll supports important feeding and nesting habitat for green turtles. The U.S. Department of the Interior technically administers Palmyra while the U.S. Navy claims territorial waters around the atoll as a Naval Defensive Sea. These designations afford some conservation value to sea turtles.

Kingman Reef supports no permanently vegetated land, but sandspits present on the atoll may be valuable resting and nesting habitat for turtles while the lagoon may support foraging habitat for turtles. The Navy claims Kingman as a Naval Defensive Sea which discourages access and affords some protection for turtles. 


\section{Hawaii}

Hawaii supports a large number of protected areas throughout the archipelago. Kure Atoll at the northwest end of the chain is a wildlife refuge of the state of Hawaii and potentially important to nesting and foraging sea turtles. The northwest atolls and islands between Pearl and Hermes to the northwest and Kaula to the southeast are part of the Hawaiian National Wildlife Refuge complex administered by the FWS with assistance from the NMFS. The complex includes the most important nesting habitat for green turtles at French Frigate Shoals in the geographic areas covered by the present plan and many of the other atolls, island reefs and lagoons in the complex afford important turtle foraging and nesting habitat for sea turtles.

The state of Hawaii administers a system of state parks and Marine Life Conservation Districts throughout the main islands, and one coastal Natural Area Preserve on Maui. The National Park Service's Hawaii Volcanoes National Park includes coastal areas on the southeast coasts of Hawaii and Maui islands. Honaunau and Pu'u Kohola are also national parks with coastal areas along the west coast of Hawaii Island. All of these areas afford protection for foraging and nesting sea turtles in Hawaii.

\section{Other Plans and Regulations}

The governments of Hawaii, Guam, American Samoa, and the Northern Marianas all administer coastal zone management programs sponsored by NOAA. These plans are authorized by legislation or executive orders and include policies to protect coastal zone resources including beaches, reefs and lagoons - habitats important to nesting and foraging sea turtles. These governments also administer a system of coastal zone permits to control development and promote sustainable and multiple uses of coastal resources including conservation. Federal activities within designated coastal zones must also achieve consistency with state or territorial coastal zone management plans. None of the other areas have established functional coastal zone management plans yet although Kosrae and Yap in the FSM are close.

Development in nearshore coastal waters is also controlled through permit programs administered by the U.S. Army Corps of Engineers (COE; discharge of dredge or fill materials and work in navigable waters) and the U.S. Environmental Protection Agency (EPA; for sewage treatment plants and outfalls). State and territorial permits are also administered by the state of Hawaii (Conservation District Use Permits) and the FSM, RMI and Palau (earthmoving permits). The CNMI and Guam may also have comparable permits. The state of Hawaii also administers a state-level endangered species act which affords protection to sea turtles in state waters and beaches.

\section{Headstart and Hatchery Programs}

The Yap state government also operated a headstart program on some of the outer atolls of Yap. The primary purpose of the program was to educate the islanders on the need to conserve and protect sea turtles. Success of the program in returning reproductively viable adults to the population was not measured. 
Sea Life Park operates a hatchery and headstart program for green turtles at its facilities in Oahu, Hawaii. However, in this case all eggs and hatchlings originate from adults held in captivity at the Park for many years. No "wild" eggs or hatchlings are brought to the Park except in times when wild nests or hatchlings are in jeopardy. The facility has released and tagged large numbers of hatchlings and has an excellent educational and outreach program. The program is wellsupported by the community. So far there is no documentation of released hatchlings returning to Hawaiian beaches as viable nesting adults.

\section{Sea Turtle Conservation and Management Plans}

Hawaii: The NMFS, Honolulu Laboratory, has prepared an Interim Recovery Plan for Hawaiian Sea Turtles (Balazs et al.1992) which has served as important guidance in actions to recover Hawaiian sea turtles.

Palau: The Republic of Palau requested assistance with preparation of a sea turtle conservation plan after closing the Micronesian Mariculture Demonstration Center (MMDC) turtle hatchery and headstart program. A draft plan was prepared (Maragos 1992) and submitted for review. Subsequently, additional studies were sponsored to fill in major gaps in the plan (Atkinson and Guilbeaux 1992, Geermans 1992, Geermans and Honigman 1992, Guilbeaux 1992, Guilbeaux et al.1994, Di Rosa 1992). A final sea turtle conservation plan has not been completed as of 1995.

\section{Research and Education}

The South Pacific Regional Environment Programme (SPREP), with headquarters in Apia, Western Samoa, funds a regional sea turtle conservation program with support for research, public education, brochures, and other activities which benefit all species of sea turtles in the insular Pacific. 1995 was declared "The Year of the Sea Turtle" by SPREP, with a major conservation awareness program in effect throughout the region.

The NMFS in Hawaii and SPREP in Apia, Western Samoa, have sponsored generalized research on sea turtles in the Pacific to promote conservation. Tagging of adult nesting sea turtles at many beaches in the tropical insular Pacific is being sponsored by the SPREP regional sea turtle conservation program with technical assistance from NMFS. Genetic research on tropical Pacific sea turtles is being conducted in Australia by the Queensland Department of Fisheries and Wildlife Resources and in Hawaii by the NMFS Honolulu Laboratory. Posters and educational pamphlets are widely distributed via SPREP throughout the recovery plan region, promoting conservation and research. Additional educational programs at the government and school level are also active on some island groups, such as American Samoa (P. Craig, Office of Wildlife and Marine Resources, Govt. of American Samoa, pers. comm.).

\section{Effectiveness of Conservation Accomplishments}

The sum total of all conservation accomplishments in each of the eight island groups covered in this recovery plan have been ineffective in all areas except Hawaii and the unincorporated islands. In all other island groups (Palau, CNMI, Guam, FSM, RMI, and American Samoa) conservation actions have not been successful to stem the precipitous decline of resident sea turtle nesting and foraging populations. The only major safe nesting areas for greens are located in the 
large protected areas of the northwest Hawaiian islands and of the northeast coast of Australia. The large nesting populations in outer Yap (FSM) are insufficiently protected. Lower levels of sea turtle foraging and nesting are relatively safe in the unincorporated islands, due largely to restricted access to military installations, wildlife refuges and to the lack of local harvesting of eggs and turtles. The situation at Helen Reef and Merir Islands of Palau is especially perilous for green turtles.

The success of conservation efforts in Hawaii is largely due to effective enforcement of the ESA, good public education outreach and research, the curtailing of harvesting of adult turtles and their eggs, and the generous establishment of protected areas. Conservation efforts must significantly be improved in the island groups where direct harvesting of adults (especially at nesting beaches) is continuing unabated, where there has been inadequate designation of protected areas, inadequate legislation to protect sea turtles and inadequate enforcement of the few reserves and regulations that have been enacted.

Most importantly, educational efforts have been unsuccessful in changing the behavior of the islanders conducting or condoning the harvests. Harvesting is the single biggest cause of sea turtle declines and conservation efforts must focus on the education of the harvesters to convince them to curtail or cease harvesting efforts. Conservation efforts in Palau, FSM, CNMI, Guam, and the RMI are so inadequate that all nesting populations of both the green and hawksbill are likely to be extirpated from the islands within the next twenty years if not sooner. No amount of research, tagging, regulatory actions and protected areas designation will succeed in reversing this trend unless the turtle and egg harvesters are educated or convinced enough to cease or drastically curtail harvesting activities. It will be virtually impossible for enforcement measures to reverse these trends by themselves; Pacific islanders are not accustomed to fining or confiscating gear of friends and neighbors or imprisoning violators. Massive education and public pressure will be essential to save the sea turtle stocks from complete collapse throughout most of the recovery region. 


\section{RECOVERY}

\section{A. Recovery Objectives}

Goal: The recovery goal is to delist the species.

Recovery Criteria: To consider de-listing, all of the following criteria must be met:

1) All regional stocks that use U.S. waters have been identified to source beaches based on reasonable geographic parameters.

2) Each stock must average 5,000 (or a biologically reasonable estimate based on the goal of maintaining a stable population in perpetuity) FENA over six years.

3) Nesting populations at "source beaches" are either stable or increasing over a 25-year monitoring period.

4) Existing foraging areas are maintained as healthy environments.

5) Foraging populations are exhibiting statistically significant increases at several key foraging grounds within each stock region.

6) All Priority \#1 tasks have been implemented.

7) A management plan to maintain sustained populations of turtles is in place.

8) International agreements are in place to protect shared stocks.

Rationale: Determining quantifiable values that can be used to determine when a sea turtle stock is recovered is quite difficult. The recovery team has tried to make such recommendations as listed above based on best available information with the following conceptual guidelines:

1) The minimum nesting stock must equal a size that could not easily be eliminated by a single catastrophic event ("natural" or "man induced").

2) Nesting population trends should be long enough to minimize the effects of natural fluctuations in numbers that are characteristic of sea turtle populations. Generally this time period is equal to the estimated one generation time for each species.

3) Habitats are adequate to support population growth once threats have been reduced or eliminated.

4) If a species is to be considered for delisting, a plan must already be in force for maintaining the population in stable or increasing condition. The team was concerned that if a species was 
delisted, and no management plan was already in force, that the species may be driven back toward extinction too rapidly for resource management agencies to implement such plans.

\section{B. Step Down Outline and Narrative for Recovery}

\section{NESTING ENVIRONMENT}

\subsection{Protect and manage turtles on nesting beaches.}

It is prudent to preserve the capacity of a population to recover from a depleted state by protecting nesting females, their nests and hatchlings and to preserve the quality of the nesting area. The killing of gravid females, poaching of nests, predation (native and feral), destruction of the habitat through mining, destruction of vegetation, artificial lighting, development, and increased human use all degrade the ability of depleted populations to recover. The following tasks are designed toward enhancing the reproductive ability of sea turtle populations at the nesting grounds. Since non-nesting adult male and female green turtles have been known to haul out diurnally on beaches, protection of these turtles is also included.

1.1.1 Eliminate directed take of turtles and their eggs.

Direct take of nesting turtles and their eggs have been identified as a primary threat to Pacific sea turtle populations. Eliminating this threat is required if populations are to recover.

1.1.1.1 Reduce directed take of turtles through public education and information.

While increased law enforcement will be effective in the short term, without support of the local populace, regulations will become ineffective. Education of the public as to the value of conserving sea turtles, is a very effective way of sustaining recovery efforts and providing support for enforcement of management regulations.

1.1.1.2 Increase enforcement of laws protecting turtles by law enforcement and the courts.

Lack of adequate support for law-enforcement activities which protect sea turtle populations is common, yet it must be understood that enforcement is as important as any other resource management activities. Enforcement, judicial, and prosecutorial personnel must receive adequate instruction about sea turtles and the importance of protecting turtle populations. Nonnesting adult green turtles that haul out diurnally on beaches must also be protected.

1.1.2 Ensure that coastal construction activities avoid disruption of nesting and hatching activities.

Coastal construction must be monitored to minimize impact on turtle beaches, both during construction, particularly during the nesting and hatching season, and in the 
long-term. Construction equipment must not be allowed to operate on the beach, remove sand from the beach, or in any way degrade nesting habitat. Nighttime lighting of construction areas should be prohibited during nesting and hatching seasons. In the long-term, structures should not block the turtle's access to the beach, change beach dynamics, or encourage human activities that might interfere with the nesting process.

1.1.3 Reduce nest predation by domestic and feral animals.

Feral animals such as the Polynesian Rat (Rattus exulans), dogs and mongooses pose a severe threat to turtle nests and hatchlings. It is important that feral predators be controlled or eliminated from nesting areas. Domestic animals such as pigs, dogs and cats can also threaten turtle nests and hatchlings, and should be controlled near nesting areas. In particular, domestic dogs should not be allowed to roam turtle nesting beaches unsupervised.

1.1.4 Reduce effects of artificial lighting on hatchlings and nesting females.

Because sea turtles (especially hatchlings) are extremely attracted to artificial lighting, lighting near nesting beaches should be placed in such a manner that light does not shine on the beach. If not, turtles may become disoriented and stray from their course.

1.1.4.1 Quantify effects of artificial lighting on hatchlings and nesting females.

It is important to quantify the impact of existing lighting in terms of nesting success and hatchling survival so that pragmatic mitigation can be applied. Also, such study can be used to guide the development of effective lighting ordinances.

1.1.4.2 Implement, enforce, evaluate lighting regulations or other lighting control measures where appropriate.

Shielding of the light source, screening with vegetation, placing lights at lowered elevations and in some cases the use of limited spectrum low wavelength lighting (e.g., low pressure sodium vapor lights) are possible solutions to beach lighting problems. Such measures should be required by law and enforced.

1.1.5 Collect biological information on nesting turtle populations.

The collection of basic biological information on nesting is critical for making intelligent management decisions. Monitoring nesting success can help to identify problems at the nesting beach or elucidate important areas for protection. Analyzing population recruitment can help in understanding population status. 
1.1.5.1 Monitor nesting activity to identify important nesting beaches, determine number of nesting females, and determine population trends.

Important nesting beaches (based on actual number of nests) must be identified for special protection. Nesting beaches need to be identified by standardized surveys during the nesting season. Informational surveys with local residents and officials should be conducted to determine current or historical nesting beaches.

One of the most crucial techniques for determining the status of sea turtle populations and for evaluating the success of management or restoration programs is long-term monitoring of annual nesting on key beaches. The surveys must be done in a standardized and consistent manner with experienced personnel. Since female turtles show fidelity to nesting beaches, long term beach censusing provides a ready means for assessing these maternally isolated populations. However, because of long maturity times for turtles, quantifying trends in population sizes and effectiveness of any restoration program may take a generation time (20+ years) to be reflected in the annual numbers of nesters. Monitoring should thus be recognized as a long-term undertaking.

1.1.5.2 Evaluate nest success and implement appropriate nest-protection measures on important nesting beaches.

One of the simplest means to enhance populations is by increasing hatchling production at the nesting beach. The first step to such an enhancement program is to determine the nesting/hatching success and to characterize factors which may limit that success. Once those limiting factors are determined, protection or mitigation measures can be implemented. If nests must be moved to prevent loss from erosion or other threats, natural rather than artificial incubation should be employed.

1.1.5.3 Define stock boundaries for Pacific sea turtles.

Because sea turtles exhibit a unique genetic signature for each major nesting assemblage, and because nesting assemblages provide an easily censused means of monitoring population status, it is useful to use genetic analysis methods to determine stock boundaries for sea turtle populations. It also enables managers to determine which stocks are being impacted by activities far removed from the nesting beaches, and thus prioritize mitigation efforts.

1.1.5.3.1

Identify genetic stock type for major nesting beach areas.

A "genetic survey" to establish the genetic signature of each nesting population must be established, before stock ranges can be determined. Such surveys are relatively simple as they require only 
a small blood sample from a statistically viable number of females within each nesting population.

\section{$(1.5 .3 .2$}

\section{Determine nesting beach origins for juvenile and subadult populations.}

Because nesting populations can form the basis for stock management, it is important to be able to pair juvenile and subadult turtles with their stock units by genetic identification. DNA analyses have begun to provide scientists and managers with this sort of data. 
Beach mining severely affects a nesting beach by reducing protection from storms, destroying native vegetation directly or indirectly and may completely destroy a nesting beach. Protective legislation and public education must be used to protect the substrate of the beaches.

1.2.3 Develop beach-landscaping guidelines which recommend planting of only native vegetation, not clearing stabilizing beach vegetation and evaluating the effects as appropriate.

Non-native vegetation may prevent access to nesting sites, prevent adequate nest digging, exacerbate erosion or affect hatchling sex ratios by altering incubation temperatures. Native vegetation, however, plays an important role in stabilizing the beach and creating the proper microclimate for nests. Guidelines for residents concerning the most appropriate plant species and the importance of a native plant base should be encouraged.

1.2.4 Ensure that beach replenishment projects are compatible with maintaining good quality nesting habitat.

Sand on sea turtle beaches has particular properties which affect hatching success (ie. compaction, gas diffusion, temperature). Any addition or replacement of sand may change these properties and make it more difficult for females to nest or reduce hatchling success. As such, beach replenishment projects should be carefully considered, use materials similar to the native sands and be carried out outside the nesting season.

1.2 .5

Implement non-mechanical beach cleaning alternatives.

Hand raking of beach debris, rather than using heavy machinery, should be encouraged on nesting beaches where cleaning is done for aesthetic reasons. The use of heavy machinery can adversely affect hatchlings directly and their nesting habitat.

1.2.6 Prevent vehicular driving on nesting beaches.

Driving on active nesting beaches should be forbidden. Vehicles cause destabilization of beaches, threaten incubating nests and leave tire ruts that hatchlings have difficulty crossing.

\section{MARINE ENVIRONMENT}

2.1 Protect and manage green turtle populations in the marine habitat.

Protection of turtles in the marine environment is a priority that is often overlooked as enforcement is difficult and quantification of the problem problematic. However, $99 \%$ of a 
turtle's life is spent at sea; thus, recovery must include significant efforts to protect turtles at that time.

\subsubsection{Eliminate directed take of turtles.}

Direct take of turtles was identified as a severe threat to population recovery in the Pacific Ocean and must be eliminated if sea turtles are to recover.

2.1.1.1 Reduce directed take of turtles through public education and information.

While increased law enforcement will be effective in the short term, without support of the local populace, regulations will become ineffective. Education of the public as to the value of conserving sea turtles, especially given the cultural history of green turtle exploitation in this region, is a very effective way of sustaining recovery efforts and providing support for enforcement of management regulations.

2.1.1.2 Increase/maintain law-enforcement efforts to reduce illegal exploitation.

One of the major threats identified for turtle populations in the Pacific was the harvest of turtles, both on the nesting beach and in the water, for food, medicine, and religious or cultural reasons. Rigorous efforts in law enforcement, with sensitivity to cultural attitudes, should be undertaken immediately to reduce this source of mortality. Such efforts need to include training of enforcement personnel in the importance of protecting turtles, as well as supplying such personnel with adequate logistical support (boats, communication and surveillance equipment etc.). Judges and prosecutors must also be educated in the importance of these matters. Trade in green turtle paraphernalia must also be restricted.

2.1.2 Determine distribution, abundance, and status in the marine environment.

In its review of information on sea turtle populations in the Pacific, the Recovery Team found that lack of accurate information on distribution and abundance was one of the greatest threats to sea turtle populations. Most existing information is anecdotal or obsolete and where new information is available, it uniformly indicates that green turtle populations are vastly smaller than commonly believed. We consider that gathering of basic information on distribution and abundance should take a very high priority in the recovery of Pacific green turtle populations.

2.1.2.1 Determine the distribution and abundance of post-hatchlings, juveniles and adults.

While little is known about the distribution of nesting beaches for the green turtle, even less is understood about distribution of foraging adult and juvenile populations with the exception of green turtle residents In the Hawaiian Islands. Quantitative surveys of foraging areas to determine 
green turtle abundance, and to identify essential habitat is of significant importance for restoration of green turtle populations.

2.1.2.2 Determine adult migration routes and internesting movements.

Like all species of sea turtle (with the possible exception of the Flatback turtle, Natator depressus), green turtles migrate from foraging grounds to nesting beaches. These migrations often mean that the turtles move through a variety of political jurisdictions where regulations regarding the stewardship of the species may vary. To preclude the problem of contradictory management strategies by these various jurisdictions, it is important to determine the migration routes green turtles follow between nesting and foraging areas. Satellite telemetry studies of both males and females are needed.

2.1.2.3 Determine growth rates and survivorship of hatchlings, juveniles, and adults, and age at sexual maturity.

Understanding the rates of growth and survivorship of turtle populations is crucial to the development of appropriate population models. Such models are important in understanding population status and how best to efficiently apply management efforts, in restoring depleted populations. For example, the application of stage-based modeling (Crouse et al. 1987) indicated that not enough effort was being expended on protecting juvenile sized loggerhead sea turtles in the southeastern United States and that without such protection, extensive nesting beach protection was having less positive benefit. A similar approach to understanding green turtle populations should be undertaken, and used to guide restoration policy.

2.1.2.4 Identify current or potential threats to adults and juveniles on foraging grounds.

Little is known about threats to foraging populations of green turtles. Studies on such threats should be undertaken immediately.

2.1.3 Reduce the effects of entanglement and ingestion of marine debris.

Entanglement due to abandoned or unmonitored fishing gear, as well as the ingestion of man-made debris is a significant problem in the marine environment.

2.1.3.1 Evaluate the extent to which sea turtles ingest persistent debris and become entangled.

Quantification of the extent to which sea turtles are impacted by marine debris should be undertaken as a first step to mitigating or preventing such impacts. The benefits of such work are that it allows the prioritization of 
recovery activities and it allows the activities to be efficiently targeted at the problem.

2.1.3.2 Evaluate the effects of entanglement and the ingestion of persistent debris on health and viability of sea turtles.

Because of the remote nature of turtle/debris interactions, the acute and chronic effects of such interaction are not often understood. Turtles may not die immediately after ingesting certain materials, but may become debilitated. Studies to further understand the impacts of such interactions, and what age classes are affected most severely, should be undertaken immediately. As with quantifying the extent to which sea turtles ingest debris, such a program allows recovery efforts to be more efficient.

2.1.3.3 Formulate and implement measures to reduce or eliminate persistent debris and sources of entanglement in the marine environment.

Once the problem of marine debris has been identified and quantified, it is important to implement (and enforce) a program to reduce the amount of debris in the marine environment, ie. removing the problem entirely, as contrasted to mitigating the problem.

2.1.4 Monitor and reduce incidental mortality in the commercial and recreational fisheries.

For some areas, incidental take in fisheries has been identified as a severe threat. These mortalities are often associated with international fleets operating on the high seas, but for the green turtle it is probably most significant in nearshore waters. Monitoring of turtle take by fisheries is extremely important for two reasons. First, it allows resource managers a means to quantify the extent of the problem, and by the very act of monitoring, tends to cause commercial fishermen to be more aware of the concern over incidental takes, and thereby encourage reduced take. The choice method for monitoring take is through the use of an unbiased observer program. Voluntary logbooks have not proven a reliable technique for quantifying incidental catch in commercial fisheries. Implementation of mortality reduction activities includes the use of Turtle Excluder Devices (TED) in shrimp trawler fisheries. Finally a serious but unquantified problem is that of fisheries vessels stopping illegally at uninhabited islets and atolls and killing turtles. This can be curtailed only by the education of fisherman, and increased enforcement on the seas and in the courts.

2.1.5 Eliminate the harassment of turtles at sea through education and enforcement.

Activities such as "petting" turtles and chasing them while snorkeling and scuba diving, water skiing, jet skis, vessel traffic, and vessel anchoring may disturb or displace turtles. These factors should be regulated or controlled to eliminate negative impacts, especially in sensitive and high density foraging and resting areas. 
Little is known about diseases in sea turtles, but there has been recent evidence that it may be a limiting factor in certain populations. Disease origin and transmission may not be limited to the marine environment.

2.1.6.1 Investigate fibropapillomas (tumors) in green turtles.

Debilitating and life threatening tumors are known to occur in Hawaiian and other (Caribbean) populations of green turtles. The magnitude of this disease during recent years has increased substantially in Hawaii. The etiology of the disease and effects as they relate to the viability of the population are presently unknown and need to be studied.

2.1.6.2 Investigate parasites and other infectious agents.

A variety of other diseases and parasites may be affecting sea turtles. The prevalence of such infections, their impact on sea turtles, and modes of transmissions need to be studied. Parasites include internal parasites such as blood flukes, external parasites such as leeches (Ozobranchus) and burrowing barnacles (Stephanolepas), and certain bacterial infections such as Vibrios.

2.1.7 Develop/maintain carcass stranding network.

Stranding networks are operated generally by volunteers who monitor beaches for stranded animals. Such networks can be useful for alerting managers to incidents causing high mortality, such as an increased fishery take or disease problems, as well as providing some basic biological data.

2.1.8 Centralize administration and coordination of tagging programs.

In general, government resource management agencies can provide the continuity required to coordinate tagging programs. The responsibility of any such agency is that they act as a central distribution point for tags, tagging training and database management. It is critically important that the coordinating agency: 1) provides adequate staff to keep the program organized and respond to tag returns immediately, and 2) remain in existence for many years $(20+)$. Without such a commitment, tagging programs have very limited usefulness, and before initiation of such a program it should be considered carefully on its scientific merits. It must be remembered that sea turtles are long-lived animals, and the most valuable information yielded by any tagging program comes from turtles which have carried identification tags for many years. Short-term tagging projects are at best very limited in the information they yield and at worst are nothing more than a form of undue harassment to the turtles. 
Centralization of tag records is useful as it makes the most efficient use of limited personnel resources, allows standardization of techniques, and can act as a screening mechanism to ensure that tagging is done for valid scientific reasons.

2.2 Protect and manage marine habitat, including foraging habitats.

Green turtles inhabit a variety of marine habitats, although we are most familiar with their coastal habitat. Increased human presence in this and other sea turtle habitats have contributed to reef degradation, primarily by coastal construction, increased recreational and fisheries use, and increased industrialization. Habitat loss and degradation must be prevented or slowed.

2.2.1 Identify important marine habitats.

These areas may include hatchling, juvenile and adult foraging areas and migratory range for all age classes. (Many of these areas will first need to be identified through actions in Section 2.1.2.1 and 2.1.2.2.)

2.2.2 Ensure the long-term protection of marine habitat.

Once marine habitats are identified, sea turtle range, refugia and foraging habitats (Sargassum beds, coral reefs and sponge habitats) need to be protected to ensure long-term survival for the species. Habitats identified as important or critical should be designated as marine sanctuaries or preserves, while others may require close monitoring. The public needs to be educated on the importance of preserving these habitats.

2.2.3 Assess and prevent the degradation or destruction of reefs and seagrass beds caused by boat groundings, anchoring, and trampling by fishermen and divers.

Physical harm done by boat hulls, anchors and persons on coral reefs can be a serious threat to reef habitats, particularly in heavily-used bays. Given that reefs recover slowly from physical damage, appropriate actions such as providing boat moorings and removal of grounded vessels should be undertaken.

2.2.4 Prevent the degradation of reef, algal and seagrass habitat caused by environmental contaminants such as sewage and other pollutants.

Protect these habitats by reducing offshore dumping of industi,al waste and offshore sewage outfalls. High water quality standards must be established and maintained for inland water treatment plants.

2.2.5 Prevent the degradation or destruction of marine habitats caused by dredging or disposal activities. 
Dredging causes mechanical destruction of reefs, adds suspended sediments that may damage corals and seagrasses and disposal of dredged materials smothers existing flora and fauna.

2.2.6 Prevent the degradation or destruction of important habitats caused by upland and coastal erosion and siltation.

These processes, often made worse by coastal construction, adversely affect coral reefs by disrupting vital trophic processes, reducing productivity and reducing species diversity. Minimum water standards upstream must be maintained. Landuse decisions must take this into account and associated projects where erosion and siltation occur must be monitored.

2.2.7 Prevent the degradation or destruction of reefs by dynamite fishing and construction blasting.

Blasting of any nature physically damages reefs and may kill turtles. It must be monitored and/or restricted.

2.2.8 Prevent the degradation of important habitat caused by oil transshipment activities.

Oil spills from tankers are a possible threat both to coastal and pelagic habitats. Also, groundings or collisions of tankers and other petroleum industry vessels may physically damage reefs, perhaps more so than other vessels because of their sheer size (see Section 2.2.3). The oil and gas industry should take necessary preventive measures (e.g., double hulled tankers). Oil spill response teams should be identified for all likely areas.

2.2.9 Identify other threats to marine habitat and take appropriate actions.

Such threats to sea turtle habitat that do not fit in the previous sections or new threats must be considered and addressed. Such threats may include commercial and recreational illegal takes of coral and "live rock" for aquaria, as well as take of tropical fish for aquaria. Chemicals used to capture the fish may also affect reefs.

\section{ENSURE PROPER CARE IN CAPTIVITY.}

Captive care of sea turtles is common in the Pacific. Some of this care is in the form of formal rearing programs and other captive care is more casual, such as rearing turtles as pets (although this is illegal in Guam, CNMI and American Samoa.) The latter should be discouraged, even where permitted. Depending on the scale of such activities such captivity can be harmful to the wild population due to excess take from the wild, or from the potential introduction of exotic diseases or unfit genetic stocks to the wild population. Captive care should be carefully regulated to minimize such problems, and all release programs should rigorously monitor the status of released turtles to ensure their proper integration into the wild. It should be noted that to be deemed successful, captive turtles that have been released to the 
wild should be shown not only to survive in the wild but should also successfully reproduce. If released turtles do not reproduce, such populations will never be self sustaining.

3.1 Develop standards for the care and maintenance of sea turtles, including diet, water quality, tank size, and treatment of injury and disease.

Standards should be developed by NMFS or other appropriate agencies. Once developed, these criteria should be published and set as requirements for any sea turtle holding facility. Facilities that comply with the criteria will receive permits to hold turtles and be inspected for compliance. A manual for diagnosis and treatment of sea turtle diseases should be compiled, published and distributed to holding facilities.

3.2 Establish a catalog of all captive sea turtles to enhance use for research and education.

The FWS and NMFS should establish a catalog of turtles at all known facilities.

\subsection{Designate rehabilitation facilities.}

FWS, NMFS and other appropriate agencies should designate these facilities based on the above criteria. Designation should be based on availability of appropriate veterinary personnel, compliance with standards of care and annual inspections. Recommendations should be made on when and where hatchlings or adults should be released.

\section{INTERNATIONAL COOPERATION}

4.1 Support existing international agreements and conventions to ensure that turtles in all lifestages are protected in foreign waters.

Considering that green turtles migrate outside of U.S. territorial waters during at least part of their life cycle, an effective recovery plan must include supporting existing cooperative agreements with other nations to protect the species. Existing agreements include CITES (see next section, adopted 1973), the Convention on Nature Protection and Wildlife Preservation in the Western Hemisphere (adopted 1940), the ASEAN Agreement on the Convention of Nature and Natural Resources (adopted 1985), the Convention for the Protection of the Natural Resources and Environment of the South Pacific Region (SPREP convention, adopted 1986), as well as a number of conventions concerning marine pollution (Eckert, 1993). Out of the SPREP convention, the South Pacific Regional Marine Turtle Conservation Programme was created to specifically implement a regional approach to the species protection. Agreements and conventions that are effective must continue to be supported.

4.2 Encourage ratification of the CITES for all non-member Pacific countries, compliance with CITES requirements, and removal of sea turtle trade reservations held by member nations.

CITES is a comprehensive wildlife treaty signed by many countries that regulates and prohibits commercial import and export of wild plant and animal species that are threatened by trade. In the north Pacific signatories include 18 countries (Eckert, 1993). It is one of the most powerful international agreements concerning threatened species. The U.S. State Department, 
Department of Commerce and Department of Interior should work with Pacific nations to encourage non-member countries to become signatories and demand compliance with CITES requirements on sea turtles from all signatories.

4.3 Develop new international agreements to ensure that turtles in all life-stages are protected in foreign waters.

New agreements must be outlined by the FWS and NMFS, and pursued by the State Department and Department of the Interior. Eastern Pacific nations should be encouraged to ratify the Regional Agreement for Investigation and Management of Marine Turtles of the American Pacific which was not put into place after being drafted in 1986.

4.4 Develop or continue to support informational displays in Republic of Palau, Guam, Hawaii, American Samoa, North Marianas, the Marshall Islands, the FSM and other airports which provide connecting legs for travelers to the area.

Airports are particularly good avenues for information about illegal trade in tortoise and tortoiseshell paraphernalia, as well as general information on sea turtle conservation. If travelers don't purchase the items, the market for them may decrease. Agencies such as NMFS, FWS and the U.S. Customs Service should collaborate on display content and placement. 


\section{REFERENCES CITED}

Alvarado, J., and A. Figueroa. 1987. The ecological recovery of sea turtles of Michoacan, Mexico. Special attention: the black turtle, Chelonia agassizii. Final Report 1986-1987 submitted to U.S.F.W.S. and W.W.F. - U.S. 46 pp. + tables/figs.

Atkinson, S., and M. Guilbeaux. 1992. Survey of hawksbill nesting activity on selected Rock Island beaches. Unpublished report to the Division of Marine Resources, Republic of Palau. 2 pp.

Balazs, G.H. 1976. Green turtle migrations in the Hawaiian Archipelago. Biol. Conserv. 9:125-140.

Balazs, G.H. 1978. Terrestrial critical habitat for sea turtles under United States jurisdiction in the Pacific region. 'Elepaio 39(4):37-41.

Balazs, G.H. 1979. Growth, food sources and migrations of immature Hawaiian Chelonia. Mar. Turtle Newsl. 10:1-3.

Balazs, G.H. 1980. Synopsis of biological data on the green turtle in the Hawaiian Islands. U.S. Dep. Commer., NOAA Tech. Memo. NMFS, NOAA-TM-NMFS-SWFC-7. 141 pp.

Balazs, G.H. 1982a. Status of sea turtles in the central Pacific Ocean. Pages 243-252 in K.A. Bjorndal (ed.), Biology and Conservation of Sea Turtles. Smithsonian Inst. Press, Washington, D.C. 583 pp.

Balazs, G.H. 1982b. Growth rates of immature green turtles in the Hawaiian archipelago. Pages 117-126 in K.A. Bjorndal (ed.), Biology and Conservation of Sea Turtles. Smithsonian Inst. Press, Washington, D.C. 583 pp.

Balazs, G.H. 1982c. Sea turtles: A shared resource of the Pacific islands. South Pac. Comm. Fish. Newsl. 232:22-24.

Balazs, G.H. 1983a. Sea turtles and their traditional usage in Tokelau. Atoll Res. Bull. 279:1-29.

Balazs, G.H. 1983b. Recovery records of adult green turtles observed or originally tagged at French Frigate Shoals, Northwestern Hawaiian Islands. U.S. Dep. Commer., NOAA Tech. Memo. NMFS, NOAA-TM-NMFS-SWFC-36. 42 pp.

Balazs, G.H. 1985a. Status and ecology of marine turtles at Johnston Atoll. Atoll Res. Bull. 285:1-46.

Balazs, G.H. 1985b. Impact of ocean debris on marine turtles: entanglement and ingestion. Pages 387-429 in R.S. Shomura and H.O. Yoshida (eds.), Proceedings of the Workshop on the Fate and Impact of Marine Debris. U.S. Dep. Commer., NOAA Tech. Memo. NMFS-SWFC-54. 582 pp. 
Balazs, G.H. 1985c. History of sea turtles at Poihua Beach on Northern Lanai. 'Elepaio, 46(1):1-3.

Balazs, G.H. 1986. Ontogenetic changes in the plastron pigmentation of hatchling Hawaiian green turtles. J. Herpetol. 20(2):280-282.

Balazs, G.H. 1991. Historical summary of sea turtle observations at Rose Atoll, American Samoa. Natl. Mar. Fish. Sci. Serv., NOAA, Honolulu, HI. Unpublished manuscript. 6 pp.

Balazs, G.H. 1994. Homeward bound: satellite tracking of Hawaiian green turtles from nesting beaches to foraging pastures. Pages 205-208 in B. A. Schroeder and B. E. Witherington (compilers), Proceedings of the Thirteenth Annual Symposium on Sea Turtle Biology and Conservation. NOAA Tech. Memo. NMFS-SEFSC-341. 281 pp.

Balazs, G.H., and S. Pooley (eds.). 1991. Research plan for marine turtle fibropapilloma. U.S. Dep. Commer., NOAA Tech. Memo. NMFS-SWFSC-156. 113 pp.

Balazs, G.H., and J.A. Wetherall. 1991. Assessing impacts of North Pacific high-seas driftnet fisheries on marine turtles: progress and problems. Doc. U001, Scientific Review of North Pacific High-seas Driftnet Fisheries, Sidney, B. C., Canada, 11-14 June 1991. 15 pp.

Balazs, G.H., R.G. Forsyth, and A.K.H. Kam. 1987. Preliminary assessment of habitat utilization by Hawaiian green turtles in their resident foraging pastures. U.S. Dep. Commer., NOAA Tech. Memo. NMFS, NOAA-TM-NMFS-SWFC-71. $107 \mathrm{pp}$.

Balazs, G.H., R.K. Miya, and M.A. Finn. 1994a. Aspects of green turtles in their feeding, resting, and cleaning areas off Waikiki Beach. Pages 15-18 in B.A. Schroeder and B.E. Witherington (compilers), Proceedings of the Thirteenth Annual Symposium on Sea Turtle Biology and Conservation. NOAA Tech. Memo. NMFS-SEFSC-341. 281 pp.

Balazs, G.H., P.Siu, and J.P. Landret. 1995. Ecological aspects of green turtles nesting at Scilly Atoll in French Polynesia. Pages 7-10 in Richardson, J.I. and T.H. Richardson (compilers), Proceedings of the Twelfth Workshop on Sea Turtle Biology and Conservation. NOAA Tech. Memo. NMFS-SEFSC-361. 274 pp.

Balazs, G.H., P. Craig, B.R. Winton, and R.K. Miya. 1994b. Satellite telemetry of green turtles nesting at Rose Atoll, American Samoa, and French Frigate Shoals, Hawaii. Pages 184187 in Proceedings of the Fourteenth Annual Symposium on Sea Turtle Biology and Conservation. U.S. Dept. Commer., NOAA Tech. Memo. NMFS-SEFSC-351.

Balazs, G.H., H. Hirth, P. Kawamoto, E. Nitta, L. Ogren, R. Wass, and J. Wetherall. 1992. Interim Recovery Plan for Hawaiian Sea Turtles. Honolulu Lab., Southwest Fish. Sci. Cent., Natl. Mar. Fish. Serv., NOAA, Honolulu, HI 96822-2396. Southwest Fish. Sci. Cent. Admin. Rep. H-92-01. 76 pp.

Bjorndal, K.A. 1985. Nutritional ecology of sea turtles. Copeia 1985:736-751. 
Bjorndal, K.A., and A.B. Bolten. 1988. Growth rates of immature green turtles, Chelonia mydas, on feeding grounds in the southern Bahamas. Copeia 1988:555-564.

Boulon, R.H., and N.B. Frazer. 1990. Growth of wild juvenile Caribbean green turtles, Chelonia mydas. J. Herpetol. 24:441-445.

Bowen, W., A.B. Meylan, J.P. Ross, C.J. Limpus, G.H. Balazs, and J.C. Avise. 1992. Global population structure and natural history of the green turtle (Chelonia mydas) in terms of matriarchal phylogeny. Evolution 46(4):865-881.

Bryan, E.H., Jr. 1974. Panala'au Memoirs. Honolulu: Bernice P. Bishop Museum.

Carr, A.F. 1952. Handbook of Turtles. Cornell Univ. Press, Ithaca, New York. 529 pp.

Carr, A.F. 1987a. New perspectives on the pelagic stage of sea turtle development. Cons. Biol. 1(2):103-121.

Carr, A.F. 1987b. The impact of nondegradable marine debris on the ecology and survival outlook of sea turtles. Mar. Pollut. Bull. 18(6b):352-356.

Carr, A.F., and M.H. Carr. 1970. Recruitment and remigration in a green turtle nesting colony. Biol. Conserv. 2:282-284.

Collard, S.B., and L.H. Ogren. 1990. Dispersal scenarios for pelagic post-hatchling sea turtles. Bull. Mar. Sci. 47:233-243.

Craig, P. and G.H. Balazs. 1995. Turtle travels from American Samoa to Polynesia. Mar. Turtle News. 70:5-6.

Crouse, O.T., Crowder, L.B. and Caswell, H. 1987. A stage based population model for loggerhead sea turtles and implications for conservation. Ecology 68(5):1412-1423.

Di Rosa, R. 1992. Palua trip report, rapid ecological assessment Sept. 26-Oct. 9, 1992. Unpup. Report to Nature Conservancy. 9 pp.

Dizon, A.E., and G.H. Balazs. 1982. Radio telemetry of Hawaiian green turtles at their breeding colony. Mar. Fish. Rev. 44(5):13-20.

Dodd, C.K., Jr. 1978. Terrestrial critical habitat and marine turtles. Bull. Md. Herpetol. Soc. 14: 233-240.

Dutton, P.H. and D.L. McDonald. 1990. Status of sea turtles in San Diego Bay, 1989 - 1990 Final Report. Sea World Research Institute Technical Report \#90-225. 18 pp.

Dutton, P.H., S.K. Davis, T. Guerra, and D. Owens. 1996. Molecular phylogeny for marine turtles based on sequences of the ND4-leucine and control regions of mtDNA. Mol. Phylogenet. Evol. 5:511-521. 
Eckert, K.L. 1993. The biology and population status of marine turtles in the North Pacific Ocean. NOAA Tech. Memo. NMFS. NOAA-TM-SWFSC-186. 156 pp.

Edson, C., and F. Curren. 1987. Report from Oroluk. Mar. Turtle Newsl. 41:1-2.

Ehrhart, L.M. 1982. A review of sea turtle reproduction. Pages 29-38 in K.A. Bjorndal (ed.), Biology and Conservation of Sea Turtles. Smithsonian Inst. Press, Washington, D.C. 583 pp.

Forbes, G.A. 1994. The diet of the green turtle in an algal-based coral reef community - Heron Island, Australia. Pages 57-59 in B.A. Schroeder and B.E. Witherington (compilers), Proceedings of the Thirteenth Annual Symposium on Sea Turtle Biology and Conservation. NOAA Tech. Memo. NMFS-SEFSC-341. 281 pp.

Forsyth, R.G., and G.H. Balazs. 1989. Species profiles: Life histories and environmental requirements of coastal vertebrates and invertebrates, Pacific Ocean region: Report 1, Green turtle, Chelonia mydas. Technical report EL-89-10, prepared by NMFS, NOAA, Honolulu, HI, for the U.S. Army Engineer Waterways Experiment Station, Vicksburg, MS. $20 \mathrm{pp}$.

Fosberg, F.R. 1969. Observations on the green turtle in the Marshall Islands. Atoll Res. Bull. 135:9-12.

Frazer, N.B., and L. M. Ehrhart. 1985. Preliminary growth models for green, Chelonia mydas, and loggerhead, Caretta caretta, turtles in the wild. Copeia 1985:789-802.

Frazer, N.B., and R.C. Ladner. 1986. A growth curve for green sea turtles, Chelonia, in the U.S. Virgin Islands, 1913-1914. Copeia 1986:798-802.

Geermans, S.H. 1992. Marine turtles in the Southwest Palau Islands. Unpub. SPREP Report.

Geermans, S., and L. Honigman. 1992. Palau Rapid Ecological Assessment: Marine turtles, seabirds, and Micronesian megapodes of Babeldaob, Peleliu, and Ngemelis. Prepared for the Republic of Palau Bureau of Natural Resources and Development and The Nature Conservancy. Sponsored by the Queensland Dept. of Environment and Heritage and the South Pacific Regional Environment Programme (SPREP) Marine Turtle Conservation Programme.

Groombridge, B. (Compiler). 1982. The IUCN Amphibia-Reptilia red data book. Part 1. Testudines, Crocodylia, and Rhynchocephalia. IUCN, Gland, Switzerland. 426 pp.

Groombridge, B., and R. Luxmoore. 1989. The green turtle and hawksbill (Reptilia: Cheloniidae): World status, exploitation and trade. IUCN Conservation Monitoring Center, Cambridge. $601 \mathrm{pp}$.

Guilbeaux, M.D. 1992. Summary report of sea turtle nesting beach suitability survey, SeptemberOctober 1992 Palau REA. Unpub. report to Nature Conservancy. 12 pp. 
Guilbeaux, M., S. Davis and P. Tonne. 1994. Survey of hawksbill nesting activity on selected Rock Island beaches. Unpublished report to the Division of Marine Resources, Republic of Palau. $1 \mathrm{p}$.

Hendrickson, J.R. 1958. The green sea turtle, Chelonia mydas (Linn.), in Malaya and Sarawak. Proc. Zool. Soc. Lond. 130(4):455-535.

Hendrickson, J.R. 1972. South Pacific Islands - marine turtle resources. FAO Report FI:SF/SOP/REG 102/6. FAO, Rome.

Herbst, L.H. Fibropapillomatosis of marine turtles. 1994. Annual Review of Fish Diseases 4: 389425.

Hiatt, R.M. 1951. Marine zoology study of Arno Atoll, Marshall Islands. Scientific investigations in Micronesia: natives uses of marine products. Atoll Res. Bull. 3-4:1-13.

Hirth, H.F. 1971a. South Pacific Islands - marine turtle resources. FAO Report FI:SF/SOP/REG/102/1. FAO, Rome.

Hirth, H.F. 1971b. Synopsis of biological data on the green turtle, Chelonia mydas (Linnaeus) 1758. FAO Fisheries Synopsis No. 85. Food and Agricultural Organization of the United Nations, Rome. 74 pp.

Hirth, H.F. 1980. Chelonia mydas (Linnaeus), green turtle. Catalogue of American amphibians and reptiles. 249:1-4.

Holthus, P.F., J.E. Maragos, J. Naughton, C. Dahl, D. David, A. Edward, M. Gawel and S. Liphei. 1993. Oroluk Atoll and Minto Reef resource survey. East-West Center Program on Environment, Honolulu, Hawaii. 94 pp.

Honigman, L. 1994. Preliminary survey to determine the status and distribution of sea turtles on the island of Tinian, Commonwealth of the Northern Mariana islands. Draft report to the U.S. Fish and Wildlife Service. 20 pp.

Johannes, R.E. 1978. Traditional marine conservation methods in Oceania and their demise. Annu. Rev. Ecol. Syst. 9:349-364.

Johannes, R.E. 1981. Words of the Lagoon: Fishing and Marine Lore in the Palau District of Micronesia. Univ. Calif. Press, Berkeley.

Johannes, R.E. 1986. A review of information on the subsistence use of green and hawksbill sea turtles on islands under United States jurisdiction in the western Pacific Ocean. NMFS Southwest Region Admin. Report SWR-86-2. 41 pp.

Kolinski, S. 1991. Outer islands turtle project: Stage 1 Final report on the Olimarao Atoll fieldwork. Marine Resources Management Division, Yap, Federated States of Micronesia, March. 21 pp. 
Kolinski, S. 1994. Carapace lesions of Chelonia mydas breeding in Yap State are diagnosed to be fibropapilloma. Mar. Turtle News. 67: 26-27.

Lessa, W.A. 1962. The decreasing power of myth on Ulithi. J. Am. Folkl. 75: 153-159.

Lessa, W.A. 1984. Sea turtles and ritual: Conservation in the Caroline Islands. Pages 1183-1201 in B. Gunda (ed.), The Fishing Culture of the World: Studies in Ethnology, Cultural Ecology and Folklore. Volume II. Akadémiai Kiadó, Budapest. Pp. 589-1253.

Limpus, C.J. 1978. The reef and uncertain land of plenty. Pages 187-222 in H. Lavery (ed.), Exploration North, A Natural History of Queensland. Richmond Hill Press, Melbourne.

Limpus, C.J. 1982. The status of Australian sea turtle populations. Pages 297-303 in K.A. Bjorndal (ed.), Biology and Conservation of Sea Turtles. Smithsonian Inst. Press, Washington, D.C. 583 pp.

Limpus, C.J., and D.G. Walter. 1980. The growth of immature green turtles Chelonia mydas under natural conditions. Herpetologica 36(2):162-165.

Limpus, C.J., P. Eggler, and J.D. Miller. 1994. Long interval remigration in eastern Australian Chelonia. Pages 85-86 in B.A. Schroeder and B.E. Witherington (compilers), Proceedings of the Thirteenth Annual Symposium on Sea Turtle Biology and Conservation. NOAA Tech. Memo. NMFS-SEFSC-341. 281 pp.

Linnaeus, C. 1758. Systema naturae per regna tria naturae, secundum classes, ordines, genera, species, cum characteribus, differentiis, synomymis, locis. Ed. 10, Tomus 1. L. Salvii, srockholm, Sweden. 823 pp.

Losey, G., G.H. Balazs, and L.A. Privatera. 1994. A cleaning symbiosis between the wrasses, Thalassoma duperry, and the green turtle, Chelonia mydas. Copeia 1994(3): 684-690.

Loshbaugh, D. 1993. Dead turtle may have set northern record. Homer News, October 28, 1993.

Maragos, J.E. 1992. Sea turtle conservation plan for the Republic of Palau. Draft report prepared for the Republic of Palau, Bureau of Resources and Development by the Nature Conservancy, Pacific Region, Honolulu. 39 pp.

Maragos, J.E. 1994. Description of reefs and corals for the 1988 protected area survey of the northern Marshall Islands. Atoll Research Bulletin 419: 1-88 + 4 appendices.

Maragos, J.E., C. Birkland, C. Cook, K. Des Rochers, R. Di Rosa, T.J. Donaldson, S.H. Geermans, M. Guilbeaux, H. Hirsh, L. Honigman, N. Idechong, P.S. Lobel, E. Matthews, K.J. McDermid, K.Z. Meier, R. Meyers, I. Otobed, R.H. Richmond, B. Smith, and R. Smith. 1994. Marine and coastal areas survey of the Main Palau Islands: Part 2. Rapid ecological assessment synthesis report (J. E. Maragos (ed.)). A report prepared for the Palau Bureau of Natural Resources and Development, Republic of Palau, by The Nature Conservancy, Pacific Region, Honolulu, Hawaii. 125 pp. 
Márquez M., R. 1990. Sea turtles of the world. An annotated and illustrated catalogue of sea turtle species known to date. FAO Species Catalog, FAO Fisheries Synopsis 11(125):81 pp.

McCoy, M.A. 1974. Man and turtle in the Central Carolines. Micronesica 10(2):207-221.

McCoy, M.A. 1982. Subsistence hunting of turtles in the Western Pacific: the Caroline Islands. Pages 275-280 in K.A. Bjorndal (ed.), Biology and Conservation of Sea Turtles. Smithsonian Inst. Press, Washington, D.C. 583 pp.

Mendonca, M.T. 1977. Comparative growth rates of wild immature Chelonia mydas and Caretta caretta in Florida. J. Herpetol. 15:447-451.

Meylan, A.B. 1982. Sea turtle migrations-evidence from tag returns. Pages 91-100 in K.A. Bjorndal (ed.), Biology and Conservation of Sea Turtles. Smithsonian Inst. Press, Washington, D.C. 583 pp.

Meylan, A.B., B.W. Bowen, and J.C. Avise. 1990. A genetic test of the natal homing versus social facilitation models for green turtle migration. Science 248:724-728.

Morreale, S.J., G.J. Ruiz, J.R. Spotila, and E.A. Standora. 1982. Temperature-dependent sex determination: current practices threaten conservation of sea turtles. Science 216:1245-1247.

Mortimer, J.A. 1982. Feeding ecology of sea turtles. Pages 102-109 in K.A. Bjorndal (ed.), Biology and Conservation of Sea Turtles. Smithsonian Inst. Press, Washington, D.C. 583 pp.

Mortimer, J.A. 1990. The influence of beach sand characteristics on the nesting behavior and clutch survival of green turtles (Chelonia mydas). Copeia 1990:802-817.

Mrosovsky, N., and C.L.Yntema. 1980. Temperature dependence of sexual differentiation in sea turtles: implications for conservation practices. Biol. Cons. 18:271-280.

National Marine Fisheries Service. 1985a. Five-year status review of sea turtles listed under the Endangered Species Act of 1973. NOAA National Marine Fisheries Service, Washington D.C., January. 90 pp.

National Marine Fisheries Service. 1985b. Review of regulations concerning the taking of sea turtles for subsistence purposes: notice of final determination and availability of review documents. Federal Register, 50, 2:278-279, 1/3/85.

National Marine Fisheries Service. 1995. Annual report on the biological opinion of June 25, 1994 concerning the take of sea turtles in the Hawaii longline fishery. Unpublished report. 11 pp.

Naughton, J.J. 1991. Sea turtle survey at Oroluk Atoll and Minto Reef. Mar. Turtle Newsl. 55:9-12. 
National Research Council. 1990. Decline of the sea turtles: causes and prevention. National Academy Press, Washington, D.C. 259 pp.

Ogren, L. 1984. Overview of the biology of the green turtle. Pages 78-80 in P. Bacon, F. Berry, K. Bjorndal, H. Hirth L. Ogren and M. Weber (eds.), Proceedings of the Western Atlantic Turtle Symposium. RSMAS Printing, Miami.

Owens, D.W. 1980. The comparative reproductive physiology of sea turtles. Am. Zool. 20(3): 549-563.

Pritchard, P.C.H. 1977. Marine turtles of Micronesia. Chelonia Press, San Francisco. 83 pp.

Pritchard, P.C.H. 1982a. Marine turtles of Micronesia. Pages 263-274 in K.A. Bjorndal (ed.), Biology and Conservation of Sea Turtles. Smithsonian Inst. Press, Washington, D.C. 583 pp.

Pritchard, P.C.H. 1982b. Marine turtles of the South Pacific. Pages 253-262 in K.A. Bjorndal (ed.), Biology and Conservation of Sea Turtles. Smithsonian Inst. Press, Washington, D.C. $583 \mathrm{pp}$.

Pritchard, P.C.H., and P. Trebbau. 1984. The turtles of Venezuela. Society for the Study of Amphibians and Reptiles. Contrib. Herpetol. 2.

Puleloa, W.K. and N. Kilma. 1992. The sea turtles of the Northern Marshalls: A research expedition to Bikar and Erikup Atolls and Jemo Island. Unpublished Report to SPREP. 72 pp.

Russell, D.J. and G.H. Balazs. 1994. Colonization and utiization of the alien marine alga Hypnea musciformis (Wulfen) J.Ag. (Rhodophyta: Gigartinales) in the Hawaiian Islands. Aquatic Botany 47(1994): 53-60.

Schweigger, A. 1812. Prodomus monographiae cheloniorum. Konigsberger Arch. Naturwiss. Math. 1:271-368;406-458.

Smith, A. 1991. M.R.M.D. working paper on turtles. Marine Resources Management Division, Yap, Federated States of Micronesia, January. 26 pp.

South Pacific Regional Environment Programme. 1991. Report of the first meeting and workshop of the Regional Marine Turtle Conservation Programme (RMTCP), Noumea, New Caledonia, 13-15 August 1991. South Pacific Commission, Noumea. 35 pp.

Suganuma, H. 1991. Green sea turtles (Chelonia mydas) in the Ogasawara Islands. Pages 125127 in I. Uchida (editorial advisor), International Symposium on Sea Turtles 1988 in Japan, Himeji City Aquarium and Chelonian Museum, Japan.

Thomas, P.E.J. (compiler). 1989. Report of the Northern Marshall Islands Natural Diversity and Protected Areas Survey, 7-24 September 1988. South Pacific Regional Environment 
Programme (SPREP), Noumea, New Caledonia, and the East-West Center, Honolulu, Hawaii. $133 \mathrm{pp}$.

Tobin, J.E. 1952. Land tenure in the Marshall Islands. Atoll Res. Bull. 11:1-36.

Tobin, J., G. Weilbacher, E. Iwaniec, F. Mahoney, S. Kaneshiro, and R. Emerick. 1957. Notes on the present regulations and practices of harvesting sea turtle and sea turtle eggs in the Trust Territory of the Pacific Islands. Anthropological Working Papers No. 1, Office of the Staff Anthropologist, Trust Territory of the Pacific Islands, Guam, M. I. 26 pp.

Tuato'o-Bartley, N., T.E. Morrell, and P. Craig. 1993. Status of sea turtles in American Samoa in 1991. Pacific Science 47(3):215-221.

Wetherall, J.A., G.H. Balazs, R.A. Tokunaga and M.Y.Y. Yong. 1993. Bycatch of marine turtles in North Pacific high-seas driftnet fisheries and impacts on the stocks. Bull. of the N. Pacific Comm. 53(III):519-538.

Whittow, G.C., and G.H. Balazs. 1982. Basking behavior of the Hawaiian green turtle (Chelonia mydas). Pac. Sci. 36:129-139.

Yntema, C.L., and N. Mrosovsky. 1980. Sexual differentiation in hatchling loggerheads (Caretta caretta). Can J Zool. 60(5):1012-1016.

Zug, G.R., and G.H. Balazs. 1985. Skeletochronological age estimates for Hawaiian green turtles. Mar. Turtle Newsl. 33:9-10. 


\section{IMPLEMENTATION SCHEDULE}

The Implementation Schedule outlines management and research actions and estimated costs for the U.S. Pacific green turtle recovery program, as set forth in this recovery plan. It is a guide for meeting the objectives discussed in Part II of this plan. This schedule indicates wherever possible, task priority, task numbers, task descriptions, duration of tasks, the agencies responsible for committing funds, and lastly, estimated costs. The agencies responsible for committing funds are not, necessarily, the entities that will actually carry out the tasks. The actions identified in the implementation schedule, when accomplished, should protect habitat for the species, stabilize the existing populations, and increase the population sizes and numbers. Monetary needs for all parties involved are identified to reach this point, whenever feasible.

Priorities in column 3 of the following Implementation Schedule are assigned as follows:

Priority 1 -

An action that must be taken to prevent extinction or to prevent the species from declining irreversibly in the foreseeable future.

Priority 2 -

An action that must be taken to prevent significant decline in species population/habitat quality or some other significant negative impact short of extinction.

Priority 3 -

All other actions necessary to provide for full recovery of the species.

\section{KEY to Implementation Table Abbreviations:}

$\begin{array}{lll}\text { CNMI } & = & \text { Commonwealth of the Northern Mariana Islands } \\ \text { COE } & = & \text { U.S. Army Corp of Engineers } \\ \text { DOC } & = & \text { U.S. Department of Commerce } \\ \text { DOI } & = & \text { U.S. Department of Interior } \\ \text { DOS } & = & \text { U.S. Deparment of State (primarily as a conduit for negotiations and } \\ & & \text { support for tasks in other political jurisdictions) } \\ \text { EPA } & = & \text { U.S. Environmental Protection Agency } \\ \text { FSM } & = & \text { Federated States of Micronesia } \\ \text { FWS } & = & \text { U.S. Fish \& Wildlife Service } \\ \text { NA } & = & \text { Not applicable } \\ \text { NMFS } & = & \text { National Marine Fisheries Service } \\ \text { NRCS } & = & \text { Natural Resources Conservation Service (Soil Conservation Service) } \\ \text { RMI } & = & \text { Republic of the Marshall Islands } \\ \text { USN } & = & \text { U.S. Navy }\end{array}$




\begin{tabular}{|c|c|c|c|c|}
\hline \multirow{11}{*}{ 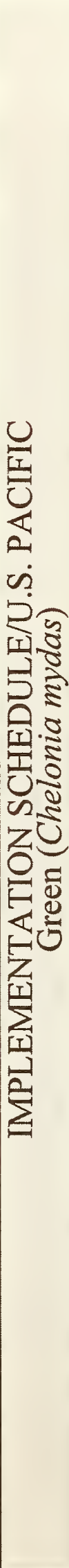 } & 产 & 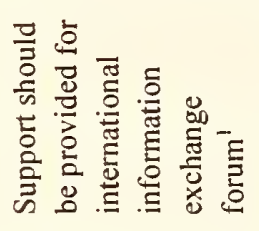 & 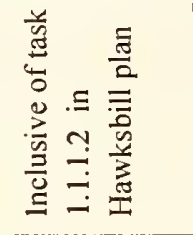 & 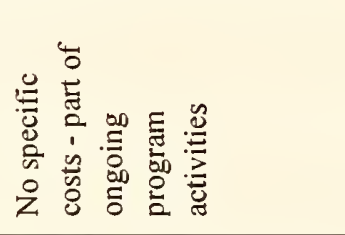 \\
\hline & \multirow{4}{*}{ 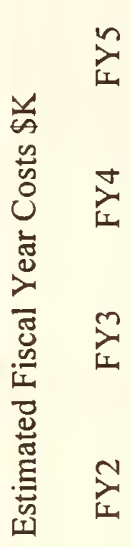 } & $\cong$ & $\approx$ & \\
\hline & & 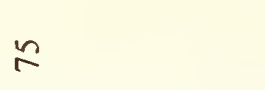 & $\approx$ & \\
\hline & & $\curvearrowleft$ & 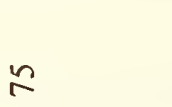 & \\
\hline & & $\cong$ & $\curvearrowleft$ & \\
\hline & 窇 & $\curvearrowleft$ & $\approx$ & \\
\hline & 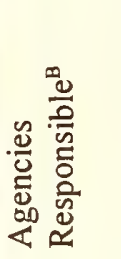 & \multicolumn{2}{|c|}{ 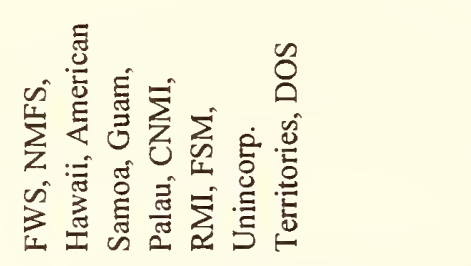 } & 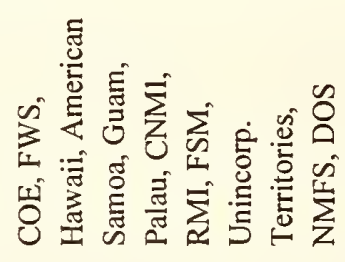 \\
\hline & 剪 & 怘 & 告 & 莣 \\
\hline & 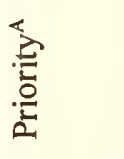 & - & - & - \\
\hline & 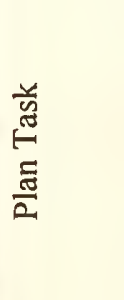 & 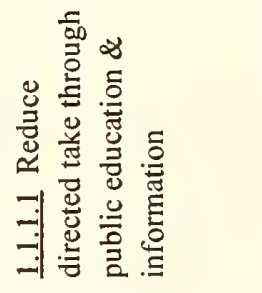 & 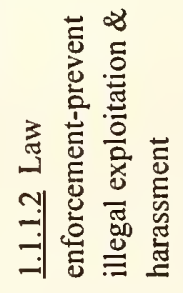 & 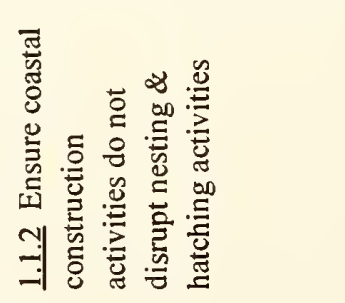 \\
\hline & 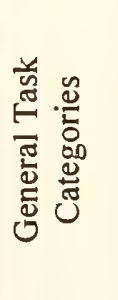 & \multicolumn{2}{|c|}{ 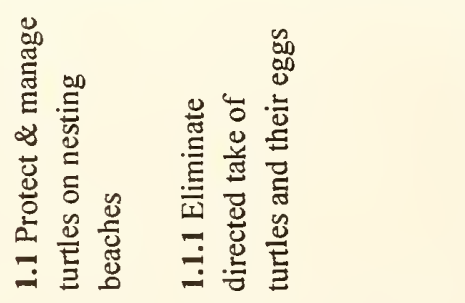 } & 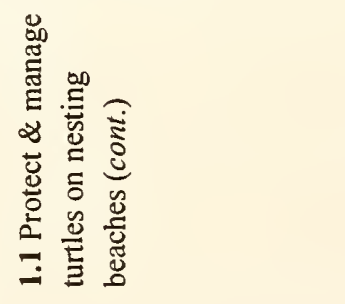 \\
\hline
\end{tabular}

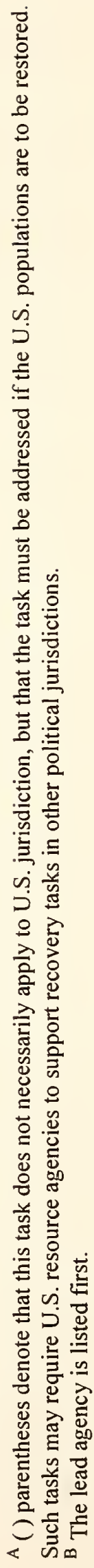



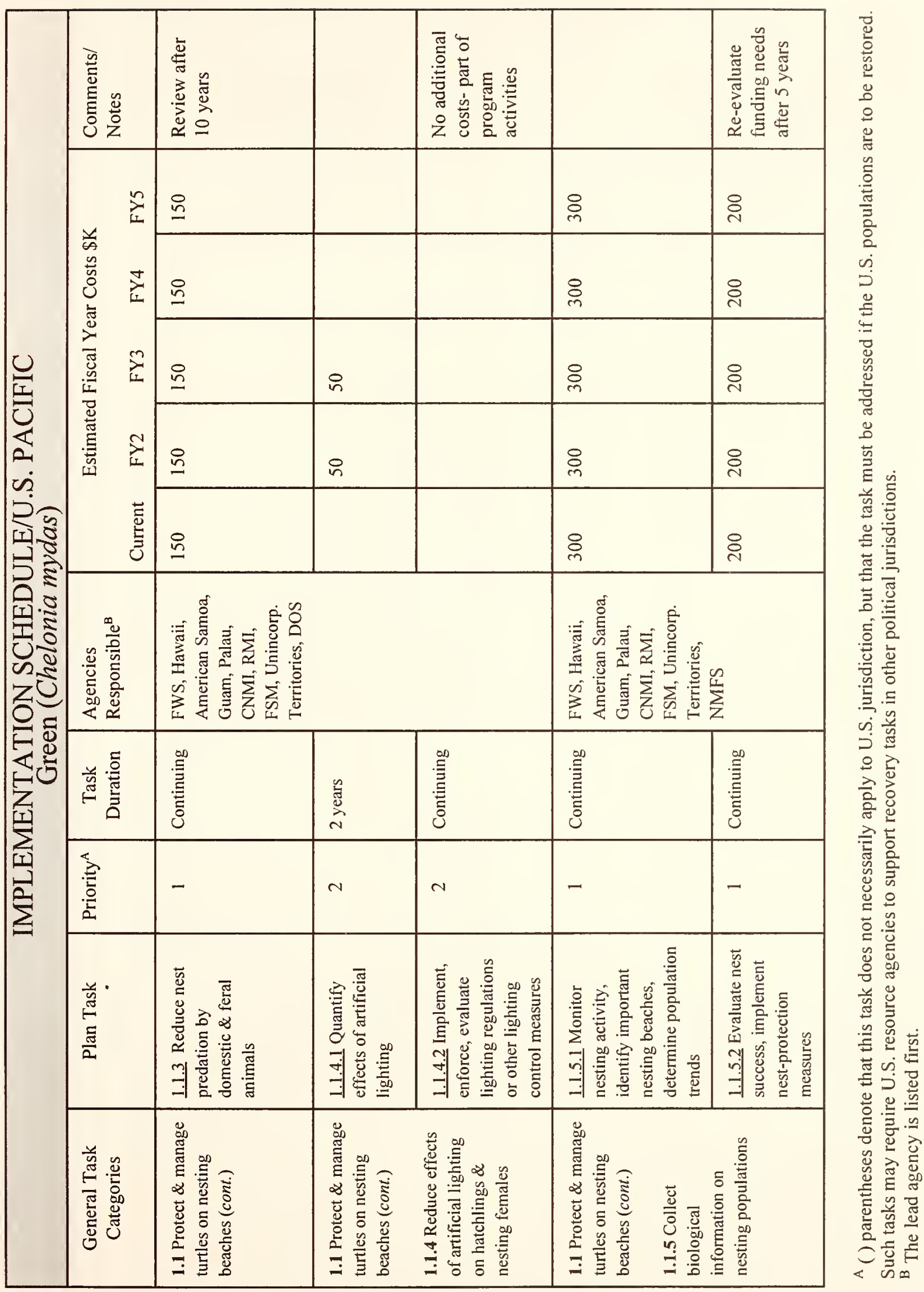


\begin{tabular}{|c|c|c|c|c|c|c|}
\hline \multirow{11}{*}{ 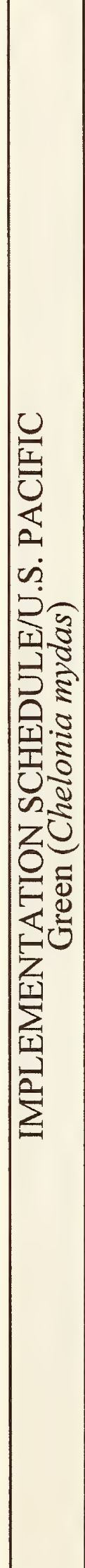 } & 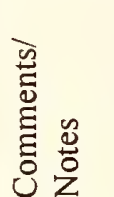 & 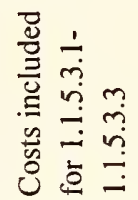 & & & & 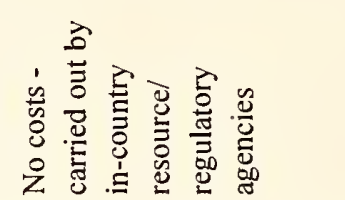 \\
\hline & 3 & 8 & & & & \\
\hline & \multirow{2}{*}{ 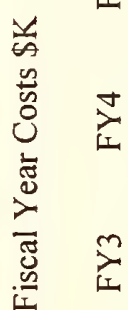 } & 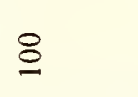 & & & & \\
\hline & & 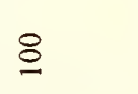 & & & & \\
\hline & 虽 袿 & 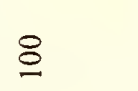 & & & & \\
\hline & (ֶ) & 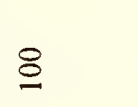 & & & & \\
\hline & 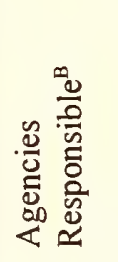 & 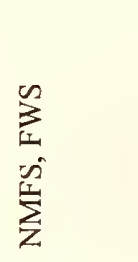 & 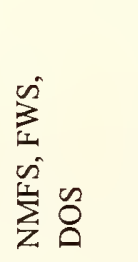 & 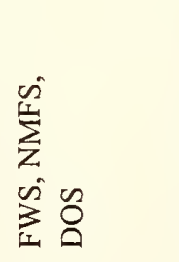 & $\begin{array}{l}\sum_{z}^{\infty} \\
\sum_{1}^{\infty} \\
\sum_{1}^{\infty}\end{array}$ & 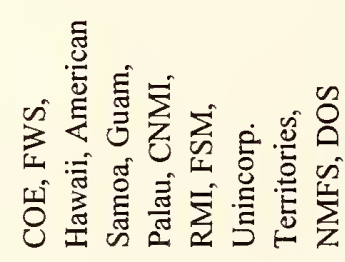 \\
\hline & 总部 & $\begin{array}{c}\frac{n}{5} \\
\stackrel{2}{2} \\
n\end{array}$ & 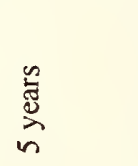 & 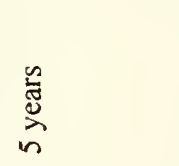 & 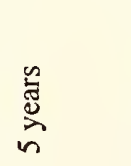 & 竞 \\
\hline & 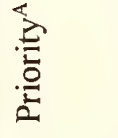 & - & - & - & - & $N$ \\
\hline & 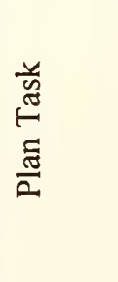 & 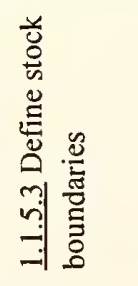 & 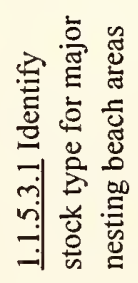 & 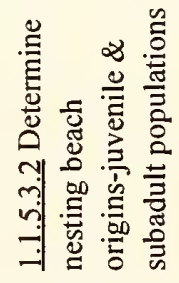 & 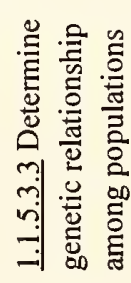 & 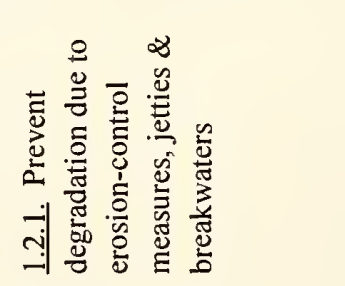 \\
\hline & 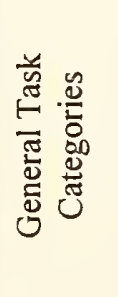 & 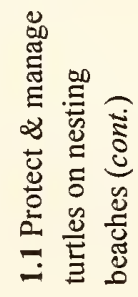 & 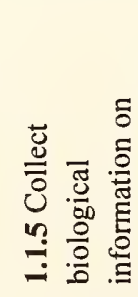 & 这 & & 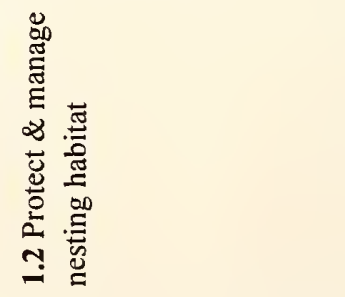 \\
\hline
\end{tabular}

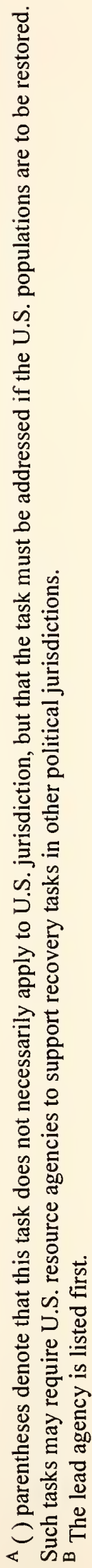



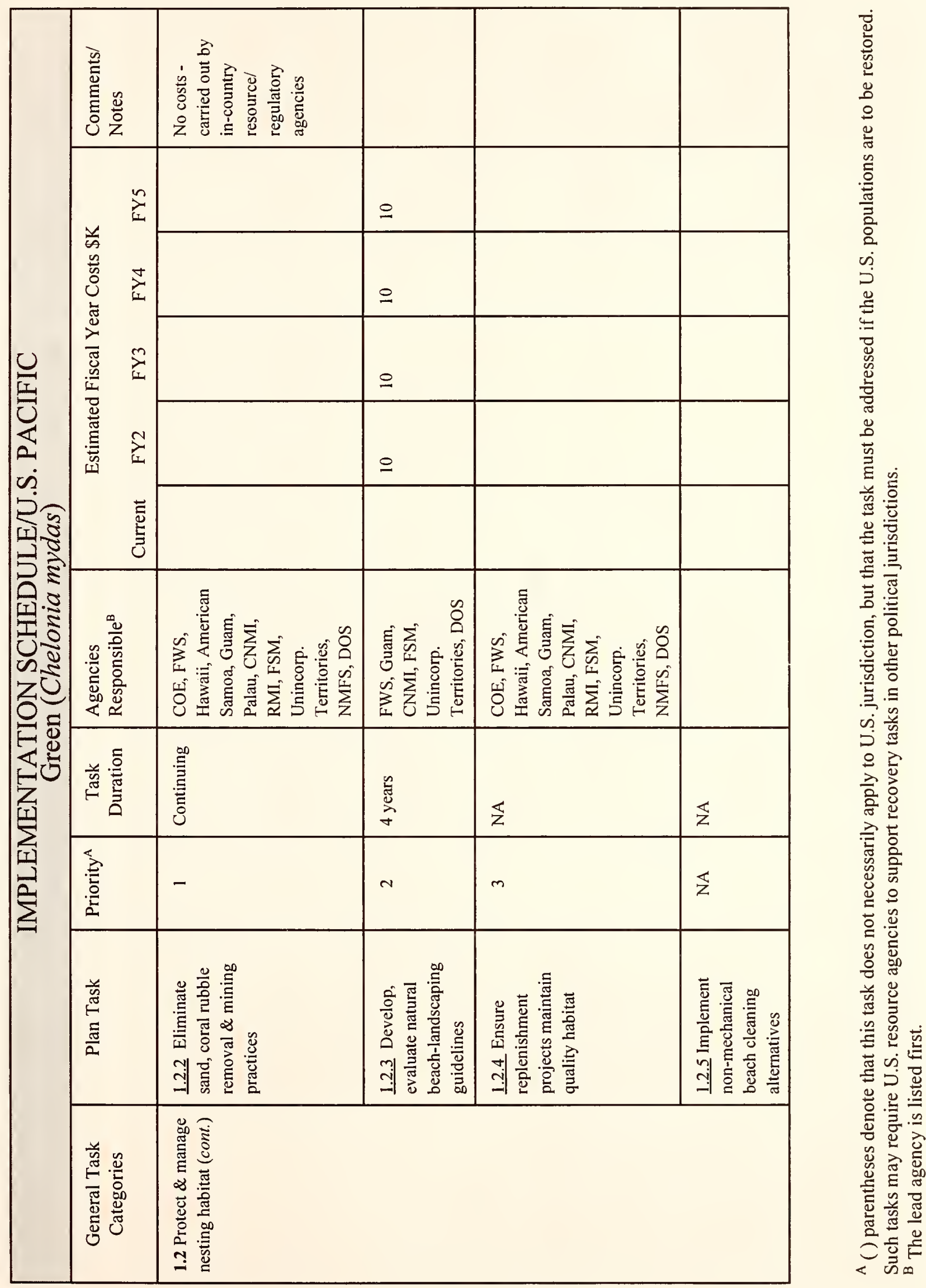


\begin{tabular}{|c|c|c|c|c|c|}
\hline \multirow{11}{*}{ 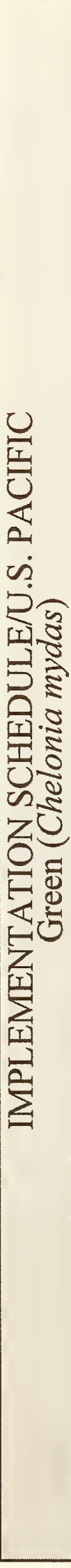 } & 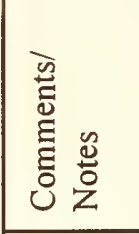 & 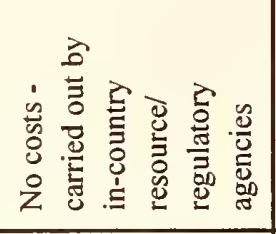 & 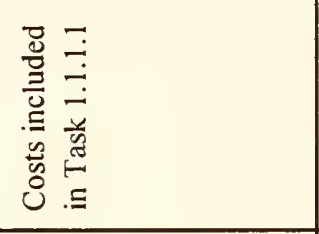 & 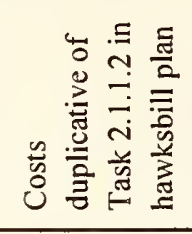 & 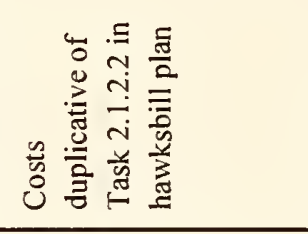 \\
\hline & & & & $\stackrel{8}{8}$ & $\stackrel{8}{8}$ \\
\hline & & & & $\stackrel{8}{9}$ & $\stackrel{8}{1}$ \\
\hline & & & & $\stackrel{8}{1}$ & 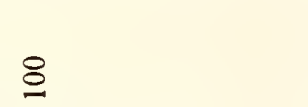 \\
\hline & 竞 & & & 8 & 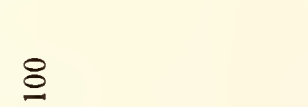 \\
\hline & $\begin{array}{l}\overline{\bar{m}} \\
\overline{\mathrm{E}}\end{array}$ & & & in & $\stackrel{m}{m}$ \\
\hline & 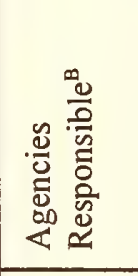 & 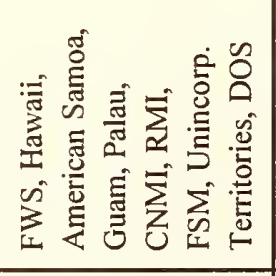 & 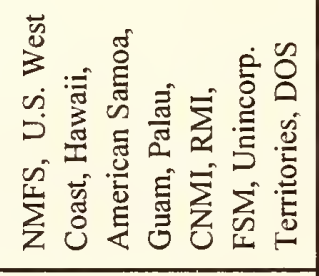 & 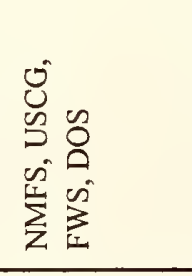 & 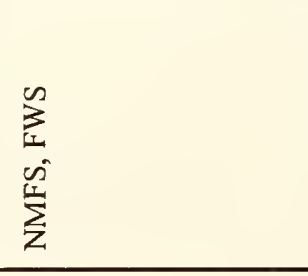 \\
\hline & 善亮 & 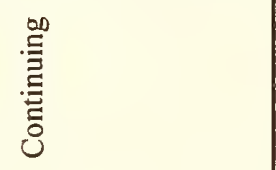 & 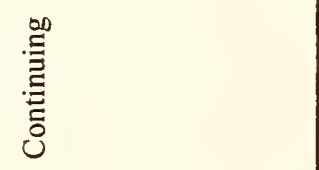 & $\begin{array}{l}\text { 吕 } \\
\text { 言 } \\
\text { 言 }\end{array}$ & 受 \\
\hline & 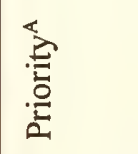 & $m$ & - & - & - \\
\hline & 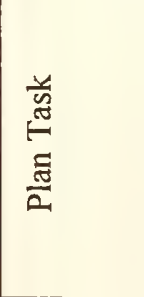 & 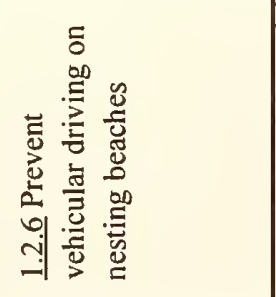 & 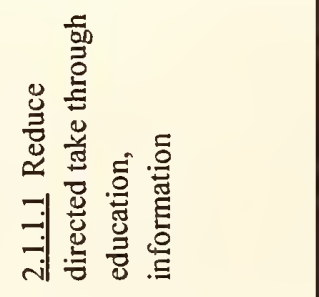 & 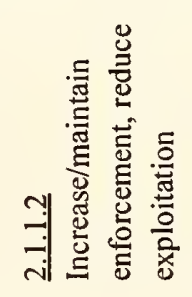 & 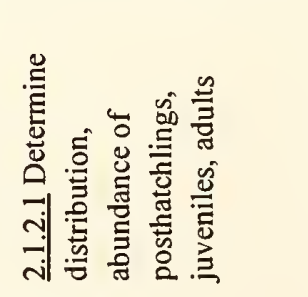 \\
\hline & 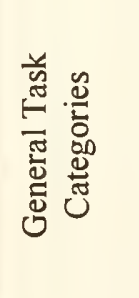 & 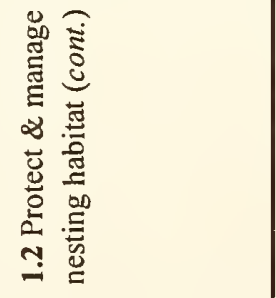 & 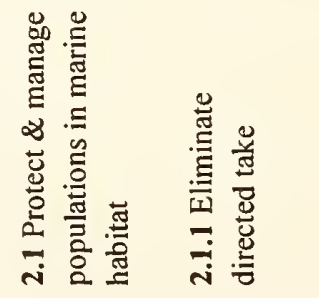 & & 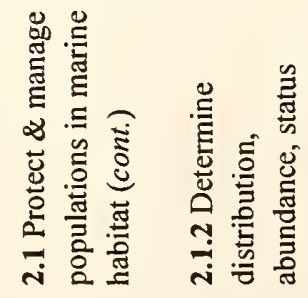 \\
\hline
\end{tabular}

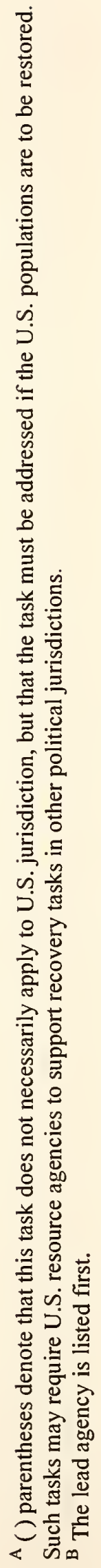




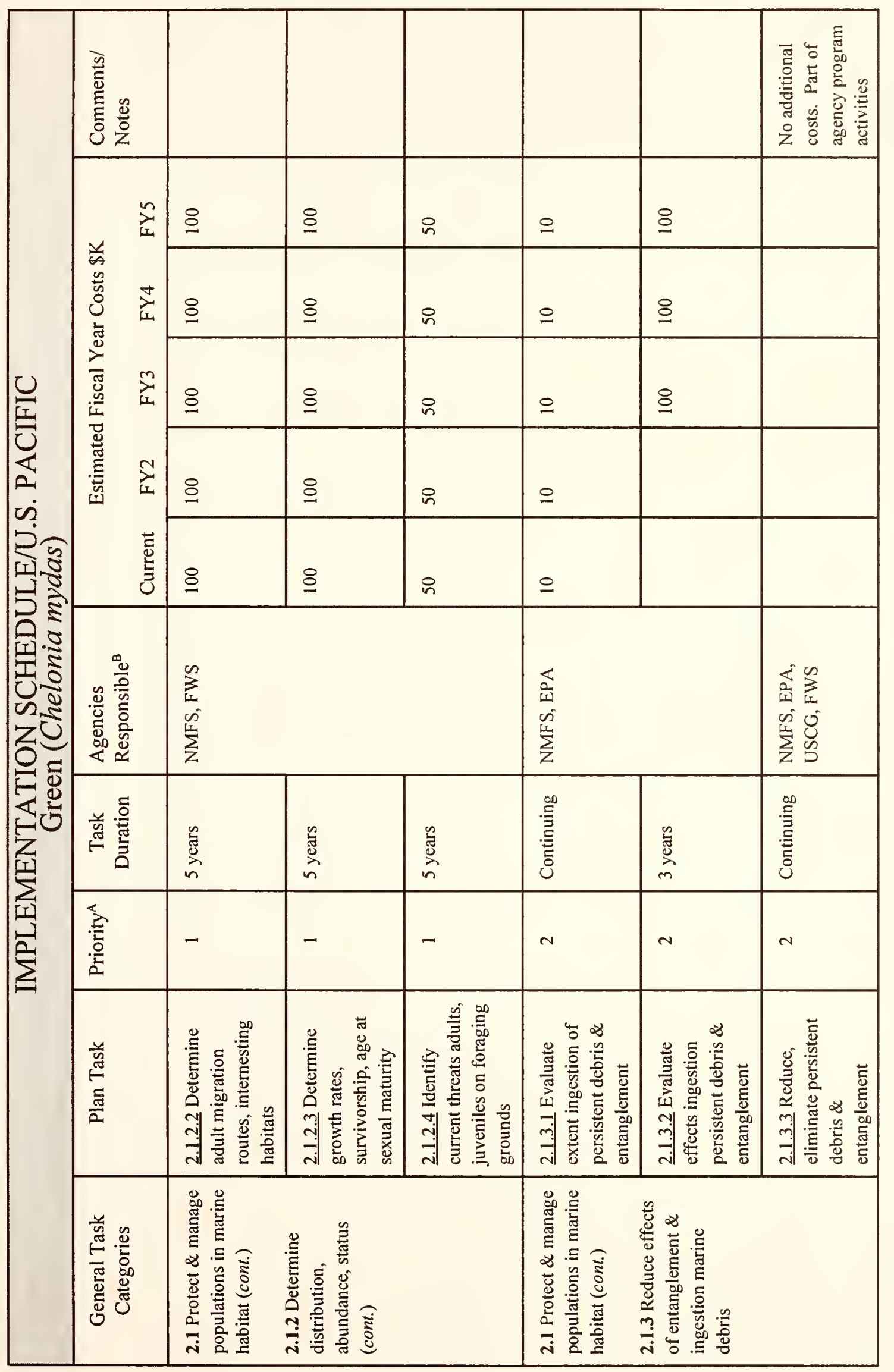

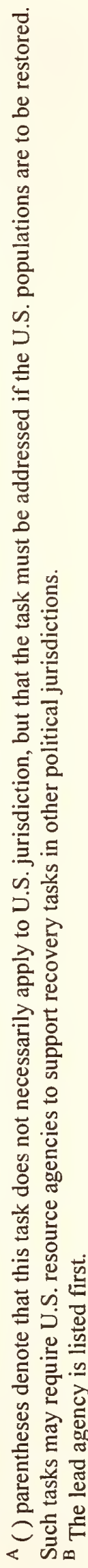



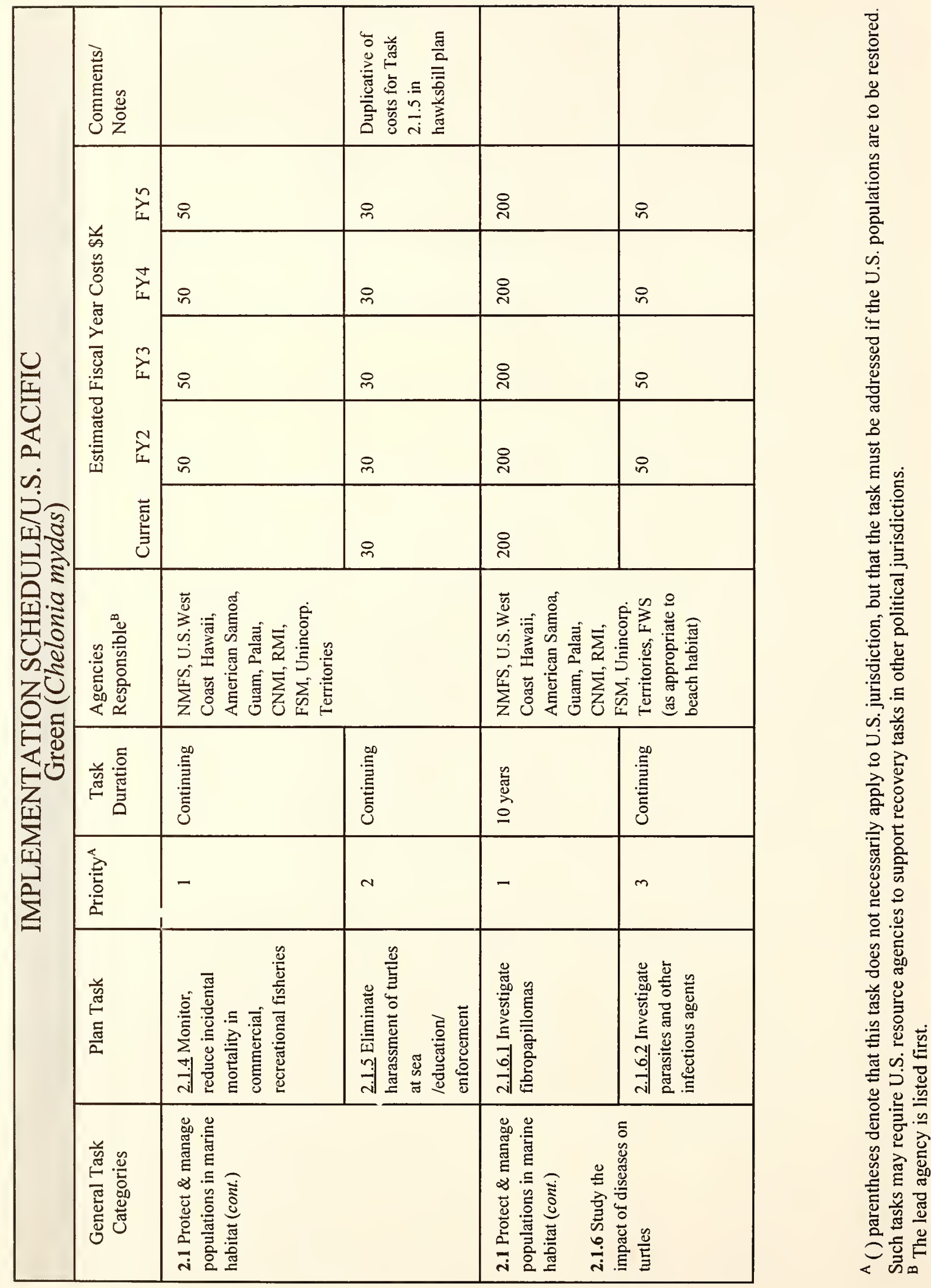

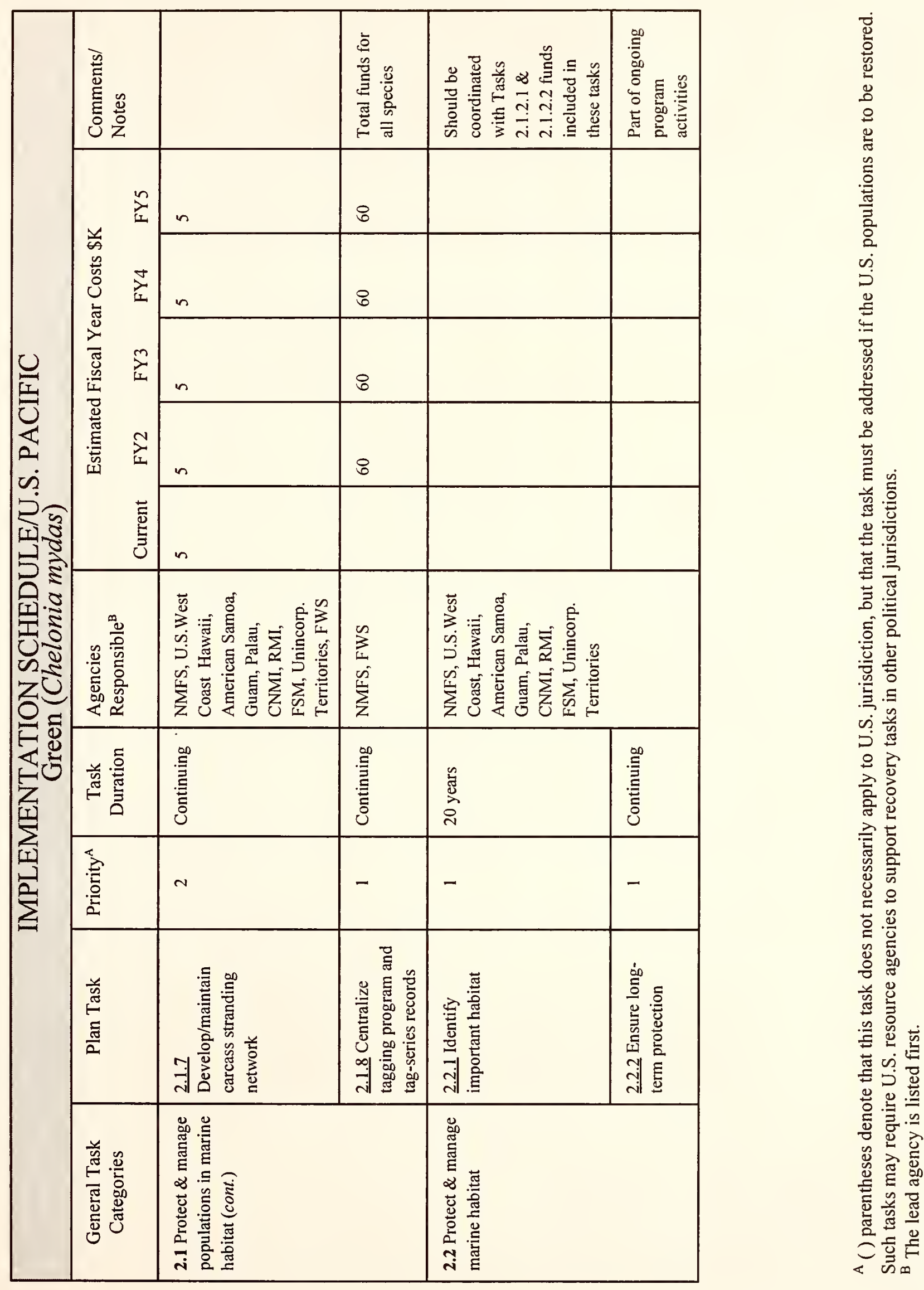

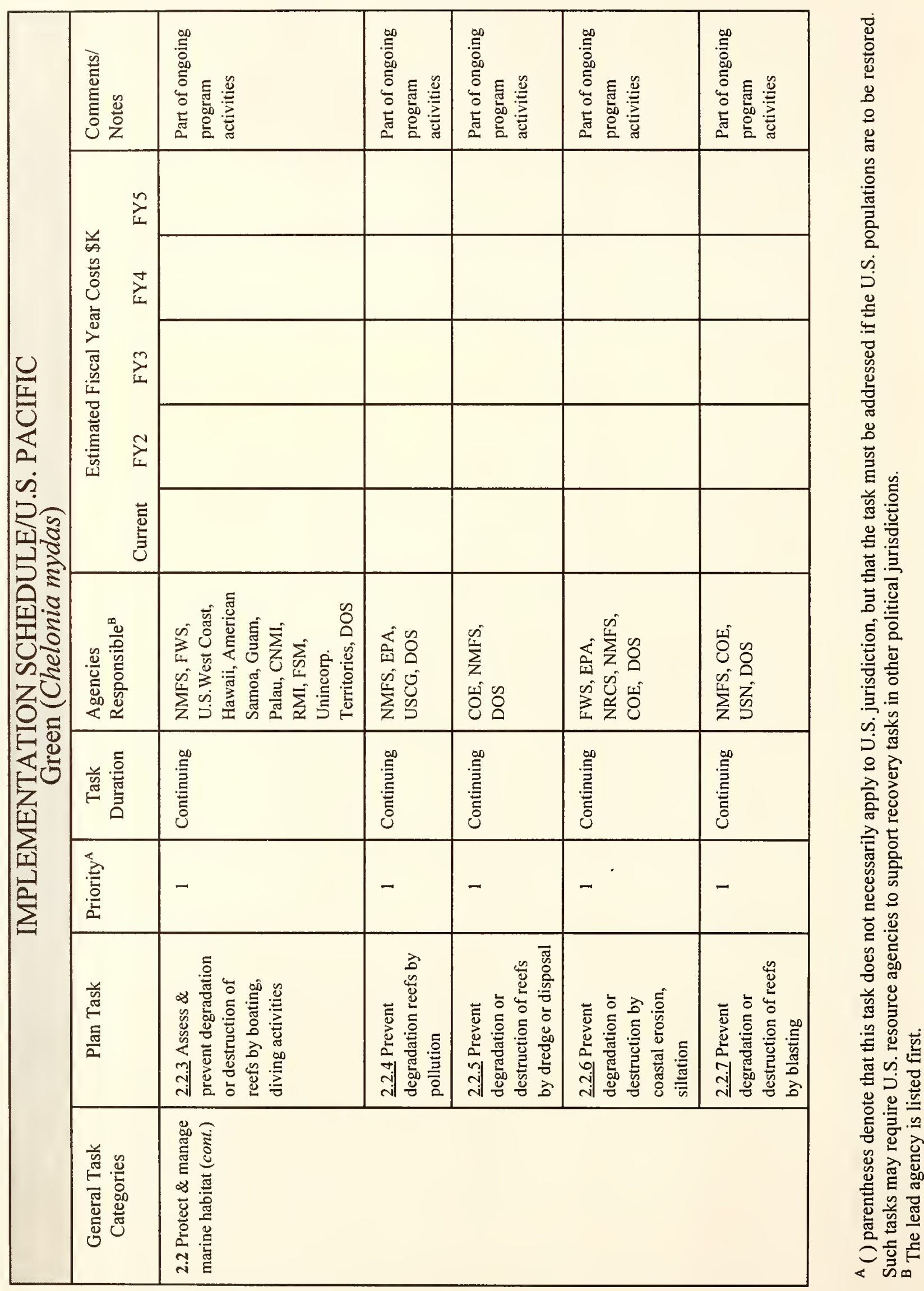

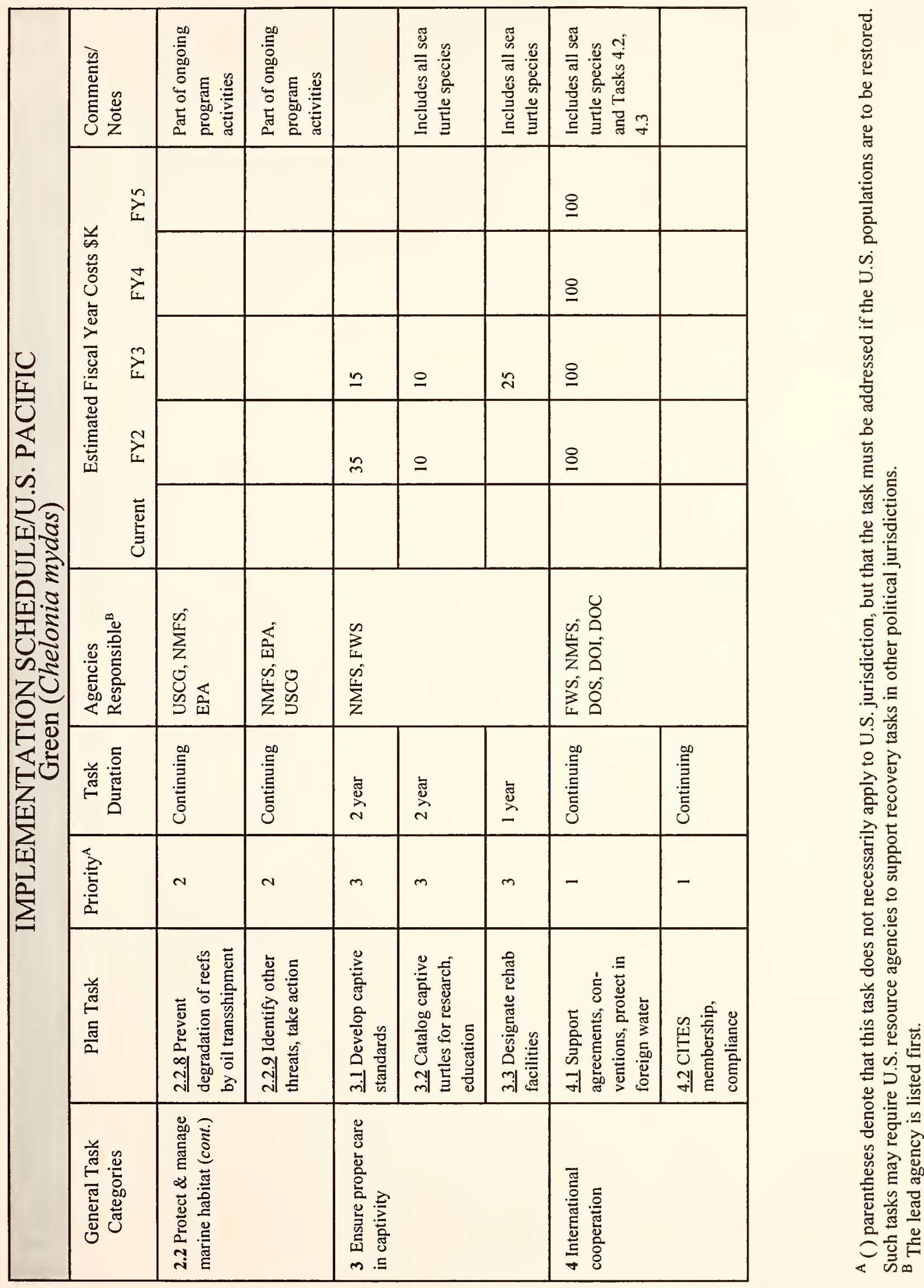


\begin{tabular}{|c|c|c|c|}
\hline & 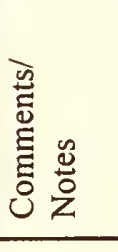 & & 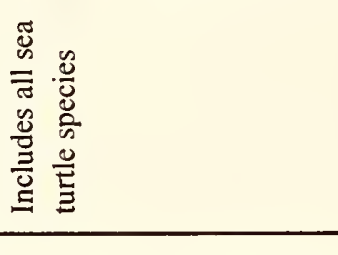 \\
\hline & శ & & $\cong$ \\
\hline & $e_{0}^{0}$ & & $\cong$ \\
\hline & 胥 & & 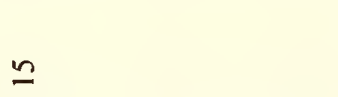 \\
\hline & 苞 记 & & $\cong$ \\
\hline $\begin{array}{l}20 \\
0 \\
0 \\
0\end{array}$ & 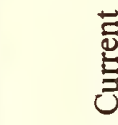 & & $\simeq$ \\
\hline 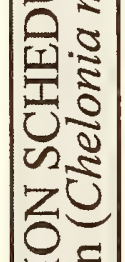 & 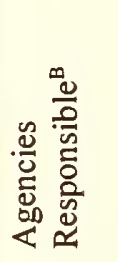 & 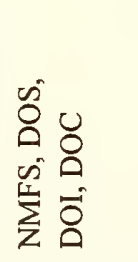 & 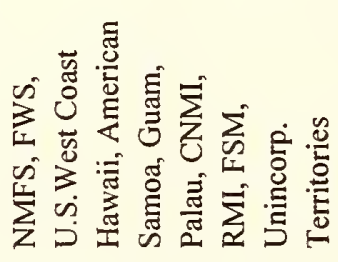 \\
\hline$\sum_{E}^{\mathbb{U}}$ & 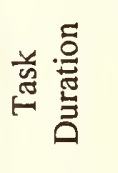 & .气 & 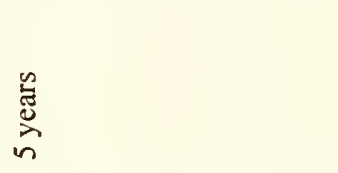 \\
\hline$\frac{61}{2}$ & 高 & - & $N$ \\
\hline & 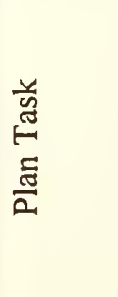 & 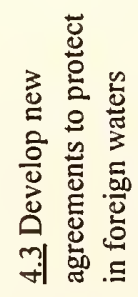 & 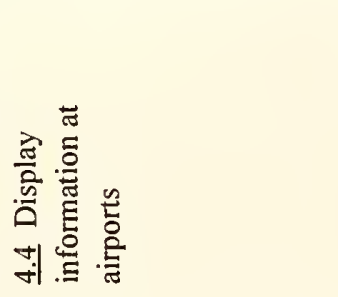 \\
\hline & 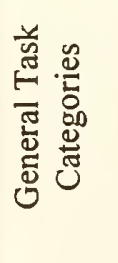 & 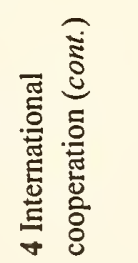 & \\
\hline
\end{tabular}

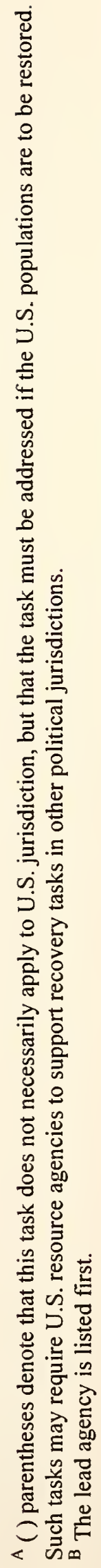





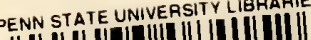

